\title{
Estimations of isoprenoid emission capacity from enclosure studies: measurements, data processing, quality and standardized measurement protocols
}

\author{
Ü. Niinemets ${ }^{1}$, U. Kuhn ${ }^{2}$, P. C. Harley ${ }^{3}$, M. Staudt ${ }^{4}$, A. Arneth ${ }^{5,6}$, A. Cescatti ${ }^{7}$, P. Ciccioli $^{8}$, L. Copolovici ${ }^{1}$, C. Geron ${ }^{9}$, \\ A. Guenther ${ }^{3}$, J. Kesselmeier ${ }^{10}$, M. T. Lerdau ${ }^{11}$, R. K. Monson ${ }^{12}$, and J. Peñuelas ${ }^{13}$ \\ ${ }^{1}$ Institute of Agricultural and Environmental Sciences, Estonian University of Life Sciences, Kreutzwaldi 1, \\ Tartu 51014, Estonia \\ ${ }^{2}$ Institut für Energie und Klimaforschung - Troposphäre (IEK-8), Forschungszentrum Jülich, Jülich, Germany \\ ${ }^{3}$ National Center for Atmospheric Research, P.O. Box 3000, Boulder, CO 80307-3000, USA \\ ${ }^{4}$ Centre d'Ecologie Fonctionnelle et Evolutive (CEFE-CNRS), 1919, Route de Mende, 34293 Montpellier cedex 5, France \\ ${ }^{5}$ Division of Physical Geography and Ecosystem Analysis, Lund University, Sölvegatan 12, 22362 Lund, Sweden \\ ${ }^{6}$ Karlsruhe Institute of Technology, Institute for Meteorology and Climate/Atmospheric Environmental Research, \\ Kreuzeckbahnstr. 19, 82467 Garmisch-Partenkirchen, Germany \\ ${ }^{7}$ European Commission, Joint Research Center, Institute for Environment and Sustainability, 21020 Ispra, Italy \\ ${ }^{8}$ Istituto di Metodologie Chimiche del CNR, Area della Ricerca di Roma 1, 00016 Monterotondo Scalo, Italy \\ ${ }^{9}$ US Environmental Protection Agency, National Risk Management Research Laboratory, Mail Drop E305-02, \\ 109 TW Alexander Dr., Research Triangle Park, NC 27711, USA \\ ${ }^{10}$ Biogeochemistry Department, Max Planck Institute for Chemistry, P.O. Box 3060, 55020 Mainz, Germany \\ ${ }^{11}$ Department of Environmental Sciences, University of Virginia, Charlottesville, VA 22904-4123, USA and \\ Xishuangbanna Tropical Botanic Garden, Melung, Yunnan, China \\ ${ }^{12}$ Department of Ecology and Evolutionary Biology and Cooperative Institute for Research in Environmental Sciences, \\ University of Colorado, Boulder, CO 80309-0334, USA \\ ${ }^{13}$ Global Ecology Unit CSIC-CEAB-CREAF, Facultat de Ciències, Univ. Autònoma de Barcelona, 08193 Bellaterra, Spain
}

Received: 4 April 2011 - Published in Biogeosciences Discuss.: 12 May 2011

Revised: 4 August 2011 - Accepted: 5 August 2011 - Published: 18 August 2011

\begin{abstract}
The capacity for volatile isoprenoid production under standardized environmental conditions at a certain time $\left(E_{\mathrm{S}}\right.$, the emission factor) is a key characteristic in constructing isoprenoid emission inventories. However, there is large variation in published $E_{\mathrm{S}}$ estimates for any given species partly driven by dynamic modifications in $E_{\mathrm{S}}$ due to acclimation and stress responses. Here we review additional sources of variation in $E_{\mathrm{S}}$ estimates that are due to measurement and analytical techniques and calculation and averaging procedures, and demonstrate that estimations of $E_{\mathrm{S}}$ critically depend on applied experimental protocols and on data processing and reporting. A great variety of experimental setups has been used in the past, contributing to study-to-
\end{abstract}

Correspondence to: $\ddot{U}$. Niinemets (ylo.niinemets@emu.ee) study variations in $E_{\mathrm{S}}$ estimates. We suggest that past experimental data should be distributed into broad quality classes depending on whether the data can or cannot be considered quantitative based on rigorous experimental standards. Apart from analytical issues, the accuracy of $E_{\mathrm{S}}$ values is strongly driven by extrapolation and integration errors introduced during data processing. Additional sources of error, especially in meta-database construction, can further arise from inconsistent use of units and expression bases of $E_{\mathrm{S}}$. We propose a standardized experimental protocol for BVOC estimations and highlight basic meta-information that we strongly recommend to report with any $E_{\mathrm{S}}$ measurement. We conclude that standardization of experimental and calculation protocols and critical examination of past reports is essential for development of accurate emission factor databases.

Published by Copernicus Publications on behalf of the European Geosciences Union. 


\section{Introduction}

Volatile isoprenoids, including isoprene, mono- and sesquiterpenes, are the major reactive plant compounds emitted into the atmosphere, and play vital roles in gas-phase atmospheric photochemistry (Chameides et al., 1988; Fuentes et al., 2000) and heterogeneous-phase chemistry that influences the optical depth of the atmosphere, e.g. through secondary organic aerosol formation (Cahill et al., 2006; Chen and Hopke, 2009; Hallquist et al., 2009; Helmig et al., 2006; Kleindienst et al., 2007; Spracklen et al., 2008; Zhang et al., 2007) and cloud formation (Huff Hartz et al., 2005; Spracklen et al., 2008). The vegetation source-strength for volatile isoprenoids is typically estimated using models based on species- or vegetation-specific emission capacity for different volatile isoprenoid classes under standardized environmental conditions ( $E_{\mathrm{S}}$, the emission factor) and environmental correction functions initially developed for light and temperature (so-called Guenther et al. algorithms, Guenther et al., 1991, 1993), and more recently for $\mathrm{CO}_{2}$ concentration (Niinemets et al., 2010c; Wilkinson et al., 2009).

$E_{\mathrm{S}}$ varies depending on past environmental conditions, plant physiological status (stressed/non-stressed), and phenology (Fischbach et al., 2002; Gray et al., 2006; Lavoir et al., 2009; Loreto et al., 2006; Niinemets, 2010a, b, c; Staudt et al., 2003), and some of these factors have also been considered in models to a certain extent (Arneth et al., 2008; Guenther et al., 2000, 2006; Keenan et al., 2009; Lehning et al., 2001). In addition to the naturally dynamic nature of $E_{\mathrm{S}}$ over days, weeks and months and genetic variability, uncertainties in emission inventories are associated with the empirical precision and accuracy of $E_{\mathrm{S}}$ estimations. Modelers tend to accept the reported values of $E_{\mathrm{S}}$ as infinitely precise and accurate. However, no standardized protocol for BVOC emissions has been established, and vastly different approaches have been used to assess emission potentials in laboratory and field studies (for reviews Brancaleoni et al., 1999; Komenda et al., 2001; Ortega and Helmig, 2008; Ortega et al., 2008; Tani et al., 2003). Intercomparisons among different experimental setups have demonstrated large differences, sometimes exceeding $100 \%$ among different BVOC quantification systems (Dindorf et al., 2006; Larsen et al., 1997; Steinbrecher et al., 1994). For more reactive compounds such as certain mono- and sesquiterpenes, complete compound loss has been shown to occur during analysis with some instrumental systems (Arnts, 2008; Fuentes et al., 2000; Helmig et al., 2003, 2004; Larsen et al., 1997; Pollmann et al., 2005; Steinbrecher et al., 1994). Lack of quantitative recovery of a major BVOC fraction has also been suggested, through indirect means, based on atmospheric reactivity measurements above vegetation (Di Carlo et al., 2004; Sinha et al., 2010).

In addition to emission measurements themselves, reliability of $E_{\mathrm{S}}$ values also depends on the way the emission data are processed. Often field measurements cannot be con- ducted under environmental conditions used for standardization of $E_{\mathrm{S}}$ values (typically leaf temperature of $30^{\circ} \mathrm{C}$ and incident light intensity of $1000 \mu \mathrm{mol} \mathrm{m} \mathrm{m}^{-2} \mathrm{~s}^{-1}$ ), and $E_{\mathrm{S}}$ is determined from measurements made under arbitrary temperatures and light intensities that are "corrected" to standard conditions by applying the Guenther et al. $(1991,1993)$ emission algorithms. Such an approach can lead to significant inaccuracies, especially if extrapolations over a large temperature or incident light range are needed. For example, in subarctic, boreal and cool temperate climates, as well as during early and late growing season in seasonal climates, observations are made across a broad range of temperatures, with none of the measurements or very few extending to $30^{\circ} \mathrm{C}$. In this situation, it has been demonstrated that the way emission data are scaled to the standard conditions can significantly alter the estimate of $E_{\mathrm{S}}$ (Ruuskanen et al., 2007), but possible extrapolation problems are often ignored when preparing emission factor databases.

Due to highly non-linear light and temperature responses of BVOC emission, estimations of $E_{\mathrm{S}}$ are also vulnerable to integration and extrapolation errors. In accordance with Jensen's inequality rules, non-linearity introduces errors in $E_{\mathrm{S}}$ estimates when average values of environmental conditions are used (for an outline of the integration problem see Cescatti and Niinemets, 2004; Niinemets and Anten, 2009). This can be a problem also when the averaging is done empirically as the result of sampling strategy, rather than mathematically. For example, averaging errors can occur when using cartridge-measurements of enclosure air (time-averaged) to derive $E_{\mathrm{S}}$ as well as when using enclosures containing a large amount of leaf area, leading to measurement across spatial heterogeneities in light intensity and leaf temperature. Analogous problems arise in using low resolution environmental data for extrapolation of emission data to determine $E_{\mathrm{S}}$ values. So far, such integration issues have not been addressed in $E_{\mathrm{S}}$ determinations.

Finally, many past emission measurements were accompanied by no information on plant physiological status (e.g. photosynthetic activity), on preceding environmental conditions, or on leaf developmental status, making it impossible to consider such effects a posteriori. Lack of crucial meta-information from the time surrounding the measurement makes it difficult, if not impossible, to assess the quality and representative nature of existing emission factor databases. Because of several technical and computational deficiencies in previous determinations of $E_{\mathrm{S}}$, and the lack of critical meta-information, several of us working with emission observations, and attending a recent conference on emissions observations and modeling ${ }^{1}$, have reached the consensus that many existing emission factors require revision.

\footnotetext{
${ }^{1}$ European Science Foundation (VOCBAS and INTROP programmes) science meeting Biogenic Volatile Organic Compounds: Sources and Fates in a Changing World, 2-5 October 2007, CNRS Montpellier, France
} 
Table 1. Summary of error sources in derivation of the BVOC emission factors and significance of different error sources.

\begin{tabular}{|c|c|c|c|}
\hline Error category & Error type & Section discussed & Error importance* \\
\hline \multirow[t]{8}{*}{ Sampling system design } & Limited environmental control & 2.1 & $1-2$ \\
\hline & $\begin{array}{l}\text { Inaccurate measurements of temperature } \\
\text { and/or light }\end{array}$ & 2.1 & $1-2$ \\
\hline & Non-steady state conditions & $2.1,2.3,2.4$ & $2-3$ \\
\hline & $\begin{array}{l}\text { Mismatch between flow rate and enclosed leaf } \\
\text { area (condensation, low/excessive BVOC } \\
\text { concentrations) }\end{array}$ & $2.1,2.2,3.4,3.5$ & $2-3$ \\
\hline & Limited turbulent mixing & 2.1 & 2 \\
\hline & Diffusion through gaskets and tubing & $2.2,2.3$ & $2-3^{\mathrm{a}}$ \\
\hline & Adsorption onto gas-exchange system surface & $2.3,2.4$ & 2 \\
\hline & $\begin{array}{l}\text { Contamination due to volatiles emitted from } \\
\text { gas-exchange system materials }\end{array}$ & 2.3 & $1-3^{\mathrm{a}}$ \\
\hline \multirow[t]{6}{*}{ Sampling methodology } & Rough handling & 2.5 & 1 \\
\hline & Incompatible adsorption traps & 3.1 & 1 \\
\hline & $\begin{array}{l}\text { Bulk flow leaks due to non-homogeneous } \\
\text { packing of adsorbent }\end{array}$ & 3.1 & $1-2$ \\
\hline & Long sample storage & $3.1,3.2$ & $1-3^{b}$ \\
\hline & Atmospheric oxidants in purge air & $2.3,3.2$ & $1-3^{b}$ \\
\hline & $\begin{array}{l}\text { Contaminated purge air (high VOC } \\
\text { backgrounds) }\end{array}$ & 3.3 & $1-3^{\mathrm{a}}$ \\
\hline \multirow[t]{2}{*}{ Emission calculations } & $\begin{array}{l}\text { Chamber BVOC buildup effects on terpene } \\
\text { storage and decomposition reactions in leaves }\end{array}$ & 3.4 & $2-3$ \\
\hline & $\begin{array}{l}\text { Effects of changes in water vapor on bulk } \\
\text { flow rate }\end{array}$ & 3.5 & 3 \\
\hline \multirow{3}{*}{$\begin{array}{l}\text { Extrapolation and integration } \\
\text { errors in } E_{\mathrm{S}} \text { derivation }\end{array}$} & Use of inexact response curve shapes & 4.1 & $2-3$ \\
\hline & $\begin{array}{l}\text { Integration errors due to variations in } \\
\text { environmental conditions }\end{array}$ & 4.2 & $2-3$ \\
\hline & Integration errors due to foliage aggregation & 4.2 & $2-3$ \\
\hline \multirow[t]{3}{*}{ Reporting and metadata errors } & Errors with expression basis of emission rates & 4.3 & 2 \\
\hline & Unit errors & 4.4 & $1-3$ \\
\hline & Metadata errors & 4.5 & $1-2$ \\
\hline
\end{tabular}

* 1 - very important. Can lead to complete lack of detection of given compound or detection of artificial compounds; 2 - important. Can result in errors on the order of $20-100 \%$; 3 - moderately important. Typically the errors are on the order of 5-20\%, but under specific conditions much larger errors can result.

a The significance of measurement error increases with decreasing the rate of compound emission.

$\mathrm{b}$ Importance of the error depends on compound reactivity.

In this review and position paper, we present our concerns about the quality of existing emission factor databases, give an outline of key methodological problems that can bias estimations of $E_{\mathrm{S}}$, and provide suggestions to improve the current methodology for estimation of $E_{\mathrm{S}}$ and to clarify the uncertainties that remain even following our best modeling efforts. We argue that in addition to the dynamic nature of $E_{\mathrm{S}}$ (Niinemets et al., 2010a, c) that requires modification of emission algorithms, there are a number of potential experimental and processing sources of errors that can affect the precision and accuracy of emission data. Therefore, we advocate splitting the available data into three broad quality classes: quantitative, semi-quantitative and non-quantitative measurements. Finally, we propose a protocol for standard- ized measurements of $E_{\mathrm{S}}$ and a list of key meta-data to be reported with any $E_{\mathrm{S}}$ estimation. The summary of the key experimental, calculation and reporting errors is provided in Table 1 with estimated importance of any given error source.

\section{Limitations in estimation of emission factors due to sampling systems}

An extensive range of measurement systems, starting from simple static (closed) systems without environmental control and monitoring to sophisticated dynamic (open) systems with full environmental control, has been employed to estimate BVOC emission fluxes (Fig. 1 for a range of systems currently in use by BVOC community). The sampling 


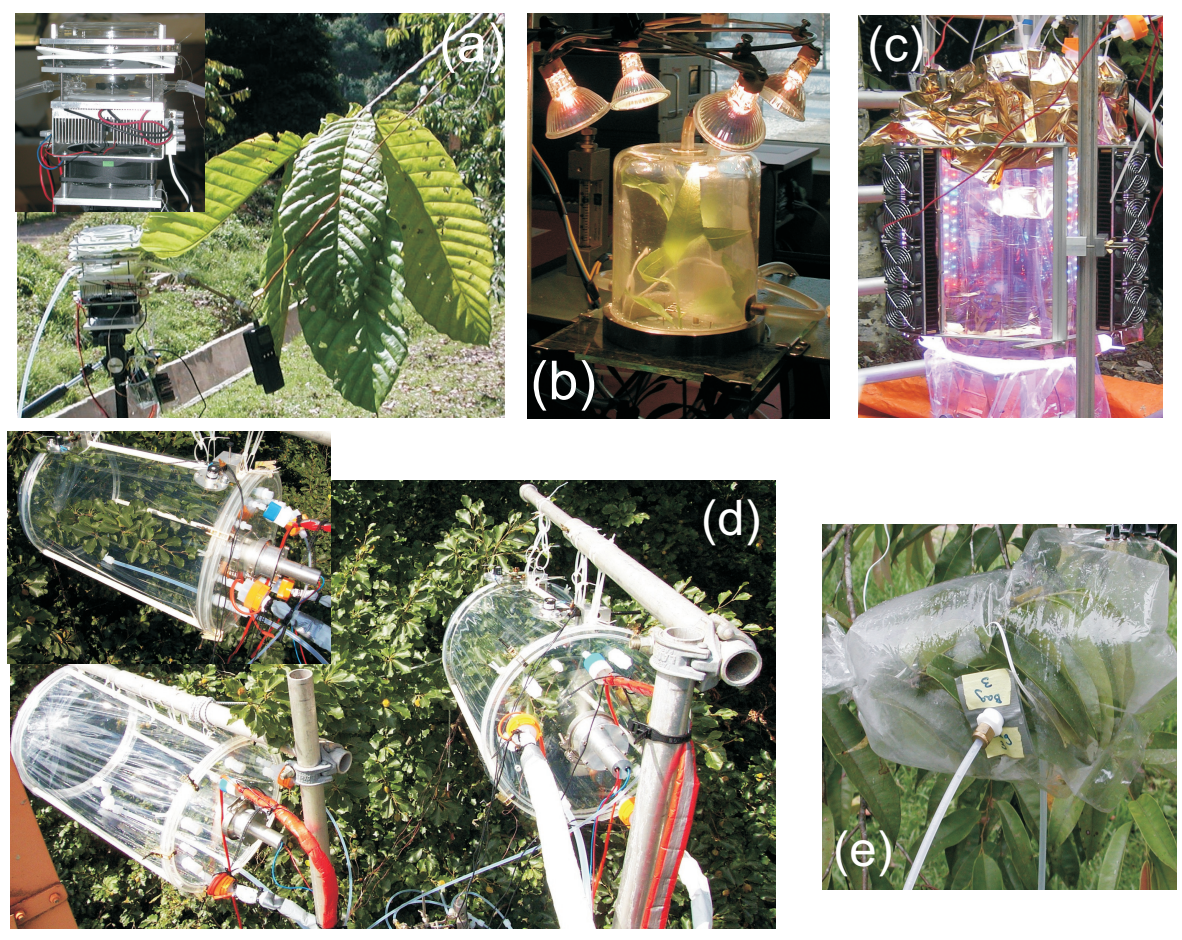

Fig. 1. Comparison of various enclosure systems currently used for measurement of BVOC emissions from plants: (a) two-halved glass cuvette with a polymer gasket and thermoelectric (Peltier) temperature control for field measurements (Peter C. Harley, NCAR, Boulder, USA), (b) double-layered glass cuvette with thermostatted water between the two glass layers for laboratory measurements (for detailed description see Copolovici and Niinemets, 2010; Rasulov et al., 2009a), (c) Teflon ${ }^{\circledR}$ (FEP) film branch enclosure for field measurements with artificial illumination by blue and red LEDs (Jürgen Kesselmeier, Max Planck Institute for Chemistry, Mainz, Germany), (d) Teflon ${ }^{\circledR}$ (FEP) film branch enclosure system for measurements under natural illumination and under ambient temperatures; the system consists of two enclosures of 751 (air flow rate $401 \mathrm{~min}^{-1}$ ), one for reference air sampling and the other for plant sampling, and each enclosure is equipped with 2 light sensors and 4 thermocouples, two attached on the leaves at the lower part of the branch and two at the upper part (for details Dindorf et al., 2006; Kuhn et al., 2002b), and (e) polyvinylfluoride (PVF, Tedlar ${ }^{\circledR}$ ) bag for field measurements (Chris D. Geron, US EPA). The enclosures are installed on tropical evergreen dipterocarps Dipterocarpus applanatus (a) and Dryobalanops aromatica (e, both experiments conducted in Danum Valley Field Centre, Sabah, Borneo, Malaysia $\left(117^{\circ} 49^{\prime} \mathrm{E}\right.$ and $\left.5^{\circ} 01^{\prime} \mathrm{N}\right)$ in June 2008$)$, on temperate deciduous shrub Salix viminalis (b) in the lab, on temperate deciduous tree Fagus sylvatica (d, experiments conducted in deciduous broadleaved forest close to Jülich, Germany, $50^{\circ} 54^{\prime} \mathrm{N}, 6^{\circ} 25^{\prime} \mathrm{E}$ ), while an empty cuvette is shown in (c).

protocols used for BVOC measurements have also varied greatly among different studies, undergoing significant evolution as more information on the performance of different adsorbents and measurement system materials has accumulated and techniques for determination of less volatile compounds have been developed (Helmig et al., 2003, 2004; Kesselmeier et al., 1993, 1996, 1997; Kuhn et al., 2002a; Pollmann et al., 2005; Schäfer et al., 1992; Tholl et al., 2006). Due to a lack of detailed technical specifications such as air turnover time, changes in chamber conditions with given incident radiation load, etc., measurement system artifacts and influences of variation in sampling protocols are difficult to assess for any single study. Analytical uncertainties have been estimated to be on the order of $20 \%$ in single lab studies (Owen, 1998). However, inter-comparisons of various measurement systems demonstrate that uncertainties can be much larger, exceeding $100 \%$ in some cases (Larsen et al., 1997; Steinbrecher et al., 1994). In fact, use of incompatible sampling methods ignoring environmental conditions (ozone presence in ambient air, for example) can lead to complete lack of detection of more reactive and/or less volatile compounds (Fuentes et al., 2000; Helmig et al., 2004; Larsen et al., 1997; Ortega and Helmig, 2008; Steinbrecher et al., 1994; Stewart-Jones and Poppy, 2006).

The methods for BVOC chemical detection and calibration, and to some degree sampling systems, have been reviewed recently (Ciccioli et al., 2002; Komenda et al., 2001; Ortega and Helmig, 2008; Tani et al., 2003; Tholl et al., 2006). In this section, we focus on uncertainties resulting from enclosure types and outline issues relevant for sampling techniques and flux calculations (Sect. 3), and data interpretation and further processing (Sect. 4), mainly focusing on dynamic systems. Although closed systems can provide useful information on species capacity to emit BVOC, we 
believe that the inherent uncertainties associated with such systems, including excessive depletion of $\mathrm{CO}_{2}$, extensive alteration of environmental conditions such as build-up of humidity and increase in temperature, large increase in BVOC concentrations, BVOC adsorption and sustained memory effects, mass-flow leaks, and risk of induction of BVOC emissions due to altered environment, are so large that these systems should not be used for quantitative characterization of BVOC emissions. Such systems might be useful for identifying types of BVOC emissions from given plant species, but accurate determination of emission flux rates is extremely difficult with closed systems.

\subsection{Enclosure chamber type and size}

The disturbance of environmental conditions (e.g. radiation, temperature, humidity, trace gas concentrations), leading to accumulation of heat and water vapor and depletion of $\mathrm{CO}_{2}$ by measurement installations should be minimized to ensure optimum plant physiological activity and maximum sensitivity of emission measurements. Ideally, measurements of BVOC concentrations are conducted under steady-state conditions. The key requirements for reliable steady-state gasexchange measurements are simple: good seal, stable gasconcentrations and environment in the enclosure, stable flow rate, well-mixed air (turbulent conditions) inside the enclosure, and accurate gas concentration measurements. For measurement of the environmental response curves (light, temperature, $\mathrm{CO}_{2}$ ), the capacity to control the major environmental variables, light, temperature, humidity and gas concentrations inside the cuvette is also needed. In fact, to assess plant physiological parameters in a steady-state, the capacity to keep key environmental factors, temperature and incident light, stable for at least over several minutes is required. Decades of gas-exchange research in plant physiology have resulted in construction of sophisticated environment-controlled leaf, branch and whole-plant chambers (Field et al., 1989; Long and Bernacchi, 2003; Long et al., 1996; Niinemets, 2011). However, in surveys and inventory studies in remote areas, fulfilling all these requirements can be difficult. Thus, simple Teflon ${ }^{\circledR}$ or Tedlar ${ }^{\circledR}$ bag systems, or large whole branch chambers without environmental control and limited turbulent mixing of air have often been used in BVOC studies (Fig. 1). Such systems impose limitations on the development of $E_{\mathrm{S}}$ databases since measurements can only be made under existing and often fluctuating environmental conditions, which are typically modified by the enclosure itself. Because of the lack of environmental control in the bag or chamber, foliage temperatures often rise substantially above ambient (Fig. 2), while foliage clustering leads to within-branch shading, implying imprecisely defined and heterogeneously-distributed leaf temperatures and incident quantum flux densities.

Leaf temperature is generally measured using thermocouples. Typically a single thermocouple is attached to the lower (a)
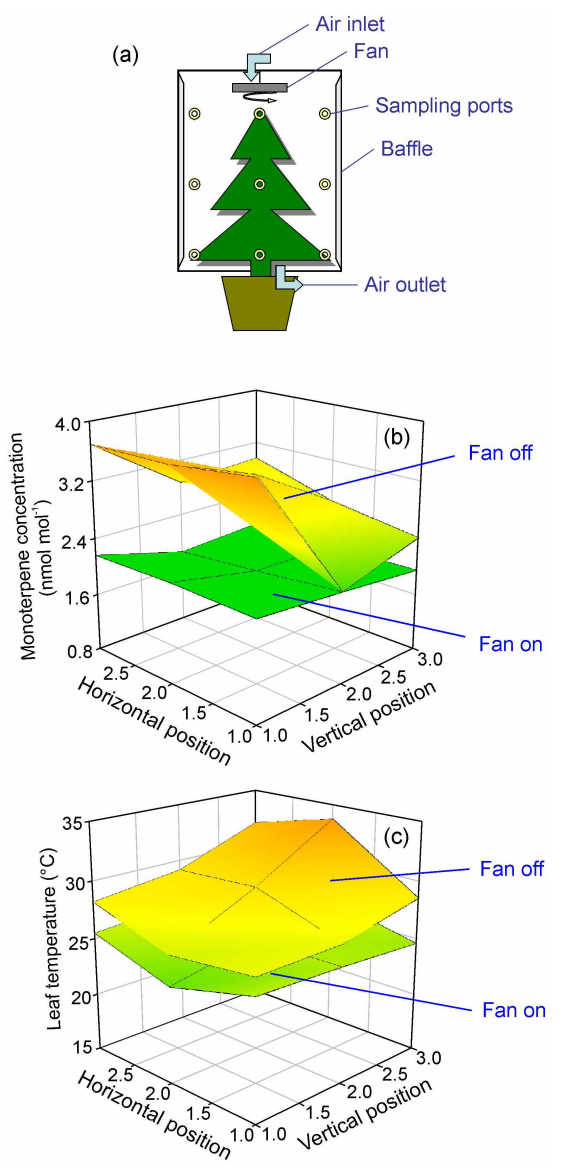

Fig. 2. Illustration of a whole plant BVOC measurement chamber for estimation of the distribution of BVOC concentrations and leaf temperatures throughout the chamber (a), and BVOC concentration (b) and leaf temperature (c) gradients with and without the mixing fan on. The vertically orientated blades of the fan and the baffles of the chamber frame optimize turbulent air mixing, thus generating a homogenous atmosphere at relatively low wind speeds (Staudt et al., 2000 for a more detailed description of the chamber system). A young Norway spruce (Picea abies) tree was enclosed in the chamber, and BVOC concentrations (b) and needle temperatures (c) were simultaneously measured at nine different positions inside the chamber either with the mixing fan off (upper plots) or with the fan on (lower plots). The chamber was located in cool air-conditioned greenhouse. BVOC concentrations and leaf temperatures are much more homogenous with the fan running than when the fan is stopped. Furthermore, when the fan is switched off, leaf and air temperatures inside the chamber increase due to decreased heat exchange between the chamber and the cool air outside the chamber in the air-conditioned greenhouse, and consequently BVOC emissions and concentrations increase. When the fan is off, highest BVOC concentrations occur in the lower part of the chamber, while the highest temperatures are in the upper part, reflecting the strongly asymmetric biomass distribution in the spruce trees as well as lack of mixing of chamber air. The measurement positions are defined for the horizontal as: 3 - west, 2 - middle, 1 - east; and for the vertical: 3 -top, 2 - middle and 1 - bottom (based on the data of Staudt, 1997). 


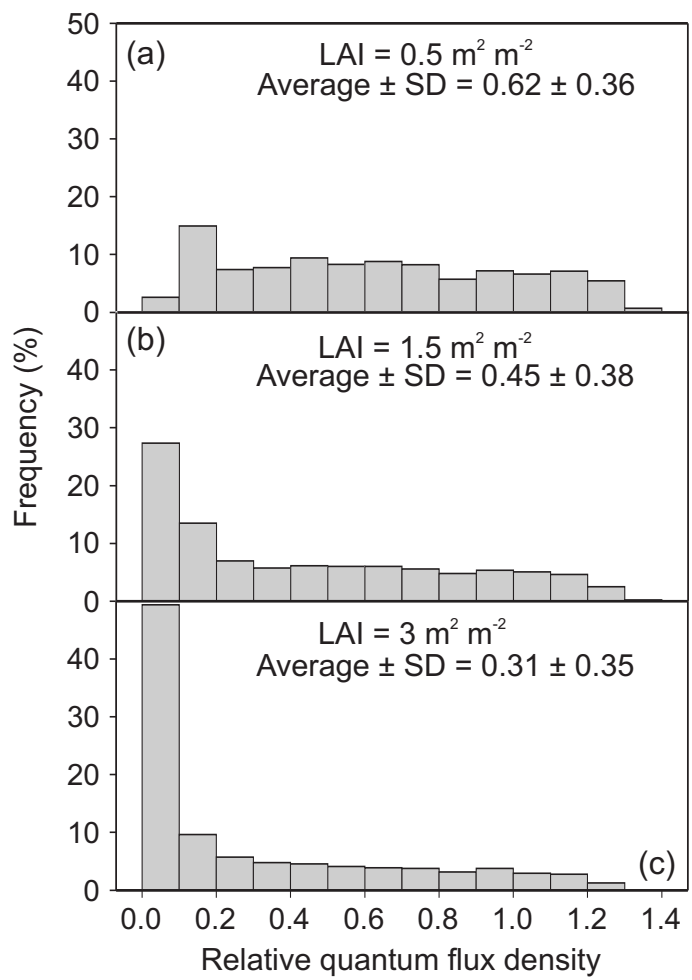

Fig. 3. Frequency distribution of light intensity on leaf surface within branch enclosures including progressively more leaf area. As a measure of leaf area enclosed in the measurement chamber, branch leaf area index, i.e. leaf area per unit flat surface area, is used. Light intensity relative to the intensity on a flat surface above the branch is computed for a solar angle of $45^{\circ}$ and assuming $80 \%$ of direct radiation. The simulation was performed with a ray tracing model for circular flat leaves having a spherical leaf angle distribution and random dispersion (Cescatti and Niinemets, 2004 for details). The gradients of light are expected to be even stronger for aggregated foliage dispersions as is common in most conifers (Cescatti and Zorer, 2003; Niinemets et al., 2006).

surface of a leaf. Due to heterogeneous distribution of leaf temperatures in the chamber, however, this single measurement is likely an inaccurate representation of the thermal state of the enclosed foliage (Fig. 2). In more elaborate systems, such as large branch enclosures (Fig. 1d) up to 4 thermocouples are used, resulting in better characterization of temperature environment, which nevertheless is far from ideal. Analogously, quantum flux density is measured above the foliage, commonly in one location in the given chamber. However, light availability strongly varies within a given branch (Fig. 3 for variation in quantum flux density), implying that one or even multiple estimates of light intensity above the branch provide limited information on the light intensity incident to individual leaves (e.g. Palva et al., 1998a, b).

For a given analytical system, exchange measurements by the dynamic chamber method are generally limited by the minimum detectable trace gas concentration difference between incoming and outgoing air. This concentration difference is proportional to the emission rate and leaf area enclosed in the chamber, and inversely proportional to the chamber air flow rate. In the case of compound preconcentration systems such as trapping on sorbent cartridges or on cryo-traps, the overall sensitivity is proportional to the time of sampling, but ideally the sampling time is kept as short as possible to avoid changes in plant physiological status during sampling. Thus, the choice of the purging air flow rate is usually a compromise between different and partly conflicting requirements for the enclosure system (detection limit of exchange rate, versus time response and modification of ambient conditions and avoidance of plant physiological status). The use of larger chambers usually involves longer air residence times unless very high flow rates are used (Niinemets, 2011 for a review of chamber size vs. air exchange time). The time-dependent change in chamber gas concentration of an empty chamber, $C_{\text {chamber }}$, can be expressed as (Li-Cor Inc., 2001; Niinemets, 2011):

$\frac{d C_{\text {chamber }}}{d t}=\frac{F}{V}\left(C_{\text {in }}-C_{\text {chamber }}\right)$,

where $F$ is the flow rate through the system $\left(1 \mathrm{~min}^{-1}\right), V$ is the chamber volume (1), $t$ is time and $C_{\text {in }}$ is the incoming gas concentration. When a plant sample is included in the chamber or when there is compound adsorption on the surface or desorption from the surface of the gas-exchange system, full mass balance equation needs to include source and/or sink terms (see Eq. 4). Integrating, and determining the integration constant at $t=0$ when the initial chamber gas concentration is $C_{\text {chamber,s }}$, yields the following expression of chamber gas concentration:

$C_{\text {chamber }}(t)=C_{\text {in }}-\left(C_{\text {in }}-C_{\text {chamber, } \mathrm{s}}\right) \exp \left(-\frac{F}{V} t\right)$.

The ratio $F / V$ is the first order rate constant of timedependent changes in the chamber gas concentration. The chamber flushing half-time is given as:

$\tau_{c}=\ln (2) /(F / V)$

A time of $4 \tau_{c}$ is needed for $94 \%$ of full system response, and this time can be taken as a satisfactory approximation of that required to reach a steady-state, assuming a constant flux. Thus, a chamber with a volume of 51 and a flow rate of $11 \mathrm{~min}^{-1}$, reaches the steady-state in ca. $14 \mathrm{~min}$, while the same chamber with a flow rate of $51 \mathrm{~min}^{-1}$ reaches the steady-state in ca. $3 \mathrm{~min}$. At the extreme, large whole-plant chambers used in BVOC studies may take more than an hour to reach the steady-state (for examples see Hüve et al., 2007; Niinemets, 2011).

The Eqs. (1-3) are based on ideal turbulent mixing in the chamber without the plant. In real chambers, especially when they contain large quantities of plant material, reaching the 
steady state typically takes longer than what was predicted here (Niinemets, 2011), and it is recommended to wait significantly longer than the minimum times predicted by first order decay kinetics, ideally checking the chamber responsiveness with a plant with real-time BVOC sensors (see below). These equations emphasize that vigorous mixing with a fan is essential for reliable measurements (Fig. 2). To avoid gas concentration gradients or pockets of dead air in the chamber, and thus excessively long chamber half-times, one must maintain a reasonable balance between the chamber size, flow rate and the amount of biomass enclosed in the chamber. As an example of a quantitative description of the modification of turbulent transport in an enclosure as compared to undisturbed ambient conditions we refer to Pape et al. (2009).

Apart from the long times needed to reach a steady-state, low flow rate through the chamber can lead to $\mathrm{CO}_{2}$ depletion and high chamber humidity or condensation due to plant gas exchange activity as well as to BVOC buildup due to plant emissions. These alterations in the chamber atmosphere can directly affect isoprenoid emission or, in the case of excessive humidity, generate considerable problems and errors downstream in BVOC sampling and in $\mathrm{CO}_{2} / \mathrm{H}_{2} \mathrm{O}$ gas exchange measurements, especially if condensation of water occurs on the surface of sampling lines and measurement chamber (Sect. 3.3 for the effects of BVOC ambient concentrations). Such problems can be avoided by matching the flow rate to the amount of biomass in the chamber.

Although smaller well-mixed chambers generally reach a steady-state rapidly, within seconds to minutes (Rasulov et al., 2010 for the use of an ultra-fast system in isoprene measurements), care needs to be taken to allow the leaf BVOC concentrations and physiological status to equilibrate with chamber conditions after leaf enclosure. This is needed as mono- and sesquiterpenes can be non-specifically stored within the leaves and leaf surface after synthesis (Niinemets et al., 2010c; Niinemets and Reichstein, 2002). This means that even if the system and plant responses can be deconvoluted, sufficient time is needed for plant emission rates to reach a steady-state for accurate estimation of the emission rate. On the basis of the Niinemets and Reichstein (2002) storage model, it can be predicted that for evergreen broadleaved sclerophyllic Quercus ilex, reaching at $99 \%$ steadystate monoterpene emission response after a stepwise increase in irradiance takes ca. $10 \mathrm{~min}$, but this time may differ for single monoterpene compounds depending on their physico-chemical properties that affect their non-specific storage.

Biochemical induction also can introduce significant delays in emission responses. For non-induced leaves, for instance after prolonged darkening, biochemical induction of photosynthesis and monoterpene (Noe et al., 2010) and isoprene (Rasulov et al., 2009b) emissions may take 20-30 min (Niinemets et al., 2010c for a review). Such non-specific storage effects and induction responses can be monitored by fast online BVOC detector systems and reaching a steadystate emission rate can be appropriately estimated. In the case of BVOC sampling on cartridges and subsequent offline gas-chromatographic analysis, ample time should be allowed for stabilization of the emission fluxes before the start of sampling. For offline systems, it is recommended that a period of at least $30 \mathrm{~min}$ be allowed for leaf stabilization after changes in environmental conditions before sampling of BVOCs, even when using chambers with rapid air turnover. Of course, for investigation of rapid transient responses, fast sampling is needed, but for $E_{\mathrm{S}}$, commonly defined as the emission rate under steady-state conditions (Niinemets et al., 2010c for a review), both chamber and plant physiology must reach a steady-state.

\subsection{Diffusion problems associated with small chambers}

The use of small commercial clamp-on chambers with environmental control (temperature, light and chamber gas concentrations) is currently gaining popularity in field studies and in many lab studies for simultaneous monitoring of leaf gas exchange activities and measurement of BVOC emissions either using fast online VOC detectors such as Proton Transfer Reaction Mass Spectroscopy (PTR-MS) or by sampling onto cartridges for offline gas-chromatographic analyses (e.g. Brilli et al., 2009; Calfapietra et al., 2008; Ekberg et al., 2009; Geron et al., 2001, 2006a, b; Lavoir et al., 2009; Okumura et al., 2008; Peñuelas et al., 2009). The smaller well-mixed chambers generally reach steady-state more quickly, within seconds to minutes, than larger chambers. For instance, with a typical flow rate of $350 \mu \mathrm{mol} \mathrm{s}^{-1}$ $\left(0.471 \mathrm{~min}^{-1}\right)$, Li-Cor 6400 (Li-Cor, Inc., Lincoln, Nebraska, USA), standard $2 \times 3 \mathrm{~cm}\left(6 \mathrm{~cm}^{2}\right)$ chamber is predicted to reach a steady state (Eqs. 2-3) in $21 \mathrm{~s}$. Despite the fast response, use of small chambers carries other challenges for accurate characterization of BVOC emissions. First, when the chambers are operated at high air flow rates, the BVOC detection limit will be poor, limiting measurement of low emissions. However, when the flow rate is kept low to result in higher BVOC concentration differences, chambers with small cross-sectional area and large chamber inner surface exposed gasket area for diffusion can generate errors in flux estimations due to diffusion of gases from the chamber air space with relatively high BVOC concentration into the ambient air with lower BVOC concentration (Flexas et al., 2007; Rodeghiero et al., 2007), especially for compounds with relatively small diffusion volume and high diffusion coefficient such as isoprene (Niinemets and Reichstein, 2003b for a comparison of diffusion coefficients for various BVOCs). In addition to BVOC, in leaf chambers, the water vapor concentration typically also increases above ambient due to leaf transpiration, resulting in diffusion of water vapor out of the chamber through the gaskets. This leads to an underestimation of transpiration rate and stomatal conductance, and erroneous interpretation of the physiological controls on 
isoprenoid emission (Rodeghiero et al., 2007). The modification of chamber $\mathrm{CO}_{2}$ concentration relative to ambient due to photosynthesis alone is relatively minor for major diffusion problems to occur. However, in studies investigating the $\mathrm{CO}_{2}$ responsiveness of isoprenoid emission, in which chamber $\mathrm{CO}_{2}$ concentration is varied over a large range, significant $\mathrm{CO}_{2}$ concentration gradients between chamber and ambient air can be present. These gradients can result in artificial increases or decreases of apparent leaf photosynthetic rate depending on the sign of the concentration gradient, with the effects being especially large for leaves with low photosynthetic capacity (Flexas et al., 2007; Rodeghiero et al., 2007). Such errors in photosynthesis measurements cause bias in photosynthesis vs. BVOC emission relations. Furthermore, changes in $\mathrm{CO}_{2}$ concentration and water vapor pressure within the enclosure will affect stomatal conductance (for classical studies on stomatal responsiveness to environmental drivers see, Ball et al., 1987; Morison, 1987; Schulze et al., 1987).

In general, the diffusion problems are larger for smaller chambers operated at high flow rates. To reduce the errors due to diffusion, chambers with relatively large enclosed leaf area $\left(A_{\mathrm{L}}\right)$ to exposed gasket surface area $\left(A_{\mathrm{G}}\right)$ are recommended. For instance, large diffusion problems have been denoted for Li-Cor $64002 \mathrm{~cm}^{2}$ chamber $\left(A_{\mathrm{L}} / A_{\mathrm{G}} \approx\right.$ $0.67 \mathrm{~cm} \mathrm{~cm}^{-2}$ ), while the errors are considerably less for LiCor $64006 \mathrm{~cm}^{2}$ standard chamber $\left(A_{\mathrm{L}} / A_{\mathrm{G}} \approx 1.0 \mathrm{~cm} \mathrm{~cm}^{-2}\right)$, or for Walz GFS-3000 $8 \mathrm{~cm}^{2}$ standard chamber $\left(A_{\mathrm{L}} / A_{\mathrm{G}} \approx\right.$ $1.11 \mathrm{~cm} \mathrm{~cm}^{-2}$ ) (Rodeghiero et al., 2007). Apart from diffusion, adsorption/desorption problems, as outlined below, also scale with the exposed enclosure surface, in particular exposed polymeric gasket surface to enclosure volume ratio, further emphasizing that the use of enclosures with small volume and large polymeric surface area should be avoided.

\subsection{Materials used in gas-exchange systems}

In addition to diffusion problems, terpene adsorption can occur on chamber walls and gasket surfaces as well as on system tubing and O-rings. Standard foam gaskets used in commercial gas-exchange systems initially designed to monitor $\mathrm{CO}_{2}$ and water vapor exchange, such as those manufactured by Li-Cor, Inc., PP-Systems, Inc., ADC Bioscientific, Ltd., Walz GmbH etc., are made of neoprene (polychloroprene) rubber (black gaskets used by default), while the O-rings are made of butyl-rubber. In addition, polyethylene foam (white foam) is also used in manufacturing gaskets. Polyethylene and combinations of polyethylene with other polymers (e.g. Bev-A-Line - polyethylene lined with ethylenvinyl acetate) are typical materials for tubing in commercial gas-exchange systems. All these materials can adsorb significant quantities of organic compounds (Harogoppad and Aminabhavi, 1991). Although the adsorption and desorption characteristics of polymers used most frequently in emission studies have not been studied quantitatively for key volatiles emitted from plants, studies on organic vapors of environmental concern have suggested that polymers such as neoprene and low-density polyethylene, used by default in commercial systems, have potentially significant adsorption/desorption problems for VOC studies (Allaire et al., 2003; Avison et al., 2001; Hartman, 1999; Hodgson et al., 1998; Manura, 1999). Apart from adsorption on polymers, in commercial gas-exchange systems, traces of silicone oil are present in O-ring seals, and in $\mathrm{CO}_{2}$ cartridges, and in the match valve of Li-Cor 6400 system, introducing additional memory effects and contamination problems due to solubilization and evaporation of anthropogenic and biogenic VOCs in oil (Geron et al., 2006a).

In addition to significant compound adsorption, the polymers used by default in the commercial systems are permeable to volatile compounds to a certain degree, amplifying the diffusion problems discussed above. As the result of slow time- and temperature-dependent decomposition, rubber and plastic materials may also constitute a contamination source of VOCs inherent to the material (Ezquerro et al., 2003; Fujii et al., 2003; Hartman, 1999; Hodgson et al., 1998; StewartJones and Poppy, 2006; Westerhout et al., 1997). Apart from tubing and chamber wall materials, adhesive tapes are often used to attach films or tubing to support structures or to attach heating wires to tubing. This can constitute a further problem as the adhesives of the tapes can further contribute to the background VOC level. This release of VOCs, together with re-emission of previously adsorbed plant BVOCs on tubing and chamber materials, generates a high level of background noise and memory effects and makes the identification and quantification of trace emissions difficult. Any adsorption effect can result in artificial time-lags between the emission from plants and detection by BVOC sensors, thus obscuring the emission kinetics. This can be especially annoying in rapid screening of plant species for BVOC emissions, especially if offline systems involving trapping onto cartridges are used and baseline emissions of empty sampling system cannot be continuously monitored, or if slow-response GCbased online systems with long sampling lines are used for measuring BVOC emission fluxes.

Adsorption to surface also increases the residence time of compounds in the chamber and thus enhances the probability of their oxidative destruction. This can be particularly significant for assessment of highly reactive monoterpene and sesquiterpene emissions (Fig. 4), especially if atmospheric oxidants such as ozone are not removed from the purge air during BVOC measurements (Sect. 3.2).

To reduce the adsorption and diffusion effects, a variety of materials with lower gas permeability and better adsorption characteristics has been used. A huge number of polymers with different brand names are available (Massey, 2003), making the selection of appropriate materials difficult. Furthermore, large differences in physico-chemical characteristics exist even within the same family of polymers (Sturm et al., 2004 for comparison of various polytetrafluoroethylene, 


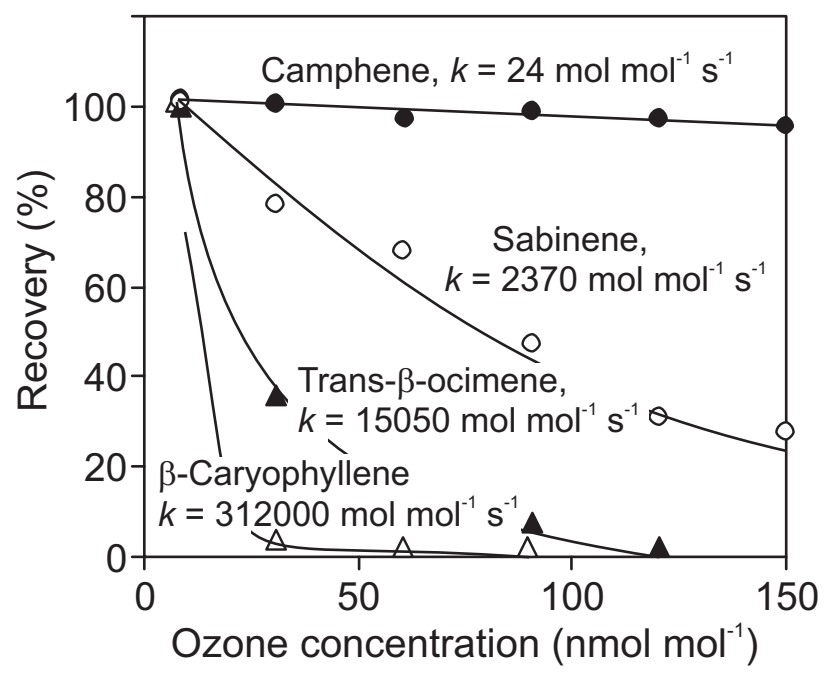

Fig. 4. Comparison of the recovery of terpenes with various reactivity sampled on polymeric adsorbent Tenax TA in atmospheres with varying ozone concentration (data from Calogirou et al., 1996). The reactivity of different terpenes is characterized by the atmospheric reaction rate constant for ozone $(k)$. The reaction rate constants as compiled in Calogirou et al. (1996).

PTFE, such as Teflon ${ }^{\circledR}$ grades). The important points to consider for gaskets and O-rings in BVOC studies are gaspermeability, adsorption capacity and flexibility (hardness). Based on comparison of physico-chemical properties and field testing (Geosyntec consultants Inc., 2009; Hayes et al., 2006; Jasse et al., 1999; Parkinson, 1985; Stewart-Jones and Poppy, 2006; Sturm et al., 2004), preferred polymeric materials for gas-exchange and BVOC studies can be outlined. For gaskets and O-rings, fluorinated hydrocarbons typically have significantly better physico-chemical properties than polyethylene, silicone, chloroprene or butyl rubber (Sturm et al., 2004). Among the recommended materials are fluoroelastomers (FKM/FPM) such as certain Viton ${ }^{\circledR}$ families (e.g. higher flexibility B and F types) and perfluorinated elastomers (FFPM/FFKM) such as Kalrez ${ }^{\circledR}$ or Parofluor ${ }^{\circledR}$ as well as polychlorotrifluoroethylene (PCTFE) such as Kel$F^{\circledR}$ (for an overview of physico-chemical characteristics of various polymers see Rodeghiero et al., 2007; Sturm et al., 2004). Although some of these materials such as PCTFE have exceptionally low gas permeabilities and adsorption capacities, disadvantage of polymers with such extraordinary physico-chemical characteristics can be excessive hardness, making it difficult to get a good seal (Sturm et al., 2004). A recommended compromise is the application of commercially available PFA-covered Viton ${ }^{\circledR}$ rings, which combine an acceptable inner hardness with good sealing properties and surface inertness.

For tubing, flexible polymer tubing with high amorphous phase polymer such as low-density polyethylene, latex, sili- cone and neoprene rubber is not recommended due to high permeability and adsorption problems (Geosyntec consultants Inc., 2009; Hayes et al., 2006). For instance, complete loss of sesquiterpenes was noted after passage through silicone tubing (Helmig et al., 2004). Low adsorption and permeability probably make stainless steel, in particular with amorphous silicone coating (e.g. SilcoSteel ${ }^{\circledR}$, Sulfinert ${ }^{\circledR}$ ) or with electropolished surface, the best material for tubing (Arnts, 2010; Geosyntec consultants Inc., 2009; Helmig et al., 2004). Good recovery of volatile terpenoids has also been observed for copper tubing, but copper tends to adsorb water vapor, which limits its utility in plant physiological studies where transpiration or conductance are of interest (Helmig et al., 2004). However, the limitation of metal tubing is low flexibility and difficulties in making good seals at connections. Among polymers, physico-chemical properties for VOC system construction are generally suitable for rigid polymers with low amorphous phase (high crystalline phase) fraction such as fluorinated hydrocarbons - PFA (perfluoroalkoxy), FEP (fluorinated ethylene propylen), and PTFE brands (e.g. Teflon ${ }^{\circledR}$ and Chemfluor ${ }^{\circledR}$ ) (Geosyntec consultants Inc., 2009; Hayes et al., 2006). Polyetheretherketone (PEEK) (Wang et al., 2006 for physico-chemical characteristics) and certain nylon brands (Massey, 2003 for physicochemical characteristics) can also yield satisfactory results and are used in VOC sampling systems (Geosyntec consultants Inc., 2009; Hayes et al., 2006).

For gas exchange enclosures (cuvettes), glass, although fragile, typically has very low adsorption capacity for most VOCs and therefore has been used in many sampling systems (Beauchamp et al., 2005; Copolovici et al., 2011; Copolovici and Niinemets, 2010; Fuentes et al., 1995; Hüve et al., 2007; Matsunaga et al., 2008; Papiez et al., 2009; Rasulov et al., 2009a; Wildt et al., 2003). Glass cuvettes without (Beauchamp et al., 2005; Copolovici et al., 2011; Hüve et al., 2007; Wildt et al., 2003) and with temperature control have been used (Fig. 1a, b, Copolovici and Niinemets, 2010; Matsunaga et al., 2008; Papiez et al., 2009; Rasulov et al., 2009a). Cuvettes made of stainless steel with glass windows and polymer seals have also been found to have satisfactory terpenoid recovery, although memory effects leading to long equilibration times have been noted as a major disadvantage (Helmig et al., 2004). Among recommended polymers for sampling are transparent fluorinated hydrocarbon films - like FEP and PFA, or opal PTFE (Teflon ${ }^{\circledR}$ ), PVF (polyvinylfluoride, Tedlar ${ }^{\circledR}$ ), PVDF (polyvinylidenfluoride, Kynar $^{\circledR}$, Dyneon ${ }^{\circledR}$, Solef ${ }^{\circledR}$ ) (e.g. Kesselmeier et al., 1993, 1996; Matsunaga et al., 2008; Niinemets et al., 2002a; Pape et al., 2009; Steinbrecher and Hauff, 1996). In addition, "polyester" (polyethylene terephthalate, PETE) films such as Mylar ${ }^{\circledR}$, and Nylon-6 films (so-called "cooking bags") have been often used in chemical ecology (Raguso et al., 2003; Stewart-Jones and Poppy, 2006; Theis, 2006). Significant background emissions due to impurities such as phthalates, 
often applied as a softener in polymers, and aliphatic hydrocarbons were noted particularly for Nylon-6, but also from PETE bags, but these interfering emissions could be reduced by pre-heating and extended purging of the bags with purified air before the measurements (Stewart-Jones and Poppy, 2006). After preconditioning, the recovery of volatile compounds for PETE bags was similar to glass, but lower for Nylon-6 (Stewart-Jones and Poppy, 2006). Although relatively inert polymers can be found for branch or whole-plant enclosures, the key problem inherent to such systems is lack of temperature control unless a very high flow-through rate is used, and for non-rigid "bag-type" systems, difficulties in maintaining enclosure volume and avoiding contact with the plant material (rough handling problems, Sect. 2.5). As to the adhesive tapes in BVOC studies, they are best avoided, but whenever they need to be used, low VOC emission tapes are recommended.

In general, absolutely inert materials for BVOC measurements have not been found, and experimentation with different polymer families marketed under different brands, can be very costly. Nevertheless, several fluorinated hydrocarbon polymers, stainless steel and glass exhibit superior performance over conventional polymers used in commercial gas-exchange systems, and are therefore recommended for BVOC measurements.

\subsection{Correcting for chamber size and other memory effects}

Allowing the system to reach a steady-state is the safest way to avoid problems resulting from system memory effects. However, excessive waiting times, sometimes many hours, are needed for very sticky compounds such as sesquiterpenes (Helmig et al., 2003, 2004). With development of fast online BVOC sensors such as PTR-MS, researchers are increasingly interested in rapid measurements of $E_{\mathrm{S}}$ as well as in rapid regulation of $\mathrm{BVOC}$ emissions in response to environment. However, not only do these long waiting times preclude fast measurements, plant physiological status may change during the time needed for the system to reach the steady-state, and the emission rate may not be stable throughout the extended waiting periods (Bertin and Staudt, 1996 for changes in monoterpene emissions under continuous constant illumination). To disentangle the system and plant effects, the change in the mass of the BVOC in the system can, in the simplest way, be expressed as (cf. Eq. 1):

$\frac{d C_{\mathrm{out}} V_{\mathrm{s}}}{d t}=F\left(C_{\mathrm{in}}-C_{\text {out }}\right)+A_{\mathrm{L}} E+A_{\mathrm{T}} \eta$,

where $V_{\mathrm{s}}$ is the system volume $\left(\mathrm{m}^{3}\right.$, chamber plus sample tubing volume), $C_{\text {out }}$ is the BVOC concentration in the system $\left(\mathrm{mol} \mathrm{m}^{-3}\right), C_{\text {in }}$ is the BVOC concentration in incoming air, $A_{\mathrm{L}}\left(\mathrm{m}^{2}\right)$ is the plant leaf area enclosed in the system, $E\left(\mathrm{~mol} \mathrm{~m}^{-2} \mathrm{~s}^{-1}\right)$ is the plant $\mathrm{BVOC}$ emission rate, $A_{\mathrm{T}}$ is the tubing and enclosure inner area, and $\eta$ is the ad- sorption/desorption rate. $C_{\text {out }}$ times $V_{\mathrm{s}}$ gives the $\mathrm{BVOC}$ mass in the system. $\eta$ is a function of the difference between the compound concentrations in the chamber or tube air (approximated by $C_{\text {out }}$ in the leaf chamber and downstream the chamber) and at chamber or tube surface $\left(C_{\mathrm{S}}\right)$. The way $\eta$ scales with this concentration difference depends on compound- and material-specific adsorption/desorption isotherms. Equation (4) is a crude simplification as $\eta$ can be difficult to predict due to lack of information on $C_{\mathrm{S}}$ and the shape of the adsorption/desorption isotherms and because, in reality, $C_{\text {out }}$ and $C_{\mathrm{S}}$ are not constant throughout the system, but can vary up- and downstream of the measurement chamber due to plant emission and adsorption/desorption effects. In addition, material properties can vary in different parts of the system, and separate adsorption/desorption terms may be needed for various components of the system in Eq. (4). Thus, quantitative consideration of the memory effects resulting from system size and adsorption of BVOC on chamber and sample line surfaces may be impossible using theoretical models such as Eq. (4), or the models may become overly complex. In practice, such effects can be considered by monitoring the rise and decay of BVOC concentrations in an empty measurement system using a stable air flow with specified BVOC concentration (Fig. 5, Rasulov et al., 2009a for further details). Such empirical responses can be considered together with models such as Eq. (4) to deconvolute the measurement system and plant BVOC emission responses. We again emphasize that water condensation in the system should be avoided as this would heavily delay the system response, especially for water soluble compounds such as methylbutenol and oxygenated monoterpenes (e.g. linalool and 1,8-cineole), and alter the system response coefficient. Thus, under high humidity experimental conditions, application of tube heating is recommended, specifically for all tubing downstream of the enclosure, where higher humidities are expected due to (i) addition of water vapor by transpiration and (ii) potentially lower ambient temperatures relative to the sunlit cuvette. Tube heating also reduces the adsorption of compounds on tubing surface, thereby speeding up the system response.

\subsection{Rough handling}

In species with specialized storage tissues for BVOCs such as glandular trichomes (species of Mentha, Salvia, Artemisia, Nicotiana etc.), oil glands (Citrus, Eucalyptus) and resin ducts (most commonly in conifers) clamp-on leaf chambers as well as non-rigid enclosure structures such as inflated bags may crush and break the terpene storage tissues, artificially increasing the emission rate. In species possessing specialized storage tissues, extremely high emission rates have been demonstrated after mechanical damage (Fig. 6, and e.g. Loreto et al., 2000). As the half-time for the evaporation of terpenes from crushed storage pools is typically on the order of hours to days (Fig. 6, e.g. Loreto et al., 2000; 


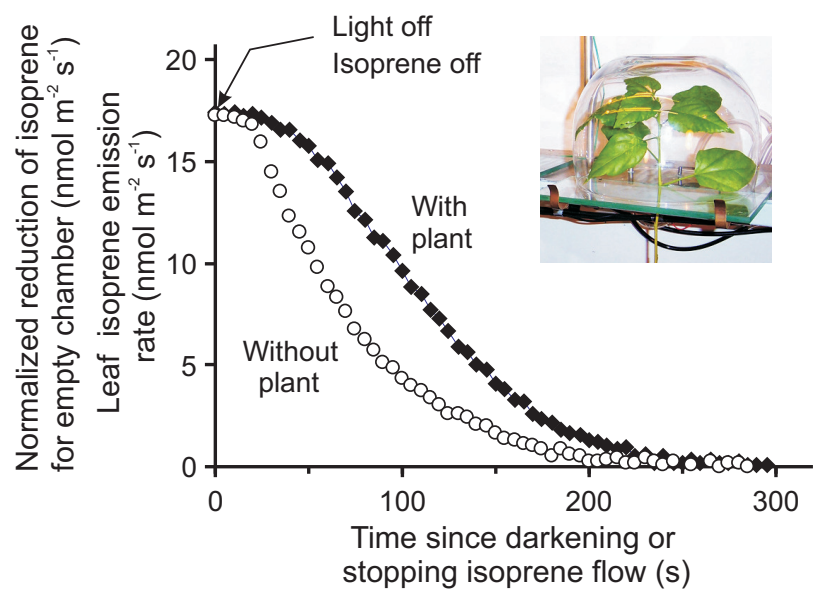

Fig. 5. Comparison of the transient responses of empty chamber and chamber with a hybrid aspen (Populus tremula $\times$ P. tremuloides, clone 200) plant included (modified from Rasulov et al., 2009a). To assess the transient response of the measurement system, a stable isoprene flow through the chamber was established using an artificial isoprene source. After the steady-state isoprene flow was reached, isoprene supply was stopped and the system transient response was recorded. In the case of measurements with the plant, the plant was kept at given environmental conditions (light intensity of $500 \mu \mathrm{mol} \mathrm{m}{ }^{-2} \mathrm{~s}^{-1}$, temperature $28-30^{\circ} \mathrm{C}$ ) until a steadystate emission rate was established. After reaching the steady-state, light was switched off, and the postillumination isoprene release recorded. The empty chamber system-specific response curve was scaled to given plant isoprene emission rate at steady-state conditions. Isoprene emission rate was measured with a Fast Isoprene Analyzer equipped with ozone generator (Hills Scientific, Boulder, CO, USA). The inset shows the 41 glass chamber used in these experiments (flow rate was $41 \mathrm{~min}^{-1}$ ).

Schuh et al., 1996), such artificial emissions can result in serious errors in derivation of $E_{\mathrm{S}}$ values. In species with specialized storage tissues, there is also evidence of significantly elevated terpene emissions with slow time-dependent decay after foliage enclosure in clamp-on chambers. In fact, in the pivotal study by Guenther et al. (1991), used to develop the terpene emission model from vegetation (Sect. 4.1 for Guenther et al. algorithms), time-dependent reductions in monoterpene emission rate were observed after enclosure of the foliage of the model species, Eucalyptus, in the measurement cuvette.

The emissions after damage eventually cease as the exposed terpenes evaporate and the wounding site is progressively sealed by oxidized terpenoids (Loreto et al., 2000). However, mechanical damage itself induces de novo synthesis of a variety of BVOCs, including rapid production of volatile compounds of lipoxygenase pathway such as several $\mathrm{C}_{6}$ aldehydes (green leaf volatiles) (e.g. Matsui, 2006; Vuorinen et al., 2004), and a variety of terpenoids (Fig. 6, Litvak and Monson, 1998; Vuorinen et al., 2004; Wang and Lincoln, 2004). Similarly, substantially increased formic

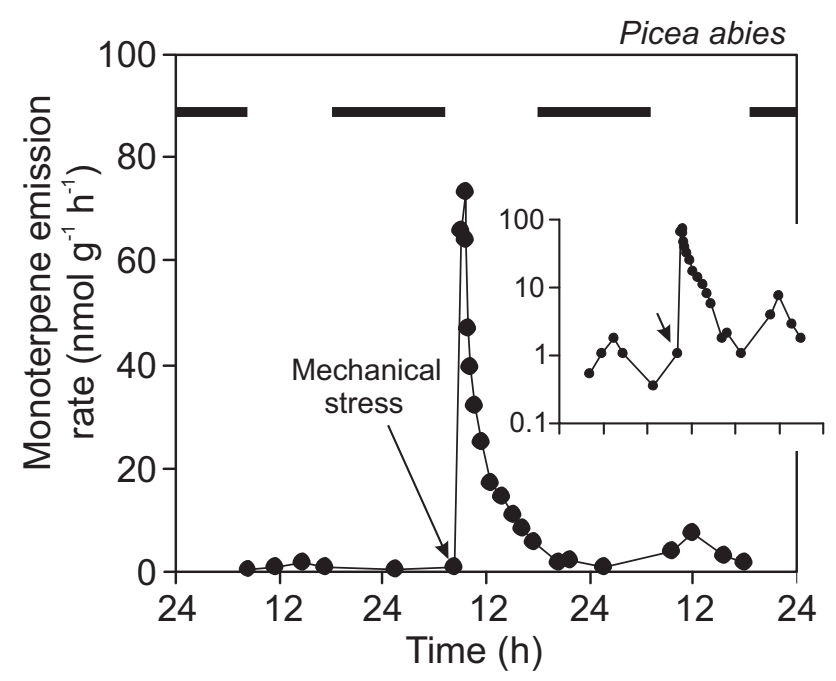

Fig. 6. Effect of mechanical disturbance on monoterpene emissions from a 7 yr old temperate conifer Picea abies tree. The whole tree crown was enclosed in the chamber (Fig. 2a for the system overview), and the emissions were monitored over three days. In the morning of day 2 the tree was shaken for 3 min (denoted by an arrow), causing a sudden increase in the emission rates by almost two orders of magnitude. The inset shows the emissions on a logarithmic scale, emphasizing that the emissions were still elevated two days after the mechanical stress. Dark periods are denoted by horizontal bars (modified from Staudt, 1997).

and acetic acid emissions from several plant species were reported by Kesselmeier et al. (1998) for several hours after enclosure of the sample. Artificially elevated emissions together with induction of emissions imply that mechanical damage makes reliable estimation of constitutive terpene emission potentials impossible. To avoid damage of the storage pools of terpenes, rigid chambers enclosing the entire shoot in needle-leaved species or entire leaf in the case of broad-leaved species should be used for measurements in species with specialized terpene storage tissues. In addition, petioles and shoot axes should be sealed in the leaf chamber with great care, ideally at least $24 \mathrm{~h}$ before the measurements to avoid release of volatiles from the site of petiole or shoot axis enclosure after removal of interfering needles/leaves and mild shoot axis compression. Ways of preparing the site of enclosure can include wrapping the shoot axis or petiole part remaining under the seal by inert tape (e.g. Teflon ${ }^{\circledR}$ tape), using low-emission glues etc.

\section{Problems of sampling and calculation of emission rates}

Apart from the measurement systems, large uncertainties, including lack of detection of some compounds, can be associated with sampling methodology. While fast BVOC sensors for online measurements such as chemiluminescence 
detection for isoprene (Hills and Zimmerman, 1990) and proton transfer reaction mass-spectrometry (PTR-MS) for methylbutenol, isoprene, and total mono- and sesquiterpenes (Lindinger et al., 1998a, b) are available, and higher mass resolution techniques such as time-of-flight (TOF) massspectrometry (PTR-TOF-MS, Bamberger et al., 2011; Cappellina et al., 2010) are becoming available, quantitative and qualitative separation of mono- and sesquiterpene species with the same molecular mass requires gas-chromatographic separation, for which samples need to be concentrated. Gaschromatographic analysis is also recommended to avoid artifacts in isoprenoid emission measurements by PTR-MS due to protonated parent ions or fragment ions with the same $\mathrm{m} / \mathrm{z}$ as the isoprenoid studied. For example, methylbutenol and several other alcohols and aldehydes can form fragment ions with $m / z$ of $69^{+}$, i.e. with the same $m / z$ as the protonated parent ion for isoprene (Fall et al., 2001; Karl et al., 2001), and several C6 aldehydes and monoterpenes can form fragments with $\mathrm{m} / \mathrm{z} 81^{+}$(Fall et al., 2001; Ishizuka et al., 2010).

Here we describe several caveats associated with sampling on cartridges as this is the methodology most commonly used for quantitative BVOC emission studies. Although electropolished stainless steel canisters or bags made of inert materials can also be used to store air samples (e.g. Apel et al., 1999; Janson et al., 1999; Plass-Dülmer et al., 2006; Wang and Austin, 2006) with the advantage that no adsorption/desorption steps are needed, they are not commonly used for field BVOC measurements due to their high cost, extra precautions needed to avoid leaks, difficulties in evaluation of compound losses during storage, and problems in coupling canisters to open gas-exchange systems, especially for replicate measurements (for possible caveats see Apel et al., 1999; Batterman et al., 1998; Plass-Dülmer et al., 2006; Wang and Austin, 2006).

After measurement of BVOC concentrations, emission flux rates need to be computed. Calculations for photosynthesis and transpiration rates have been elaborated in the plant physiological literature (Ball, 1987; von Caemmerer and Farquhar, 1981), but little attention has been paid to calculations of BVOC emission rates. Here we highlight the effects of BVOC ambient air concentrations, BVOC buildup in the measurement enclosure and the influences of changes in water vapor concentration on BVOC flux calculations.

\subsection{Caveats with sampling on cartridges}

In the absence of real-time portable on-line BVOC analyzers, $E_{\mathrm{S}}$ measurements in the field commonly combine trapping of BVOC from plant enclosures with subsequent offline analysis in the laboratory. With real-time fast analyzers such as PTR-MS that cannot distinguish between compounds with the same molecular mass, off-line analysis by gaschromatographic systems is also needed to identify emitted mono- and sesquiterpenes. For practical purposes, BVOCs are most commonly trapped by passing a known volume of chamber air through adsorbent cartridges. The trapped BVOCs are subsequently eluted from the adsorbent, usually by one or two stage thermodesorption, resulting in flash injection of the total amount of sampled BVOCs into the analytical system (Ciccioli et al., 2002).

Cartridges for BVOC sampling are made of glass or stainless steel internally coated with fused silica and contain a defined amount of adsorbent(s) for BVOC trapping. The requirements for the solid adsorbents for sampling volatile isoprenoids are simple: they should retain at ambient temperatures the largest number of compounds ranging from C5 to $\mathrm{C} 15$ present at ppt to ppb level in ca. 51 samples. At the same time, they must be able to quantitatively release all of them at temperatures that prevent possible decomposition of BVOCs $\left(\sim 250^{\circ} \mathrm{C}\right)$. The adsorbents used in BVOC studies can be polymer-resin based such as Tenax ${ }^{\circledR} \mathrm{TA}$, graphitized carbon blacks such as Carbopack ${ }^{\circledR}$, Carbotrap ${ }^{\circledR}$ and Carbograph ${ }^{\circledR}$, resin-derived carbon molecular sieves such as Carboxen ${ }^{\circledR}$ or Carbosieve ${ }^{\circledR}$ or combined polymer resin/graphitized carbon adsorbents such as Tenax ${ }^{\circledR}$ GR. The choice of adsorbent for BVOC sampling depends on the compounds under investigation and on the measuring conditions. Lower molecular weight highly volatile isoprenoids such as isoprene require the use of stronger polymeric or graphitized carbon-based adsorbents with larger specific surface area to avoid breakthrough during sampling (for surface area estimates of different adsorbents see e.g. Ciccioli et al., 2002; Dettmer and Engewald, 2002). For isoprene, graphitized carbon based adsorbents with large specific surface area $\left(100-500 \mathrm{~m}^{2} \mathrm{~g}^{-1}\right)$ such as Carbotrap B, Carbopack X and Carbograph 5 or carbon molecular sieves such as Carboxen 569 have been used successfully (Brancaleoni et al., 1999; Dettmer et al., 2000; Lärstad et al., 2002; Loivamäki et al., 2008; Loreto et al., 2001).

However, adsorbents used for isoprene are not necessarily suitable for less volatile isoprenoids such as mono- and sesquiterpenes that can be bound too strongly or even irreversibly to strong adsorbents, such that their release during thermal desorption would require excessive temperatures. In practice, such high temperatures result in compound thermodestruction and condensation, leading to major compound losses. For instance, rearrangement of monoterpenes at high temperatures needed for desorption has been noted for adsorbents with high surface area such as polymeric adsorbents (Chromosorb 101, 103, 105, 106, and Ambersorb XE340, surface area $\left.400-800 \mathrm{~m}^{2} \mathrm{~g}^{-1}\right)$ as well as for carbon molecular sieves (Spherocarb with surface area of $730 \mathrm{~m}^{2} \mathrm{~g}^{-1}$, Carboxen 569 with surface area of $485 \mathrm{~m}^{2} \mathrm{~g}^{-1}$ ) (Cao and Hewitt, 1993; Coeur et al., 1997; Matisová and Škrabáková, 1995; Riba et al., 1985). Decomposition of monoterpenes at high temperatures has also been noted for strong graphitized carbon based adsorbents such as Carbotrap B (surface area $100 \mathrm{~m}^{2} \mathrm{~g}^{-1}$ ) (Cao and Hewitt, 1993; Rothweiler et al., 1991) and for carbon molecular sieves such as Carboxen 569 
(Coeur et al., 1997). Therefore, other adsorbents such as Carbotrap C $\left(10 \mathrm{~m}^{2} \mathrm{~g}^{-1}\right)$ and Tenax TA $\left(35 \mathrm{~m}^{2} \mathrm{~g}^{-1}\right)$ with lower surface area are commonly used for quantitative sampling and recovery of higher molecular weight isoprenoids (Arnts, 2010; Helmig et al., 2004).

On the other hand, adsorbents suitable for sesquiterpenes have little capacity for isoprene adsorption, and thus, have low breakthrough volumes for isoprene. To efficiently capture a broad range of compounds, multi-layered adsorbent cartridges combining several size fractions and/or types of adsorbents have been used (Brancaleoni et al., 1999; Ciccioli et al., 1992, 1993, 2002; Copolovici et al., 2009; Llusià and Peñuelas, 2000; Mastrogiacomo et al., 1995). When using multi-adsorbent traps, the amount of each adsorbent must be sufficient to trap quantitatively the diverse compound classes under all sampling conditions. For instance, as compound volatility increases exponentially with temperature, the breakthrough volume of any adsorbent is strongly temperature dependent (principle of thermodesorption) and this should be considered in construction of cartridges for field sampling. For multi-bed cartridges, it is also critical to respect the flow directions during sampling and desorption. During sampling, air should first pass through the weakest adsorbent, followed by increasingly stronger adsorbents, while the flow direction should be reverse during desorption.

In general, different adsorbents with similar surface area and mesh size have broadly similar compound adsorption efficiencies (Ciccioli et al., 2002; Dettmer and Engewald, 2002). However, there are several key differences among various adsorbents with important implications for field sampling. In particular, different adsorbents vary greatly in water vapor adsorption capacity (Dettmer and Engewald, 2002; Helmig and Vierling, 1995). Typically, graphitized carbon blacks and Tenax-type of polymeric adsorbents, which retain molecules by pure physical adsorption and do not tend to form hydrogen bonds with water (hydrophobic adsorbents), have low water adsorption capacity, while carbon molecular sieves have high water adsorption capacity (Ciccioli et al., 2002; Dettmer and Engewald, 2002, 2003; Gawlowski et al., 1999; Helmig and Vierling, 1995), likely reflecting the presence of surface oxides in carbon molecular sieves leading to hydrogen bond formation (Dettmer and Engewald, 2002) or due to generation of strong adsorption fields inside the micropores of 5-7 $\AA$ as the result of overlapping dispersion forces of neighboring pore walls (Ciccioli et al., 2002; Gawlowski et al., 1999). For adsorbents with high water affinity, water vapor can reduce BVOC adsorption efficiency by blocking adsorption sites and thus, reducing the surface area available for BVOC adsorption (Ciccioli et al., 1992; Helmig and Vierling, 1995). Presence of adsorbed water can also create large problems in gas-chromatographic analysis, including clogging cryo-focusing traps with ice, shifts in retention time as well as interference with compound detection (Ciccioli et al., 1992; Gawrys et al., 2001; Helmig and Vierling, 1995; McClenny et al., 2002; Palluau et al., 2007). In addition, adsorbed water can lead to terpene rearrangements during desorption (Zabaras and Wyllie, 2002). As water adsorption scales with atmospheric humidity (Helmig and Vierling, 1995; Ortega and Helmig, 2008), sampling in the field where atmospheric humidity is often high can be particularly problematic. In addition, to maintain high plant physiological activity, measurements of plant gas exchange and BVOC emissions are preferably made in humid ( $>50 \%$ relative humidity) chamber atmospheres, i.e. in atmospheres with high enough humidity that can result in large amounts of water adsorbed, leading to serious problems (Gawrys et al., 2001). Moderate heating up of the traps during sampling can significantly reduce water adsorption (Gawrys et al., 2001), but unfortunately, also BVOC adsorption. Traps filled with water absorbing chemicals can be used in front of the BVOC adsorption cartridges, but these can lead to compound losses and memory effects (Dettmer and Engewald, 2003). Alternatively, Nafion ${ }^{\circledR}$, a copolymer of PTFE (Teflon ${ }^{\circledR}$ ) and sulfonated tetrafluoroethylene, membranes have been used to remove the water vapor with good VOC recovery in most cases, except for smaller volatiles that may also penetrate the membrane (Dettmer and Engewald, 2003; Palluau et al., 2007).

Stability of different adsorbents also varies widely, with important implications for repeated use of cartridges. Repeated heating cycles during thermodesorption and preconditioning can lead to decomposition of polymeric adsorbents such as Tenax, resulting in shrinking of the adsorbent (but see Arnts, 2010; Helmig et al., 2004). For quantitative BVOC sampling, any adsorption material must be homogenously packed in the cartridges and secured at both ends by glass wool to ensure the passage of sample air only through the adsorbent column and avoid any bulk flow leaks (channeling) bypassing the adsorbent. However, it is important to consider that the glass wool itself can function as an adsorbent (Arnts, 2010). In addition, cartridge wall material can affect the compound recovery as well due to adsorption and chemical reactions on wall surface (Arnts, 2010). To further reduce the risk of air-channeling and reactions on the wall surface, vertical arrangement of cartridges during both sampling and the desorption procedure is recommended (e.g. Kuhn et al., 2005). Due to loss of volume during repeated heating cycles, polymeric adsorbent cartridges have to be regularly repacked or replaced. For polymeric adsorbents susceptible to volume changes, adsorption tubes made of glass are recommended as these allow for visual inspection of the condition of the packing.

In summary, a wide variety of adsorbents and adsorbent mixtures has been used in the past, and is currently being used in different laboratories. Although BVOCs of interest can be efficiently captured and desorbed using different adsorbents or different mixtures of adsorbents (Brancaleoni et al., 1999; Ciccioli et al., 2002; Helmig et al., 2004), all adsorbents are vulnerable to artifacts and analytical problems 
as no perfectly inert adsorbent exists in nature. Combining different adsorbents in multibed cartridges as well as using less hydrophobic adsorbents can minimize such potential artifacts. Unfortunately, it is virtually impossible to retrospectively assess the error in $E_{\mathrm{S}}$ determinations in past studies due to problems with compound adsorption.

\subsection{Sampling in polluted atmospheres}

BVOC sampling in polluted atmospheres can constitute another challenge due to artifact formation and significant losses of highly reactive compounds such as certain monoand sesquiterpenes. In particular, the polymeric adsorbent Tenax has been shown to react with ozone and $\mathrm{NO}_{2}$ resulting in formation of artifacts (Clausen and Wolkoff, 1997; Klen $\varnothing$ et al., 2002; Lee et al., 2006; McClenny et al., 2002). Apart from reactions of air pollutants with polymer molecules, oxidation of sampled BVOC can occur on adsorbent surface. For instance, sampling at an ambient ozone concentration of $50 \mathrm{nmol} \mathrm{mol}^{-1}$ led to complete loss of highly reactive $\beta$-caryophyllene, but only to a minor loss of the less reactive limonene (Fuentes et al., 2000). Surface-oxidation of sampled BVOC molecules has been observed for both Tenax (Calogirou et al., 1996; Lee et al., 2006) and carbonbased adsorbents (Carbopack B, Carbosieve III etc.) (Fig. 4, Bates et al., 2000; Calogirou et al., 1996; Lee et al., 2006; McClenny et al., 2002; Palluau et al., 2007; Pellizzari and Krost, 1984; Pollmann et al., 2005). Although it has been stated that decomposition of BVOC is less of a problem on carbon-based adsorbents (Larsen et al., 1997), Pollman et al. (2005) observed that some reactive sesquiterpenes were decomposed to a similar degree whether trapped on Tenax TA, Tenax GR, or Carbotrap C and Carbotrap B (previously marketed as Carbotrap). Sesquiterpene oxidation results in the formation of oxidized sesquiterpenes and formaldehyde (Calogirou et al., 1997b), and such oxidized decomposition products may be erroneously considered to be plant emissions. The oxidation or thermal decomposition problems may explain observed emissions of compounds considered non-biogenic such as reported toluene emissions from plants (Heiden et al., 1999).

Even for less reactive compounds, decomposition losses on cartridges can be large if the samples are stored over long periods extending several days to weeks. The decomposition losses lead to overall underestimation of the emission rates, and can also strongly distort the emission signatures, specifically reducing the concentrations of more reactive isoprenoids (Calogirou et al., 1996). Such decomposition losses of BVOC can be reduced for any type of cartridge packing if ozone and water are removed from traps immediately after sampling. This can be achieved by purging the trap with a defined amount of an inert gas such as helium or pure nitrogen (Oliver et al., 1996; US Environmental Protection Agency, 1999). By reducing the contact between adsorbed BVOCs and ozone, losses arising from long-time storage can also be limited. Although this method can reduce the losses of already trapped BVOCs, it does not remedy for losses inevitably occurring within the gas-exchange chamber before trapping unless ozone is removed from the air entering the cuvette.

As oxidant scrubbers are commonly positioned in front of the plant chamber, such effects are more of a problem for measuring ambient air BVOC concentrations than for enclosure studies. So far, a variety of oxidant, in particular, ozone traps has been suggested (Bates et al., 2000; Calogirou et al., 1997a; Ciccioli et al., 1999; Helmig, 1997; Hoffmann, 1995; Ortega and Helmig, 2008; Pollmann et al., 2005), but different traps have varying efficiency of ozone-capture and can themselves lead to artifact formation as the result of reactions with VOCs sampled as well as adsorption/desorption effects (Fick et al., 2001; Helmig, 1997; Helmig and Greenberg, 1995). For monoterpene sampling, most ozone traps seem to perform well (Fick et al., 2001), but it has been observed that commercial manganese dioxide scrubbers can result in adsorption effects if the air is completely dry (U. Kuhn et al., unpublished data, 2004); and complete loss of some monoand sesquiterpenes even in ozone-free atmospheres has also been shown (Arnts, 2008; Pollmann et al., 2005). A promising method to control ozone is the addition of a low flow of reactive hydrocarbon not produced by plants, such as trans2-butene, into the air stream, effectively scavenging the bulk of the ozone, while not interfering with gas-chromatographic detection of BVOC (Arnts, 2008).

Efficiency of BVOC storage on cartridges also varies for different adsorbents. Dettmer et al. (2000) demonstrated large losses of isoprene on carbon molecular sieve adsorbents (Carboxen 569, Carboxen 1003 and Carbosieve SIII) even after only $24 \mathrm{~h}$ storage, but no losses from the graphitized carbon adsorbent Carbotrap X. Analogous results were obtained by Lärstad et al. (2002). This may indicate decomposition reactions taking place with adsorbent surface oxides, irreversible adsorption (Dettmer et al., 2000), and polymerization (Dettmer and Engewald, 2002, 2003) in the carbon molecular sieve adsorbents. Keeping sampled traps at temperatures below $0{ }^{\circ} \mathrm{C}$ significantly slows down BVOC degradation, and is recommended to limit decomposition losses during cartridge storage (Ciccioli et al., 2002).

Apart from adsorbent-adsorbate reactions occurring inside the cartridges, decomposition reactions also occur in the gas-phase within the measurement chamber as well as on chamber wall surface, especially when water condensation occurs, leading to liquid-phase oxidation reactions. Such reactions are of particular concern for enclosures with long air turnover times, where BVOC concentrations build up (Sects. 3.3 and 3.4). Wall losses due to selective adsorption and partition processes can be particularly severe for some polar monoterpenoid compounds, such as linalool, menthol or 1,8-cineol (eucalyptol), as they tend to stick on solid surfaces and dissolve into water droplets more readily than non-polar compounds. Thus, BVOC concentrations 
may significantly decrease due to such decomposition reactions before compound adsorption on the adsorbents. This can significantly reduce the apparent emission rate of reactive isoprenoids, in particular for chambers operated with long air residence times (Kulmala et al., 1999). Such reactions can also increase the apparent emission of compounds produced secondarily from primary emissions (Neeb et al., 1996). Models can be used to determine the chamber BVOC concentrations in the absence of atmospheric oxidants (Kulmala et al., 1999; Neeb et al., 1996), but application of these models is subject to significant uncertainties due to lack of pertinent rate coefficients as well as difficulties in determining $\mathrm{OH}$ and $\mathrm{NO}_{3}^{-}$radical concentrations. Clearly, use of oxidant traps in front of the plant chamber is recommended to gain insight into plant capacity to emit BVOC. From a cautionary perspective, chronic ozone exposure itself can affect the leaf's capacity for isoprene and monoterpene emissions (Velikova et al., 2005a, b), and removal of ozone would abolish such effects. However, modification of foliage capacity for isoprene and monoterpene emissions by ozone is typically time-consuming, taking from several hours (for exceptionally high ozone concentrations) to days (Loreto and Schnitzler, 2010), and thus, the effects of ozone removal on the emission capacity are of concern only for longer term measurements.

\subsection{Influence of ambient BVOC air concentrations on calculation of emission rates}

In field environments, when ambient air is used, background atmospheric BVOC concentrations and air pollutants can interfere with the measurements. For isoprene, daytime ambient air concentrations as high as $2-10 \mathrm{nmol} \mathrm{mol}^{-1}$ (ppb) can be observed above vegetation in rural sites dominated by broad-leaved evergreen Eucalyptus plantations (Cerqueira et al., 2003), evergreen conifer Abies borisii-regis forests (Harrison et al., 2001), mixed deciduous broad-leaved Quercus and evergreen Juniperus woodlands (Wiedinmyer et al., 2001), mixed deciduous broad-leaved Populus and evergreen Picea forests (Tiwary et al., 2007), and at remote tropical rain-forests during wet season (Kesselmeier et al., 2000, 2002). Isoprene concentrations as high as $30 \mathrm{nmol} \mathrm{mol}^{-1}$ have been observed above remote tropical rainforest ecosystems during the dry season (Kesselmeier et al., 2002).

In the case of monoterpenes, ambient air concentrations during the day are significantly less, typically between $0.2-0.7 \mathrm{nmol} \mathrm{mol}^{-1}$ in rural sites supporting monoterpeneemitting species (Cerqueira et al., 2003; Filella and Peñuelas, 2006; Harrison et al., 2001; Kesselmeier et al., 2000, 2002), mainly as the result of lower emission rates and rapid reactions with $\mathrm{OH}$ radicals and ozone in the case of most reactive monoterpenes (Harrison et al., 2001). A few studies have looked at ambient concentrations inside the vegetation canopy, and these data suggest that much higher concentrations are present within the vegetation. In undisturbed $P i$ - nus sylvestris forest, ambient air monoterpene concentrations as high as $0.5-1.5 \mathrm{nmol} \mathrm{mol}^{-1}$ were observed (Räisänen et al., 2008). In disturbed forests, the concentrations can increase to more than $3 \mathrm{nmol} \mathrm{mol}^{-1}$, for instance after clearcutting (Räisänen et al., 2008) or in resin-tapped pine forests (Pio and Valente, 1998). To correct for the background concentrations, ambient air can be sampled and concentrations subtracted from those measured in air exiting the cuvette. Although the air entering the cuvette is often sampled to estimate the background concentration, a true background estimate is obtained by sampling the air exiting the sampling chamber without leaf (BVOC concentration, $X_{\mathrm{in}}$, mol BVOC $\mathrm{m}^{-3}$ ). In this way, possible background due to BVOC adsorbed on the sampling system surface can be accounted for. Ideally, the background sample is taken before and after taking the sample with the leaf enclosed. Simultaneous use of two cuvettes, one enclosing the plant and one reference (empty) cuvette can also be used (Fig. 1d), avoiding the problem with possible temporal variation of incoming air BVOC concentration that can occur if the blank sample is taken before or/and after sampling with foliage enclosed. However, in such a case, possible memory effects of the empty chamber due to former presence of foliage cannot be assessed.

Determining the concentration of BVOC in the exhaust air with the leaf enclosed $\left(X_{\text {out }}\right)$, the emission rate $E$ $\left(\mathrm{mol} \mathrm{m}^{-2} \mathrm{~s}^{-1}\right)$ is given as:

$E=\frac{\left(X_{\text {out }}-X_{\text {in }}\right)}{A_{\mathrm{L}}} F$,

where $A_{\mathrm{L}}\left(\mathrm{m}^{2}\right)$ is enclosed leaf area, and $F\left(\mathrm{~m}^{3} \mathrm{~s}^{-1}\right)$ is the flow rate through the measurement system. Converting BVOC concentrations to molar units $\left(\mathrm{nmol} \mathrm{mol}^{-1}\right)$, the build-up of BVOC concentration inside the chamber, $\Delta \sigma$, can be expressed from Eq. (5) as:

$\Delta \sigma=\left(\sigma_{\text {out }}-\sigma_{\text {in }}\right)=\frac{E A_{\mathrm{L}}}{F_{\mathrm{m}}}$,

where $\sigma_{\text {out }}$ is the BVOC concentration (nmol mol${ }^{-1}$ ) in the cuvette exhaust air and $\sigma_{\text {in }}$ that in incoming air, and $F_{\mathrm{m}}$ is the molar flow rate $\left(\mathrm{mol} \mathrm{s}^{-1}\right)$. Thus, for a moderately high isoprene emission rate of $30 \mathrm{nmol} \mathrm{m}^{-2} \mathrm{~s}^{-1}$, enclosed leaf area of $6 \mathrm{~cm}^{2}$ (Li-Cor 6400 standard cuvette) and a flow rate of $500 \mu \mathrm{mol} \mathrm{s}^{-1}\left(\sim 0.67\right.$ standard $\left.1 \mathrm{~min}^{-1}\right)$ typically used with the Li-Cor 6400 system, the predicted isoprene buildup in the chamber is $36 \mathrm{nmol} \mathrm{mol}^{-1}$. For a moderate emission rate of $5 \mathrm{nmol} \mathrm{m}^{-2} \mathrm{~s}^{-1}, \Delta \sigma$ is $6 \mathrm{nmol} \mathrm{mol}^{-1}$, and for a low emission rate of $1 \mathrm{nmol} \mathrm{m}^{-2} \mathrm{~s}^{-1}, \Delta \sigma$ is only $1.2 \mathrm{nmol} \mathrm{mol}^{-1}$. Thus, the $\Delta \sigma$ in low and moderate emitters can be of the same magnitude as ambient air isoprene concentrations. Consequently, even small fluctuations in ambient BVOC concentration, on the order of $0.5-1 \mathrm{nmol} \mathrm{mol}^{-1}$, can result in large uncertainties in the estimation of emission potentials under high ambient background conditions for low to moderate emitters. 
Although ambient monoterpene concentrations are typically lower than those of isoprene during the daytime, monoterpene emission rates are frequently small, and ambient air monoterpene concentrations of $0.5-1.5 \mathrm{nmol} \mathrm{mol}^{-1}$ will lead to analogous problems in measuring monoterpene emissions.

To remedy the problems with high background concentrations, incoming air can be scrubbed of BVOC along with ozone using scrubbers, e.g. charcoal filters (Geron et al., 2006b; Manes et al., 1999; Okumura et al., 2008) or catalytic converters (pure air generator), or alternatively, synthetic air can be used. Nevertheless, it is important to be aware that most methods for gas cleaning provide zero air with certain background of impurities. In some cases, the hydrocarbon background can be moderately high such as for the synthetic air prepared from technical grade $\mathrm{N}_{2}, \mathrm{O}_{2}$ and $\mathrm{CO}_{2}$ (common in photosynthesis measurements) relative to the synthetic air prepared using GC-grade component gases. In addition, diffusion of BVOCs from the ambient air into the measurement enclosure can still result in background air effects under particularly high ambient BVOC levels.

\subsection{Effects of BVOC buildup in the measurement chamber on calculated emission rates}

As seen above, high emissions coupled with relatively low flow rates can lead to a large buildup of BVOC in the enclosure. BVOC buildup in the cuvette may potentially inhibit the emission rate, and may even result in BVOC uptake at very high cuvette BVOC concentrations. In a steady-state, the emission rate, $E$, can be expressed in dependence on cuvette $\mathrm{BVOC}$ concentration, $\sigma_{\mathrm{a}}\left(\sigma_{\mathrm{a}}=\sigma_{\text {out }}\right.$ for turbulent mixing in the cuvette as is typical in most systems), BVOC concentration in the gas-phase in intercellular air space inside the leaf $\left(\sigma_{\mathrm{i}}\right)$ and in the leaf liquid phase $\left(\sigma_{\mathrm{L}}\right)$, and stomatal $\left(g_{\mathrm{s}}\right)$ and liquid-phase $\left(g_{\mathrm{L}}\right)$ conductances $\left(\mathrm{mol} \mathrm{m}^{-2} \mathrm{~s}^{-1}\right)$ for specific BVOC species (Niinemets and Reichstein, 2003b):

$E=g_{\mathrm{s}}\left(\sigma_{\mathrm{i}}-\sigma_{\mathrm{a}}\right)=g_{\mathrm{L}}\left(\sigma_{\mathrm{L}}-\frac{\sigma_{\mathrm{i}}}{H_{\mathrm{cc}}}\right)$,

where $H_{\mathrm{cc}}\left(\mathrm{mol} \mathrm{mol}^{-1}\right)$ is the dimensionless Henry's law constant (gas-liquid phase partition coefficient) that converts the gas-phase concentration to liquid-phase equivalent concentration. Implicit in this equation is that the diffusion flux of BVOC occurs through stomata. This assumption has been experimentally verified for isoprene and monoterpenes, where bulk of the emission flux occurred through the leaf lower side harboring the stomata (Fall and Monson, 1992; Loreto et al., 1996). In addition, very low cuticular monoterpene permeabilities have been demonstrated (Schmid, 1991).

Analogously, $E$ can be expressed in dependence on lipid$\left(\sigma_{\text {Lip }}\right)$ and liquid-phase concentrations, and lipid-phase conductance $\left(g_{\mathrm{Lip}}\right)\left(\mathrm{mol} \mathrm{m}^{-2} \mathrm{~s}^{-1}\right)$ to given BVOC species (Niinemets et al., 2002b):

$E=g_{\mathrm{s}}\left(\sigma_{\mathrm{i}}-\sigma_{\mathrm{a}}\right) \approx g_{\mathrm{Lip}}\left(\sigma_{\mathrm{Lip}}-\sigma_{\mathrm{L}} K_{\mathrm{OW}}\right)$, where $K_{\mathrm{OW}}\left(\mathrm{mol} \mathrm{mol}^{-1}\right)$ is the octanol to water partition coefficient that approximately converts liquid-phase concentration to lipid-phase equivalent concentration. When $\sigma_{\mathrm{i}} \gg \sigma_{\mathrm{a}}$, ambient BVOC concentrations and mild BVOC build-up in the cuvette do not significantly affect isoprenoid emission. However, in weak emitters and non-emitters, the values of $\sigma_{\mathrm{i}}$ and $\sigma_{\mathrm{a}}$ may be similar. When $\sigma_{\mathrm{i}}=\sigma_{\mathrm{a}}$, there is no net emission from the leaves, i.e. BVOC uptake and emission rates are equal (BVOC compensation point). When $\sigma_{\mathrm{i}}<\sigma_{\mathrm{a}}$, plants will absorb BVOC from the ambient air. For instance, terpene uptake from the ambient air has been measured both in non-emitting and emitting species (Copolovici et al., 2005; Noe et al., 2008).

From Eqs. (7) and (8), it becomes clear that the degree to which the ambient gas-phase BVOC concentrations can affect emissions depends on the compound partitioning to leaf liquid and lipid phases, i.e. the capacity of $\sigma_{\mathrm{i}}$ to rise above $\sigma_{\mathrm{a}}$. A compound that is strongly partitioned to leaf liquid (low $H$ ) and/or lipid phases (high $K_{\mathrm{OW}}$ ) supports lower $\sigma_{\mathrm{i}}$ and accordingly, the equilibrium $\sigma_{\mathrm{i}}=\sigma_{\mathrm{a}}$ is reached at lower ambient BVOC concentrations. Isoprene and most terpenes are preferably partitioned to the gas phase, but can be significantly stored in the leaf lipid phase, while oxygenated terpenes support a much lower gas-phase concentration for given leaf liquid and lipid phase concentrations (Copolovici and Niinemets, 2005). Thus, significant ambient air concentrations more readily affect the apparent emission rates of oxygenated terpenes.

The use of synthetic air or scrubbed air without BVOC may also be criticized on the grounds that low BVOC concentrations inside the chamber produce an artificial plant to atmosphere BVOC gradient, and that this results in an overestimation of natural emission rates. In contrast, use of ambient air can even result in reversal of the flux direction in the case of strong deposition velocities, especially for compounds with high potential deposition rate such as highly lipid-soluble terpenoids and highly water-soluble oxygenated compounds (Bamberger et al., 2011; Karl et al., 2005; Noe et al., 2008). However, as shown above, in reality, this is only a potential problem in species with low emission rates that can build up only a low chamber BVOC concentration close to or below typical ambient concentrations.

While the compound buildup is generally moderate in dynamic flow-through systems (but dependent on flow rate), much larger BVOC build-up occurs in static (closed) systems. In the static system, the emission rate can be derived assuming a constant rate of emission during the sampling:

$E=\frac{\Delta X_{\mathrm{B}} V_{\mathrm{B}}}{A_{\mathrm{L}} \Delta t}$,

where $\Delta X_{\mathrm{B}}\left(\mathrm{nmol} \mathrm{m}^{-3}\right)$ is the buildup of BVOC volumetric concentration in the enclosure (difference between the concentrations inside and outside the enclosure), $V_{\mathrm{B}}\left(\mathrm{m}^{3}\right)$ is the enclosure volume and $\Delta t$ is the time for sampling. 
This equation is valid only when the compound concentration is far from saturating concentration. In fact, for most common plant BVOCs, the saturating concentrations are relatively large. For instance, at $25^{\circ} \mathrm{C}$, the saturating concentration is $0.727 \mathrm{~mol} \mathrm{~mol}^{-1}$ for isoprene and $5840 \mu \mathrm{mol} \mathrm{mol}^{-1}$ (ppm) for $\alpha$-pinene (Copolovici and Niinemets, 2005 for a review of vapor pressures of key plant VOCs). Given an emission rate of $30 \mathrm{nmol} \mathrm{m}^{-2} \mathrm{~s}^{-1}$ from an enclosed foliage area of $300 \mathrm{~cm}^{2}\left(0.03 \mathrm{~m}^{2}\right)$ in $41 \mathrm{bag}$ for $10 \mathrm{~min}$, and zero ambient BVOC concentration, BVOC concentration in the bag will rise to a value of $3024 \mathrm{nmol} \mathrm{mol}^{-1}$ (ca. $3 \mathrm{ppm}$ ). This concentration is small compared with the saturating concentration, but is still much larger than observed in ambient atmospheres under normal conditions, leading to a large equilibrium concentration inside the leaf.

A crude estimate of the underestimation of the emission rate due to BVOC buildup can be obtained by determining the within-leaf storage of the synthesized BVOC after enclosure of the foliage in the bag (Kirschbaum et al., 2007 for calculations). Assuming a leaf dry mass per unit area of $90 \mathrm{~g} \mathrm{~m}^{-2}$, leaf tissue density of $0.4 \mathrm{~g} \mathrm{~cm}^{-3}$, total plant mass in the bag will be $2.7 \mathrm{~g}$ and total plant volume $6.75 \mathrm{~cm}^{3}$. Assuming further that leaf air space volume fraction is $0.3 \mathrm{~m}^{3} \mathrm{~m}^{-3}$ (Kirschbaum et al., 2007; Niinemets and Reichstein, 2003a), leaf dry to fresh mass ratio is $0.4 \mathrm{~g} \mathrm{~g}^{-1}$ (Poorter et al., 2010) and crude leaf lipid content is $5 \%$ and given the lipid density of $0.8 \mathrm{~g} \mathrm{~cm}^{-3}$ (Noe et al., 2008), leaf gas-phase volume is $2.03 \mathrm{~cm}^{3}$, liquid volume is $4.05 \mathrm{~cm}^{3}$ and lipid volume $0.17 \mathrm{~cm}^{3}$. Using the values of $H$ and $K_{\mathrm{OW}}$ for isoprene (Copolovici and Niinemets, 2005), the amount of isoprene stored in leaf gas, liquid and lipid phases is $2.3 \mathrm{nmol}$ that corresponds to ca. $0.5 \%$ of that synthesized in the bag during the $10 \mathrm{~min}$ time period. In contrast, for more-lipid soluble $\alpha$-pinene (Copolovici and Niinemets, 2005 for physicochemical characteristics), the corresponding value will be ca. $123 \mathrm{nmol}$, i.e. $22 \%$ of the total amount (that inside the leaf + that in the bag) synthesized, leading to a very large underestimation of $\alpha$-pinene emission. Of course, this is a very simplified calculation not considering possible inhibition of BVOC synthesis by product buildup inside the leaves that can reduce the emissions much more dramatically (for inhibitory effect of terpenes on metabolism see e.g. Copolovici et al., 2005; Gog et al., 2005; Klingler et al., 1991). Even if the BVOC concentration inside the chamber is far from saturation, such an inhibition of BVOC emission by product buildup would lead to a non-linearity of BVOC concentration increase in the chamber that can be detected by on-line analyzers such as PTR-MS.

These calculations also do not consider the possible consumption of BVOC inside the leaves. Although there is apparently no rapid enzymatic turnover of volatile isoprenoids inside the leaves (e.g. Gershenzon et al., 1993), both isoprene and monoterpenes can react inside the leaves with reactive oxygen species (ROS) (Copolovici et al., 2005; Loreto and Velikova, 2001). Thus, especially under stressed conditions when ROS concentration is expected to be high, and stomata are closed, an increase in BVOC concentrations inside the leaves may imply that the leaves become a stronger biochemical sink for BVOC. In addition to storage inside the leaves, there can be further BVOC deposition on leaf surfaces, e.g. in the cuticular wax (Guth and Frenzel, 1989), further reducing apparent emission rate. Huge bag concentrations also result in an extensive diffusion gradient between the bag and outside air, making the closed system very vulnerable to diffusion leaks.

The capacity of plants to store non-oxygenated terpenes in the leaf lipid phase and oxygenated terpenes in the liquid phase implies that terpenes may be exchanged with ambient air even by species not synthesizing them. If ambient concentrations are high, uptake can occur, and these compounds may then be re-emitted when ambient concentrations are low (Himanen et al., 2010; Niinemets, 2008; Noe et al., 2008). When the foliage of "non-emitting" species that has previously been exposed to ambient air with significant BVOC concentrations is enclosed, and synthetic air with no BVOC or ambient air with lower than the equilibrium $\sigma_{\mathrm{a}}$ is being used, apparent emissions of monoterpenes have been observed from the foliage of species incapable of synthesizing the terpenes themselves (Himanen et al., 2010; Noe et al., 2008). Such effects may partly explain why some species are found to be low-level terpene-emitters in certain studies but not in others, and may also explain trace-level emissions of compounds considered anthropogenic in origin.

\subsection{Consideration of water vapor effect on calculated emission rates}

So far, we have not considered the effect of water vapor concentration on the calculation of emission rates. However, water vapor is the third major component of the atmosphere after $\mathrm{N}_{2}$ and $\mathrm{O}_{2}$ with concentrations typically varying between $1-5 \%$. After leaf enclosure in the chamber, water vapor concentrations increase as the result of plant transpiration. As the saturated water vapor concentration increases exponentially with temperature, plant transpiration rate commonly increases with increasing temperature, even if the closure of stomata at high temperature partly inhibits the rise of transpiration rate. Thus, the increase in chamber water vapor concentration is particularly dramatic in non-temperature controlled cuvettes where temperature also increases after foliage enclosure, especially in low turbulence conditions (Fig. 2). For BVOC emission rate calculations, it is important to recognize that the increase in water vapor concentration dilutes chamber BVOC concentration and thereby reduces the apparent emission rate calculated by Eqs. (5) and (9). Due to water vapor buildup, the incoming air flow rate, $F_{\text {in }}$ $\left(\mathrm{mol} \mathrm{s}^{-1}\right)$, typically measured by mass flow controllers in commercial gas-exchange systems, is actually smaller than the outgoing air flow rate $F_{\text {out }}\left(\mathrm{mol} \mathrm{s}^{-1}\right)$ that is normally not 
measured. The mass balance of water vapor in the system is given as:

$\lambda A_{\mathrm{L}}=F_{\text {out }} W_{\text {out }}-F_{\text {in }} W_{\text {in }}$,

where $W_{\text {in }}$ is the water vapor concentration of air entering, and $W_{\text {out }}\left(\mathrm{mol} \mathrm{mol}^{-1}\right)$ of that exiting the enclosure, and $\lambda$ $\left(\mathrm{mol} \mathrm{m}^{-2} \mathrm{~s}^{-1}\right)$ is the leaf transpiration rate. $F_{\text {out }}=F_{\text {in }}+\lambda A_{\mathrm{L}}$, and thus,

$\lambda A_{\mathrm{L}}=\left(F_{\text {in }}+A_{\mathrm{L}} \lambda\right) W_{\text {out }}-F_{\text {in }} W_{\text {in }}$.

From this, $\lambda$ becomes

$\lambda=\frac{W_{\text {out }}-W_{\text {in }}}{A_{\mathrm{L}}\left(1-W_{\text {out }}\right)} F_{\text {in }}$.

Analogously, the incoming and outgoing flow rates are actually different in Eq. (5). The true mass balance for the BVOC is:

$$
E A_{\mathrm{L}}=F_{\text {out }} \sigma_{\text {out }}-F_{\text {in }} \sigma_{\text {in }}=\left(F_{\text {in }}+A_{\mathrm{L}} \lambda\right) \sigma_{\text {out }}-F_{\text {in }} \sigma_{\text {in }} .
$$

Rearranging:

$E=\frac{\sigma_{\text {out }}-\sigma_{\text {in }}}{A_{\mathrm{L}}} F_{\text {in }}+\lambda \sigma_{\text {out }}$.

For the Li-Cor $64006 \mathrm{~cm}^{2}$ cuvette, $F_{\text {in }}$ of $500 \mu \mathrm{mol} \mathrm{s}{ }^{-1}$, and relatively high transpiration rate of $9 \mathrm{mmol} \mathrm{m}^{-2} \mathrm{~s}^{-1}$ corresponding to stomatal conductance of water vapor $\left(g_{\mathrm{s}}\right)$ of $0.3 \mathrm{~mol} \mathrm{~m}^{-2} \mathrm{~s}^{-1}$ and water vapor deficit between the leaf and ambient air $(v)$ of $0.03 \mathrm{~mol} \mathrm{~mol}^{-1}\left(\lambda=g_{\mathrm{s}} v\right)$, the contribution of the transpiration correction will be ca. $1 \%$ of $E$. However, the correction $\lambda \sigma_{\text {out }}$ very much depends on the flow rate through the system that alters $\sigma_{\text {out }}$, and on transpiration rate. The rate of transpiration scales positively with temperature due to temperature effects on $v$ (nearly exponentially when vapor pressure is far from saturation), and temperature also positively affects $\sigma_{\text {out }}$. For non-climatized cuvettes, where leaf temperature increases well above ambient, the transpiration correction may be $10 \%$ or more, especially if a large amount of leaf area (relative to cuvette flow rate, Eq. 2) is enclosed (Fig. 7). Many BVOC emission studies do not include concomitant measurements of $\lambda$, and in such cases, no correction for water vapor buildup can be made.

\section{Extrapolations, units, meta-data and other scaling limitations}

In addition to the importance of precise measurements of BVOC emission rates, the accuracy of $E_{\mathrm{S}}$ values can strongly depend on the way the emission measurements are standardized and summarized. $E_{\mathrm{S}}$ values used in the simulation models are frequently taken not from primary literature, but from databases that have already synthesized information from multiple studies. Meta-database construction typically involves evaluation of the quality of the data (use/do not use),

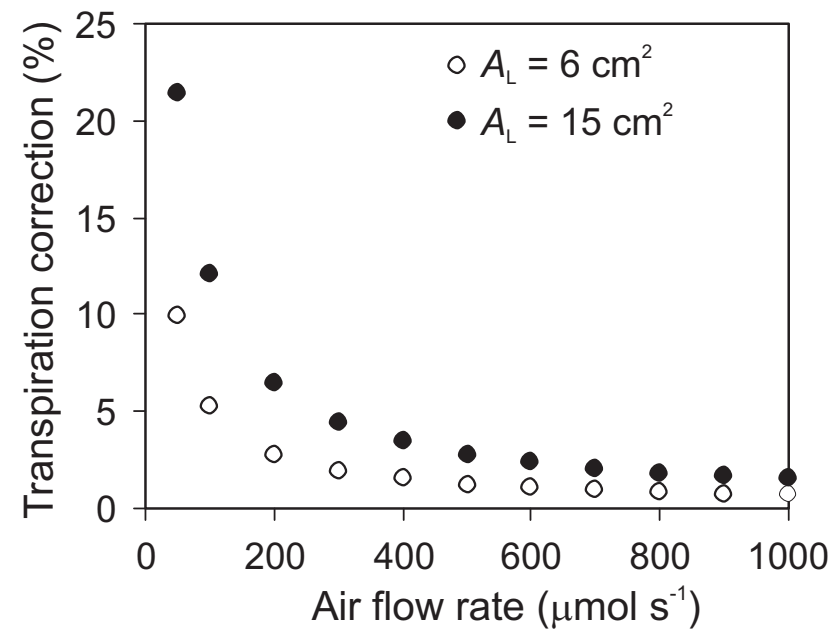

Fig. 7. Simulation of the effect of transpiration correction (Eq. 14) on the emission rate in dependence on the incoming air flow rate for cuvettes enclosing $6 \mathrm{~cm}^{2}$ and $15 \mathrm{~cm}^{2}$ leaf area. In these simulations, we used a moderately high transpiration rate of $9 \mathrm{mmol} \mathrm{m}^{-2} \mathrm{~s}^{-1}$, incoming BVOC concentration of $3 \mathrm{nmol} \mathrm{mol}^{-1}$ and an emission rate of $12 \mathrm{nmol} \mathrm{m}^{-2} \mathrm{~s}^{-1}$. For given air flow rate and leaf area, the correction is the larger the larger is the leaf transpiration rate and the larger is the BVOC concentration in incoming air.

unit harmonization, data scaling to common environmental conditions and averaging. All these steps can have a major effect on the quality of the $E_{\mathrm{S}}$ values in the meta-databases, and therefore on the quality of BVOC model predictions.

\subsection{Standard conditions for $E_{S}$ and the influence of extrapolations}

Standardized conditions in seminal papers defining $E_{\mathrm{S}}$ were $30^{\circ} \mathrm{C}$ for leaf temperature $\left(T_{\mathrm{L}}\right)$ and $1000 \mu \mathrm{mol} \mathrm{m}^{-2} \mathrm{~s}^{-1}$ for incident quantum flux density $(Q)$ (Guenther et al., 1991, 1993). Ideally, the measurements of $E_{\mathrm{S}}$ should be conducted at standardized conditions. However, this is often not possible, especially when the measurements are carried out in the field using simple non-climatized cuvettes (Fig. 1). In the worst cases, in simple static bag systems under high radiation loads, leaf temperatures may easily rise more than $10^{\circ} \mathrm{C}$ above ambient (Stewart-Jones and Poppy, 2006). The emission measurements conducted at these "non-standard" environmental conditions are then converted to desired $T_{\mathrm{L}}$ and $Q$ using light, $f(Q)$, and temperature, $f\left(T_{\mathrm{L}}\right)$, response functions (Guenther et al., 1991, 1993) (see also Niinemets et al., 2010c for a review). For light-dependent emissions of isoprene and monoterpenes in non-storing species, the emission rate is given as:

$E=E_{\mathrm{S}} f(Q) f_{\mathrm{S}}\left(T_{\mathrm{L}}\right)$ 
where $f_{\mathrm{S}}\left(T_{\mathrm{L}}\right)$ is the temperature response function for BVOC synthesis. The light response function is defined as:

$f(Q)=\frac{C_{\mathrm{L}_{1}} \alpha Q}{\sqrt{1+\alpha^{2} Q^{2}}}$

where $\alpha$ is the apparent (standardized) quantum yield of isoprenoid emission and $C_{\mathrm{L}_{1}}$ is a scaling constant to yield $f(Q)=1.0$ at the standardized value of $Q$ (Guenther et al., 1991, 1993). The temperature response function describes a curve with an optimum at $T_{\mathrm{m}}$ (Guenther et al., 1991, 1993):

$f_{\mathrm{S}}\left(T_{\mathrm{L}}\right)=\frac{\exp \left[\frac{C_{\mathrm{T}_{1}}\left(T_{\mathrm{L}}-T_{\mathrm{S}}\right)}{R T_{\mathrm{S}} T_{\mathrm{L}}}\right]}{1+\exp \left[\frac{C_{\mathrm{T}_{2}}\left(T_{\mathrm{L}}-T_{\mathrm{m}}\right)}{R T_{\mathrm{S}} T_{\mathrm{L}}}\right]}$.

In this equation, $C_{\mathrm{T}_{1}}$ and $C_{\mathrm{T}_{2}}$ are parameters $\left(\mathrm{J} \mathrm{mol}^{-1}\right)$ describing the activation and deactivation energies of the emission, $R$ is the gas constant $\left(8.314 \mathrm{~J} \mathrm{~mol}^{-1} \mathrm{~K}^{-1}\right), T_{\mathrm{L}}$ is the absolute leaf temperature and $T_{\mathrm{S}}$ is the standard temperature (typically $303.16 \mathrm{~K}$ ). The equation parameters, $C_{\mathrm{T}_{1}}$ and $C_{\mathrm{T}_{2}}$, are typically chosen to yield $f_{\mathrm{S}}\left(T_{\mathrm{S}}\right)=1$, although as originally parameterized in Guenther et al. (1993) $f_{\mathrm{S}}\left(T_{\mathrm{S}}\right)$ was 0.946.

For emissions assumed to result only from compound evaporation from specialized storage tissues such as resin ducts in conifers, the emissions are assumed to be insensitive to light and only depend on temperature (Guenther et al., 1991, 1993):

$E=E_{\mathrm{S}} f_{\mathrm{E}}\left(T_{\mathrm{L}}\right)$,

and the temperature response function is given as:

$f_{\mathrm{E}}\left(T_{\mathrm{L}}\right)=\exp \left[\beta\left(T_{\mathrm{L}}-T_{\mathrm{S}}\right)\right]$,

where $\beta\left(\mathrm{K}^{-1}\right)$ is a scaling coefficient assumed to describe the exponential increase of the terpene vapor pressure and velocity of diffusion with increasing temperature. However, a significant part of monoterpene emission from conifers can originate from synthesis (Ghirardo et al., 2010; Shao et al., 2001), and in such cases hybrid algorithms based on both temperature effects on synthesis and emission may need to be used for data standardization (Niinemets et al., 2010c).

To compare the temperature responsiveness of different processes, so called $Q_{10}$ values, reflecting the increase in process rate resulting from a $10^{\circ} \mathrm{C}$ increase in temperature, are often used:

$Q_{10}=\frac{f\left(T_{\mathrm{L}}+10\right)}{f\left(T_{\mathrm{L}}\right)}$.

The $Q_{10}$ concept assumes strictly exponential increase of process rate (Eq. 19, where $Q_{10}=\exp (10 \beta)$ ), but since the initial part of the temperature dependence is exponential for both Eqs. (17) and (19), the $Q_{10}$ concept is also approximately valid for the exponentially increasing parts of biological response functions having an optimum. Using the original parameterizations reported by Guenther et al. (1991, 1993), $Q_{10}$ of 3.5 for the rise of temperature from 20 to $30^{\circ} \mathrm{C}$ is obtained for isoprene (Eq. 17, also employed for monoterpenes not stored in specialized tissues) and $Q_{10}$ of 2.5 for monoterpenes emitted from specialized storage pools (Eq. 19).

As the information on light and temperature response function parameters, $\alpha, C_{\mathrm{L}_{1}}, C_{\mathrm{T}_{1}}, C_{\mathrm{T}_{2}}, T_{\mathrm{m}}$, and $\beta$ is seldom available for given leaves, the values originally defined in Guenther et al. $(1991,1993)$ are commonly employed to extrapolate from measurements conducted under some arbitrary set of conditions to standard conditions. This is a reasonable approximation if the deviations of experimental conditions from standard conditions are small. However, when measurements are made under conditions differing greatly from the standard conditions (e.g. Lindskog and Potter, 1995), the extensive extrapolations required can result in large errors in $E_{\mathrm{S}}$ due to both light and temperature standardization procedures.

The key problem with data extrapolation using previously published response curve parameterizations is that the shapes of both light and temperature response functions can vary among species and upon acclimation to different environmental conditions (Niinemets et al., 2010c for a review). Moreover, it is even not always known whether the emissions come directly from synthesis, indicating that Eq. (17) is appropriate for standardization, or rely on storage, suggesting that Eq. (19) should be used for standardization. For instance, due to lack of knowledge of the emission controls in broad-leaved temperate deciduous Betula pendula, the emissions were standardized based on terpene evaporation (Eq. 19) in Hakola et al. (1998). However, now it has been established that the temperature response of monoterpene emissions in this species can be described by temperature effects on terpene synthesis (Eq. 17) (Ghirardo et al., 2010).

Any discrepancy between the "true" and "standard" curves will result in errors, but how large are such extrapolation errors? In the case of temperature, $Q_{10}$ values of biochemical reactions typically vary between $2-3$, but for terpene emissions, the range can be as high as $2-6$, possibly due to the interaction of temperature effects on physico-chemical terpene characteristics (volatility) with temperature effects on terpene synthesis (Niinemets et al., 2010c for a review). The emission rate at temperature, $T_{2}, E_{\mathrm{T}_{2}}$, is related to the emission rate at temperature $T_{1}, E_{\mathrm{T}_{1}}$ and $Q_{10}$ as:

$E_{\mathrm{T}_{2}}=E_{\mathrm{T}_{1}} \exp \left(\frac{T_{2}-T_{1}}{10} \operatorname{Ln} Q_{10}\right)$.

From Eq. (21), one can calculate that when the measurements are conducted at $25^{\circ} \mathrm{C}$, extrapolation to $30^{\circ} \mathrm{C}$ with $Q_{10}=3$ will overestimate the "true" $E_{\mathrm{S}}$ by $22 \%$ if the "true" $Q_{10}=2$, and underestimate $E_{\mathrm{S}}$ by $13 \%$ if "true" $Q_{10}=4$. Extrapolating from 20 to $30^{\circ} \mathrm{C}$, the extrapolation error increases to $50 \%$ for the first and $25 \%$ for the second scenario. 


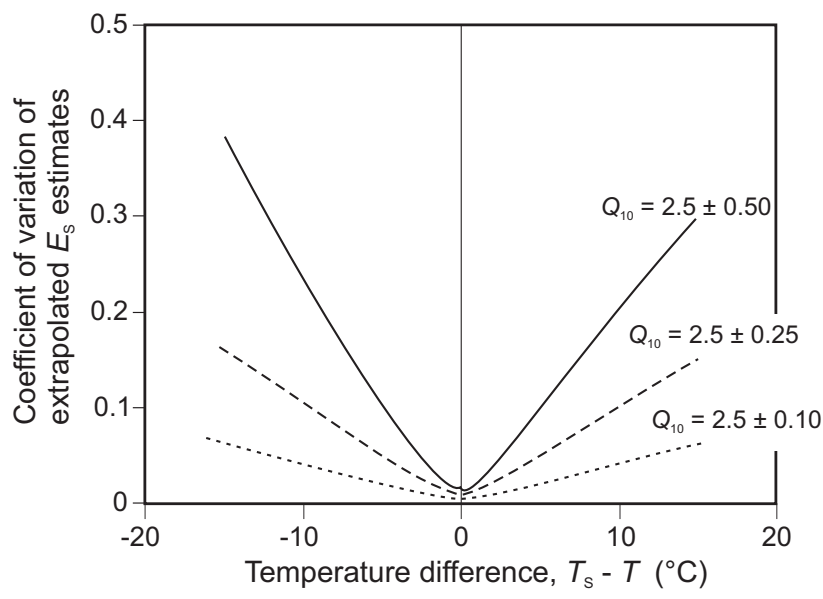

Fig. 8. Analysis of the errors in estimates of the BVOC emission factors, $E_{\mathrm{S}}$, due to extrapolations beyond the measurements, i.e. the coefficient of variation (standard deviation per sample mean) of $E_{\mathrm{S}}$ estimates extrapolated to given temperature using uncertain temperature scaling functions. Often, especially in the field, the measurements are conducted at a temperature, $T$, different from the standardized temperature, $T_{\mathrm{S}}$ (that is typically taken as $30^{\circ} \mathrm{C}$ ), and these values are then extrapolated to $T_{\mathrm{S}}$. When there is no information about the shape of the isoprenoid emission vs. temperature response curve, the original parameterization for the temperature functions of Guenther et al. (1991, 1993) is used as default. In this analysis, we characterize the shape of the temperature response curve by $Q_{10}$ value, i.e. the process rate at a temperature $T+10{ }^{\circ} \mathrm{C}$ relative to the rate at the temperature $T$ (Eq. 20). This analysis demonstrates that even minor changes in the shape of the temperature response of the emissions result in large errors in $E_{\mathrm{S}}$, especially if the data are extrapolated over a large temperature range $\left(T_{\mathrm{S}}-T\right)$. The simulation analysis is based on stochastic perturbations in $Q_{10}$ using Monte Carlo method. For each simulation, 1000 different estimates of $Q_{10}$ and $E_{\mathrm{S}}$ were used.

A more detailed sensitivity analysis further demonstrates that even minor uncertainties in temperature responsiveness, $Q_{10}$, have disproportionate effects on the uncertainty in $E_{S}$, with the uncertainty increasing essentially linearly with the extrapolation range (Fig. 8).

Apart from the errors in the exponential part of the temperature response curve, extrapolation of isoprene and lightdependent terpene emissions becomes particularly dangerous close to the optimum temperatures. The original Guenther et al. (1991, 1993) algorithm parameterization suggests an optimum temperature ( $T_{\mathrm{m}}$ in Eq. 17$)$ of $41^{\circ} \mathrm{C}$. However, temperature optima vary among and within species, being occasionally as low as $30^{\circ} \mathrm{C}$ or lower in some, and above $41{ }^{\circ} \mathrm{C}$ in other cases (for reviews of temperature relationships see Niinemets et al., 1999, 2010c), and assumptions about $T_{\mathrm{m}}$ can potentially introduce large errors in $E_{\mathrm{S}}$ estimations.

Analogously, for light dependence, measurements conducted at the rapidly rising, nearly linear part of the light response curve, typically up to $Q$ values of ca. 300-
$500 \mu \mathrm{mol} \mathrm{m} \mathrm{m}^{-2} \mathrm{~s}^{-1}$ (Niinemets et al., 2010c for a comparison of shapes of the light response curves), provide no information on the saturation point. Thus, the extrapolation to the standardized value of $1000 \mu \mathrm{mol} \mathrm{m}^{-2} \mathrm{~s}^{-1}$ that typically lies on the saturating part of the response curve is potentially associated with large errors. The value of the initial quantum yield for isoprene emission $(\alpha$ in Eq. 16) of $0.0027 \mathrm{~mol} \mathrm{~mol}^{-1}$ has been recommend to simulate isoprene emission across species (Guenther et al., 1993), but $\alpha$ varies in dependence on long-term light availability and can differ among the species (Harley et al., 1996, 1997). For instance, in broad-leaved temperate deciduous species Liquidambar styraciflua a value of $\alpha$ of $0.0017 \mathrm{~mol} \mathrm{~mol}^{-1}$ has been observed for upper canopy leaves and a value of $0.0040 \mathrm{~mol} \mathrm{~mol}^{-1}$ for lower canopy leaves. For measurements conducted at a quantum flux density of $300 \mu \mathrm{mol} \mathrm{m}^{-2} \mathrm{~s}^{-1}$, the use of the general shape of the response curve with $\alpha$ fixed at $0.0027 \mathrm{~mol} \mathrm{~mol}^{-1}$ will result in $30 \%$ underestimation of $E_{\mathrm{S}}$ for upper canopy leaves and $31 \%$ overestimation for lower canopy leaves. These extrapolation errors are ca. $20 \%$ if the measurements are conducted at a light intensity of $500 \mu \mathrm{mol} \mathrm{m}^{-2} \mathrm{~s}^{-1}$.

In addition, any error in the measurement of quantum flux density at relatively low light can have a significant impact on estimation of $E_{\mathrm{S}}$. For example, for this range of $\alpha$ values, a $10 \%$ error in quantum flux density measurement will result in ca. 5-40\% error in $E_{\mathrm{S}}$ estimations.

Overall, if extrapolation is needed, measurement of full response curves seems to be the most straightforward way to derive emission factors and check the validity of "standard" emission response curves for given plant species and under specific environmental setting. When the information about the response curve shapes is not known, we suggest that the temperature extrapolation should not exceed $\pm 5{ }^{\circ} \mathrm{C}$ and light extrapolation $\pm 300 \mu \mathrm{mol} \mathrm{m}^{-2} \mathrm{~s}^{-1}$. At any rate, the range of extrapolation, and function used should be reported along with the $E_{\mathrm{S}}$ values.

Another question is whether the standardized environmental conditions as defined initially are always appropriate. In particular, in sub-arctic, boreal and cool temperate environments, leaf temperatures may never or rarely reach $30^{\circ} \mathrm{C}$ (e.g. Ekberg et al., 2009; Noe et al., 2011), and temperatures that high may constitute a significant stress for the plant. Analogously, temperatures are low in the beginning and end of the growing season when the emission measurements can be conducted at ambient temperatures at most of 10-15 ${ }^{\circ} \mathrm{C}$ (Hakola et al., 2006; Ruuskanen et al., 2007; Sun et al., 2009, 2011; Tarvainen et al., 2005). Due to seasonal changes in the shape of the temperature response curve (Tarvainen et al., 2005), these low temperature measurements cannot be reliably extrapolated to $30^{\circ} \mathrm{C}$. Thus, in cooler climates, and in periods with lower temperatures, we suggest that standard temperatures lower than $30^{\circ} \mathrm{C}$ be used for $E_{\mathrm{S}}$ determination. Although it may initially seem confusing as it is convenient to use one single standard temperature for 

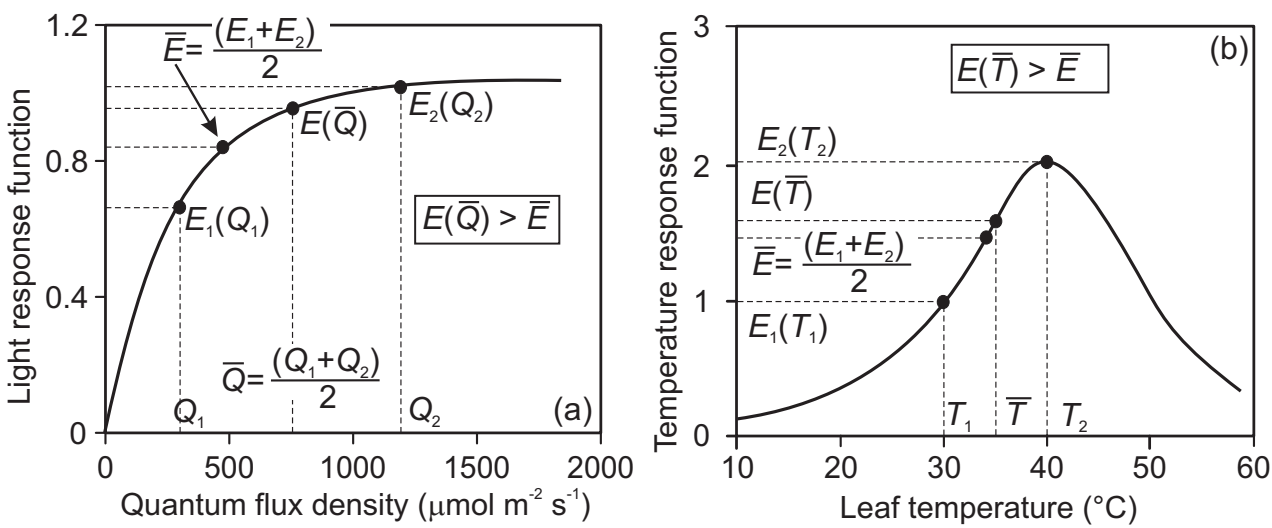

Fig. 9. Illustration of the averaging problem in isoprene emission responses to light, $Q$, (Eq. 16, a) and leaf temperature, $T_{\mathrm{L}}$ (Eq. 17, b). Because of non-linearity of isoprene emission vs. light responses (a), the average of any two isoprene emission rates $(\bar{E})$ simulated at light intensities $Q_{1}$ and $Q_{2}\left(E\left(Q_{1}\right)\right.$ and $\left.E\left(Q_{2}\right), \bar{E}=\left(E\left(Q_{1}\right)+E\left(Q_{2}\right)\right) / 2\right)$, is always lower than the value predicted using the average light, $E(\bar{Q})$ (Jensen's inequality for concave functions), except if both the $Q_{1}$ and $Q_{2}$ values come either from a region of the curve where the emission rate is independent of light (light saturation) or from very low light, where the emission rate scales close to linearly with quantum flux density. Analogously, the true average emission rate simulated for two different temperatures is lower than that predicted for the average temperature $(\bar{T})$ in (b) in the local concave range of the temperature response curve. However, as the temperature response curve is convex in lower temperatures, the true average is larger than the one predicted using average temperature for this range. For instance, the true average response factor for temperatures 15 and $25^{\circ} \mathrm{C}$ is 0.347 , while the response factor corresponding to the average $T$ of $20^{\circ} \mathrm{C}$ is 0.281 . Averaging the values above and below the temperature optimum can also result in either higher or lower values of true average vs. the average based on $\bar{T}$. These simulations were conducted with original Guenther et al. (1991) isoprene emission model parameterization.

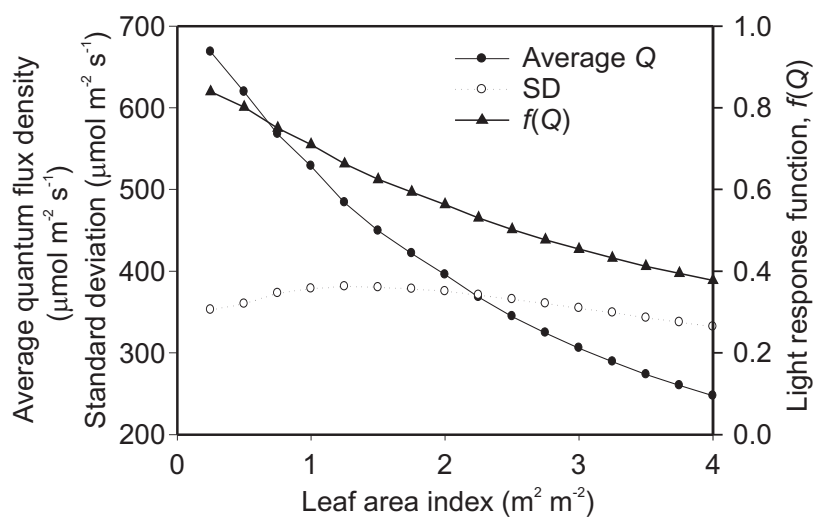

Fig. 10. Mean and standard deviation of the leaf average quantum flux density and corresponding true values of branch light response $f(Q)$ function (Eq. 16) in relation to the amount of leaf area enclosed in the cuvette. $f(Q)$ is taken as 1.0 at the single leaf level. In these simulations, incoming quantum flux density on horizontal surface above the branch was taken as $1000 \mu \mathrm{mol} \mathrm{m} \mathrm{m}^{-2} \mathrm{~s}^{-1}$. Further details of the simulation as in Fig. 3.

all emission measurements conducted across the globe, the above discussion indicates that there are good reasons to use ecosystem-specific standard temperatures in emission inventories.

\subsection{Integration problems}

The response of isoprene, methylbutenol and light-dependent emissions of mono- and sesquiterpene emission rates to incident quantum flux density is highly non-linear (Eq. 16, Fig. 9a). This means that linear averaging of emission rates and values of environmental drivers can result in large errors in $E_{\mathrm{S}}$ estimation over most of the response curve. Linear averaging is only justified in the region of the curve where the emission rate is independent of light ( $Q \geq Q_{\mathrm{s}}$, where $Q_{\mathrm{s}}$ is $Q$ for light saturation) or at very low light ( $Q \leq Q_{\mathrm{cr}}$, where $Q_{\text {cr }}$ is the value of $Q$ at which the response becomes nonlinear) where the emission rate scales close to linearly with quantum flux density. To demonstrate the principle of integration problem, consider average emission rate $(\bar{E})$ of any two measurements $\left(E_{1}\right.$ and $\left.E_{2}\right)$ conducted at light intensities $Q_{1}$ and $Q_{2}$, whereas either $Q_{1}$ or $Q_{2}$, or both $Q_{1}$ and $Q_{2}$ are larger than $Q_{\mathrm{cr}}$ and smaller than $Q_{\mathrm{s}}$. Under these constraints, $\bar{E}$ is always smaller than the value predicted for average $Q\left(Q_{1}+Q_{2}\right) / 2$ (Figs. 9a, 10, Cescatti and Niinemets, 2004; Lappi and Smolander, 1984; Lappi and Smolander, 1988; Niinemets and Anten, 2009). Analogous integration problem may occur for temperature that also affects the emissions in non-linear manner (Eqs. 17 and 19), but the use of average temperature may over- or underestimate the true response depending on the response curve shape and range of averaging (Fig. 9b).

The integration problem may introduce errors in several steps in $E_{\mathrm{S}}$ determination. First, measurements of BVOC 
emissions using sampling on cartridges are time-consuming. Typically, the chamber air is sampled for 10-30 min. In field conditions, for non-climatized cuvettes, both incident light, and leaf temperature can fluctuate during this time period. The conventional approach to cope with this variability is to find average light, $\bar{Q}$, and temperature, $\bar{T}$, and use these values to derive $E_{\mathrm{S}}$ estimates as described in Sect. 4.1. This will necessarily introduce integration errors as outlined in Fig. 9. Analogous integration errors can occur if different estimates of emission rate conducted under different environmental conditions, for instance for different leaves sampled during various parts of the season, are averaged and again average $\bar{Q}$ and $\bar{T}$ values for these leaves are used in converting the emission rates to standardized conditions (Sect. 4.1). As an example of integration problems, different $E_{\mathrm{S}}$ estimates have been obtained using $\bar{Q}$ and $\bar{T}$ and $\bar{E}$ averaged for entire day or using instantaneous estimates (e.g. as in Owen, 1998; Owen et al., 2001; Street et al., 1997).

In the case of multiple estimates of $E$ measured under different light and temperature conditions, correct average $E_{\mathrm{S}}$ can be determined by first computing $E_{\mathrm{S}}$ values for each emission rate estimate using instantaneous $Q$ and $T$ values and then calculating the average. Correct $E_{\mathrm{S}}$ values can also be obtained by fitting $E$ against the product $f(Q) f_{\mathrm{S}}\left(T_{\mathrm{L}}\right)$ (Eq. 15) or $f_{\mathrm{E}}\left(T_{\mathrm{L}}\right)$ (Eq. 18) when appropriate.

Sampling on cartridges under fluctuating light and temperature conditions constitutes a special case of integration. Upon sampling on a cartridge, there is only one estimate of emission rate and no instantaneous $Q$ and $T$ corresponding to the time-averaged $\bar{E}$ derived from the cartridge measurements. Nevertheless, $E_{\mathrm{S}}$ values free from integration problems can be obtained by considering that:

$\bar{E}=\frac{E_{\mathrm{S}}}{t_{2}-t_{1}} \int_{t_{1}}^{t_{2}} f(Q) f_{\mathrm{s}}\left(T_{\mathrm{L}}\right) d t$,

where $t_{2}-t_{1}$ is the time period of measurements, and the light and temperature functions are as defined by Eqs. (16) and (17). When the measurements or $E, Q$ and $T_{\mathrm{L}}$ are conducted with equal time steps, Eq. (22) simplifies to:

$\bar{E}=E_{\mathrm{S}} \frac{\sum_{i}^{n} f\left(Q_{\mathrm{i}}\right) f_{\mathrm{S}}\left(T_{\mathrm{L}, \mathrm{i}}\right)}{n}$,

where $Q_{\mathrm{i}}$ and $T_{\mathrm{L}, \mathrm{i}}$ are the instantaneous estimates of light and temperature and $n$ is the number of measurements of $Q$ and $T$ conducted during sampling on the cartridge. However, as discussed in Sect. 4.1, all these approaches critically depend on the availability of correct shapes of response curves $f(Q)$ and $f(T)$. Overall, integration problems are best avoided by reducing environmental fluctuations during sampling, for instance by using artificial light sources and temperature-controlled cuvettes.

Apart from these issues during $E_{\mathrm{S}}$ determination, integration problems also occur if aggregated foliage samples are used for BVOC emission measurements. As discussed in 2.1, big chambers enclosing a large amount of foliage biomass such as a branch or a whole plant have been used in many BVOC studies. However, due to non-linearity of isoprenoid emissions to light and temperature, the response of a collection of leaves exposed to incident light and ambient temperature is different than the response of a single leaf exposed to given light and temperature. Typically, in large enclosures, incident $Q$ and chamber air temperatures or temperatures of one or more leaves are used in determining $E_{\mathrm{S}}$ values. Because a significant fraction of enclosed plant foliage is shaded and have diverse orientation relative to the sun or artificial light source, using these values of climatic drivers results in a biased estimate of $E_{\mathrm{S}}$. Even if $\bar{Q}$ and $\bar{T}$ can be determined for a collection of leaves, these average values still lead to significant integration errors (Figs. 9, 10). Thus, it is important to consider that $E_{\mathrm{S}}$ values estimated using branch or whole plant measurements (e.g. for whole tree measurements see Lindskog and Potter, 1995; Pier, 1995; Pier and McDuffie, 1997) include both physiological effects (the emission capacity) and structural effects (the degree of shading within the plant foliage), and are therefore not equivalent with estimates made on a single leaf, even if the values are expressed per unit leaf area enclosed.

No simple conversion procedure is available to convert shoot-level, branch-level or whole-plant emission factors to leaf-level emission factors because foliage inclination angles and spatial aggregation are highly variable (e.g. Cescatti and Niinemets, 2004). Nevertheless, whole-plant emission factors can be valuable on their own in parameterization of "big-leaf" BVOC emission models and for verification of layered models parameterized on the basis of leaf-level $E_{\mathrm{S}}$ values (Niinemets et al., 2010c). Analogously, shoot- or branch-level emission factors can be employed in parameterization of canopy models employing shoots or branches as functional units (Fleck, 2003; Planchais and Sinoquet, 1998; Stenberg et al., 1994, 1998). What can be highly misleading is that all the different $E_{\mathrm{S}}$ estimates are commonly expressed per unit leaf area, although they will be numerically different due to the integration issues outlined above.

One more point concerning the differences among leaflevel and aggregated emission factors is that the measurements made using bigger cuvettes include VOC exchange of the stem and bark. This can be especially significant for measurements of young branches with developing leaves and relatively large bark to leaf area ratio. As little is known of bark emissions, the effect of the presence of woody tissue in the measurement cuvette is difficult to assess. Yet, bark emissions can be significant in certain plant genera, e.g. in pines where they play an important role in deterring bark beetles (e.g. Dendroctonus spp.) (Seybold et al., 2006). Due to large terpene storage in bark and woody tissue in conifers, these emissions can significantly increase in response to mechanical damage (Schade and Goldstein, 2003). 
In conclusion, we argue that in compilations of BVOC emission factors, it is important to clearly distinguish between leaf $\left(E_{\mathrm{S} \text {, leaf }}\right)$, shoot $\left(E_{\mathrm{S} \text {, shoot }}\right)$, branch $\left(E_{\mathrm{S} \text {, branch }}\right)$ and whole plant $\left(E_{\mathrm{S}, \text { plant }}\right)$ emission measurements, and use these different estimates only in appropriate model frameworks.

\subsection{Expression basis of $E_{S}$}

Isoprenoid $E_{\mathrm{S}}$ values can be expressed on the basis of either leaf area $\left(E_{\mathrm{S}, \mathrm{A}}\right)$, dry mass $\left(E_{\mathrm{S}, \mathrm{DM}}\right)$ or fresh mass $\left(E_{\mathrm{S}, \mathrm{FM}}\right)$, and all have been used in different studies. These three different bases of expression are related as:

$E_{\mathrm{S}, \mathrm{A}}=E_{\mathrm{S}, \mathrm{DM}} M_{\mathrm{A}}=E_{\mathrm{S}, \mathrm{FM}} M_{\mathrm{A}} / D_{\mathrm{F}}$

where $M_{\mathrm{A}}$ is the leaf dry mass per unit area $\left(\mathrm{g} \mathrm{m}^{-2}\right)$ and $D_{\mathrm{F}}$ is the leaf dry to fresh mass ratio $\left(\mathrm{g} \mathrm{g}^{-1}\right)$. Both $M_{\mathrm{A}}$ and $D_{\mathrm{F}}$ vary significantly both within and between species (for reviews see Poorter et al., 2009a, b). For instance, $M_{\mathrm{A}}$ increases 2 to 4 -fold from bottom to top of plant canopies (e.g. Niinemets, 2007; Niinemets et al., 2010b), with increasing leaf age from developing to fully mature leaves (Hanson et al., 1994; Jurik, 1986; Niinemets et al., 2004) and from seedlings to mature trees (Day et al., 2001; Niinemets, 2002, 2010a).

Among the three bases of expression, $E_{\mathrm{S}, \mathrm{FM}}$ is discouraged in BVOC studies, because fresh mass is a less stable characteristic than either leaf area or dry mass. Apart from environmental and developmental modifications, $D_{\mathrm{F}}$ can vary due to changes in plant water status, over the course of a day or during the season, and $E_{\mathrm{S}}$ expressed on a fresh mass basis will track all these changes that are not directly associated with modifications in foliage BVOC emission capacity.

In species with non-laminar foliage elements, such as conifers, the estimates of $E_{\mathrm{S}, \mathrm{A}}$ will differ depending on whether projected $\left(A_{\mathrm{P}}, E_{\mathrm{S}, \mathrm{AP}}\right)$ or total $\left(A_{\mathrm{T}}, E_{\mathrm{S}, \mathrm{AT}}\right)$ leaf surface area is used. These two different expression bases are related as:

$E_{\mathrm{S}, \mathrm{AP}}=E_{\mathrm{S}, \mathrm{AT}} A_{\mathrm{T}} / A_{\mathrm{P}}$

where $A_{\mathrm{T}} / A_{\mathrm{P}}$ is the leaf total to projected area ratio. In conifers, $A_{\mathrm{T}} / A_{\mathrm{P}}$ ratio is typically larger for thicker high-light acclimated foliage and smaller for thinner low-light acclimated foliage, and $A_{\mathrm{T}} / A_{\mathrm{P}}$ ratio can vary more than by a factor of two within plant canopies (Niinemets, 2007 for a review). So far, there is no consensus on the appropriate basis of expression of $E_{\mathrm{S}, \mathrm{A}}$ in conifers, and some studies report values expressed per unit $A_{\mathrm{P}}$, some per unit $A_{\mathrm{T}}$.

To further complicate the matters, some studies also report the $E_{\mathrm{S}}$ values of broad-leaved species with laminar foliage elements on a total surface area basis, dividing the projected area based values by 2 to account for the doubling of surface area (e.g. Steinbrecher et al., 1997). This is highly confusing as the majority of $E_{\mathrm{S}}$ values in broad-leaved species are expressed per unit projected area. Projected area for laminar leaves is also the standard for expression of physiological activities of broad-leaved species in ecology and physiology. We believe that for broad-leaved species, projected leaf area should be used. For conifers and for other species with nonlaminar foliage, the expression basis can be either projected or total area, but the expression basis should be clearly stated. We strongly recommend that $A_{\mathrm{T}} / A_{\mathrm{P}}$ ratio estimates be provided for conifers.

In general, we feel that the expression basis of $E_{S}$ has not been given due weight in BVOC studies with a few exceptions (e.g. Komenda et al., 2001 for due consideration of total to projected surface area and dry mass estimations). Details of dry mass, fresh mass and leaf area determination are often lacking. In extreme cases, results have been reported without stating whether the emission rates are expressed per unit dry or fresh mass, or per unit projected or total area. In addition, area-based values may be incorrectly converted to mass based values, for instance, due to incorrect $M_{\mathrm{A}}$ values. Even lack of details of dry mass estimation can be a problem as the dry mass depends on the duration of drying and temperature during drying (Garnier et al., 2001). The reported temperatures used for foliage drying among different studies vary between $40-105^{\circ} \mathrm{C}$, and this alone can result in differences in dry mass of ca. 10-15\% (Zeiller et al., 2007). Several factors need standardization for representative values of leaf area, dry and fresh mass with particular care needed for leaf fresh mass estimation (Garnier et al., 2001). We suggest that for BVOC studies, dry mass should be determined after drying for at least $48 \mathrm{~h}$ at $60-70^{\circ} \mathrm{C}$.

Given the large variations in $M_{\mathrm{A}}, D_{\mathrm{F}}$ and $A_{\mathrm{T}} / A_{\mathrm{P}}$ due to environment, and significant variations in $M_{\mathrm{A}}$ and $D_{\mathrm{F}}$ due to experimental protocols, the expression basis of $E_{\mathrm{S}}$ values is not trivial. In particular, environmental sources of variation, such as within-canopy gradients in light, can easily introduce several-fold variation in $E_{\mathrm{S}}$ estimates per unit area and dry mass (e.g. Niinemets et al., 2010b). Thus, we strongly suggest that $M_{\mathrm{A}}$ values be reported along with either area- or mass-based $E_{\mathrm{S}}$ estimates in all BVOC emission inventories.

\subsection{Standardized units}

In addition to the basis of expression, a variety of units has been used to express the area- and mass-based $E_{\mathrm{S}}$ values. In BVOC emission studies, $E_{\mathrm{S}, \mathrm{A}}$ is typically expressed in $\mathrm{nmol} \mathrm{m}{ }^{-2} \mathrm{~s}^{-1}$ and $E_{\mathrm{S}, \mathrm{DM}}$ as $\mu \mathrm{g} \mathrm{g}^{-1} \mathrm{~h}^{-1}$. However, BVOC mass units have been used in the case of leaf area-expressed variables (e.g. $\mu \mathrm{g} \mathrm{m}^{-2} \mathrm{~s}^{-1}$ ) and BVOC molar units in the case of leaf mass-based estimates (e.g. $\mathrm{nmol} \mathrm{g}^{-1} \mathrm{~h}^{-1}$ ). Different units have also been used in the denominator, e.g. $\mathrm{cm}^{2}$ for area, min for time etc. Some studies have chosen to avoid unit prefixes and multiply the $E_{\mathrm{S}}$ units by powers of ten. This may seem a trivial point, since one can obviously convert from one set of units to another, but for the novice in the field, this heterogeneity of units can be highly confusing, and even for experienced users, lack of consistent units 
is very frustrating and requires heightened scrutiny in metadatabase construction.

With mass-based measures of BVOC amounts, a further difficulty is that some studies report the values as $\mu \mathrm{g} \mathrm{C}$ emitted (especially BVOC inventory studies conducted by US authors, e.g. Geron et al., 2000b) (but also in some studies by European authors, e.g. Kuhn et al., 2004), while other studies report the values as $\mu \mathrm{g}$ BVOC emitted (especially BVOC inventory studies conducted by European authors, e.g. Kesselmeier and Staudt, 1999). It is important to consider that these two ways of expressing the amounts of emitted BVOC are not the same. Isoprene and nonoxygenated monoterpenes such as $\alpha$-pinene contain $88.1 \%$ carbon. Thus, in the case of the unit using BVOC content, the $E_{\mathrm{S}}$ value is 1.135 times larger than if the unit is based on C-content. Oxygenated monoterpenes such as linalool and $\alpha$-terpineol contain $77.8 \%$ carbon, and accordingly the conversion factor is 1.29 . In some cases, these two ways of expressing $E_{\mathrm{S}}$ values have been used interchangeably in the same paper (e.g. Street et al., 1997), while many papers fail to report which way the numerators have been expressed. Lack of clear explanation has led to mixing up $\mathrm{C}$ and mass-based units in some meta-analyses based on published data, e.g. Drewitt et al. (1998) data in the meta-analysis of Kesselmeier and Staudt (1999).

Given that the stoichiometry of chemical reactions, including atmospheric oxidation reactions, follows molar stoichiometry not mass stoichiometry, we suggest that all measurements of BVOC emissions should always be reported only in molar units, whether expressed per unit leaf mass or area. Consistent use of molar units would avoid the confusion with numerators based on the mass of $\mathrm{C}$ or the mass of BVOC emitted. Also, we strongly encourage the community to consistently use SI units with appropriate unit prefixes, typically $\mathrm{nmol} \mathrm{m} \mathrm{m}^{-2} \mathrm{~s}^{-1}$ for area-based and $\mathrm{pmol} \mathrm{g}^{-1} \mathrm{~s}^{-1}$ for mass-based estimates. Unit multiplication by powers of ten is discouraged; where necessary, tabulated values of $E_{\mathrm{S}}$, not units, can be multiplied by powers of ten. Overall, given that light interception scales with leaf area, we encourage use of area-based values, especially if the further goal is to employ these emission data in modeling BVOC emissions from leaf to stand.

\subsection{Meta-data errors}

When Zimmerman (1979) compiled emission rate measurements into the first emission factor database used for regional gridded biogenic emission estimates, e.g. in BEIS (Pierce and Waldruff, 1991), it was a fairly straightforward exercise because there was only one available dataset. Guenther et al. (1994) were faced with a somewhat more challenging task when they combined observations reported by six research groups using different emission measurement techniques to construct the updated emission factor database that was used in BEIS2. Among the concerns associated with that activ- ity were that some studies had only one or a few measurements on a species or genus and that some investigators used techniques that likely resulted in biased emission factor estimates. In particular, the earliest studies were thought to have overestimated monoterpene emission rates by disturbing the foliage and underestimated isoprene emission rates by primarily using shaded branches that are found in the more easily accessed part of a canopy. Guenther et al. (1994) used an approach of assigning tree genera to just four (for isoprene), five (for monoterpenes) or one (for other BVOC) broad emission factor categories which emphasized that most of the observations were semi-quantitative and that there was a large range in the reported values for these emission factors. The impact of the updated emission factors was dramatic with BEIS2 estimating isoprene emission rates that were about a factor of 5 higher than BEIS (Geron et al., 1994). Guenther et al. (1995) extended this approach to the global scale using the results of 22 field studies. A significant difference in the Guenther et al. (1995) approach was that they did not average the results of the 22 studies, but instead used the study considered to have most accurate observations when there was a difference between two or several studies.

Currently, with richer information on species emission potentials, BVOC emission modelers commonly use review papers and databases summarizing the species-specific estimates of $E_{\mathrm{S}}$ (e.g. Kesselmeier and Staudt, 1999; Ortega et al., 2008; Wiedinmyer et al., 2004) (http://bai.acd.ucar.edu/Data/ BVOC/index.shtml and http://www.es.lancs.ac.uk/cnhgroup/ iso-emissions.pdf). In addition, several modeling studies have derived their own emission factor estimates based on the aforementioned meta-studies and additional literature observations (Parra et al., 2004; Simpson et al., 1995, 1999; UNECE/EMEP Task Force on Emissions Inventories and Projections, 2007). However, many previous meta-analyses have consisted of mechanical collection of emission factors without considering attached information on experimental conditions during the sampling, sampling methodology or scaling method (for exceptions Ortega et al., 2008) (http://bai.acd. ucar.edu/Data/BVOC/index.shtml). Once published in the database, species-specific values have been accepted at face value in many simulation studies to follow. Yet $E_{\mathrm{S}}$ estimates in these early databases were frequently less reliable, and we have learned now that the estimates reported for some species were wrong. For instance, important wide-spread species including the Mediterranean evergreen Quercus suber and temperate deciduous Betula spp. and Fagus sylvatica were initially reported as non-emitters, whereas recent studies have shown that these species are important monoterpene emitters (Dindorf et al., 2006; Hakola et al., 2001, 1998; Moukhtar et al., 2005; Staudt et al., 2004).

Benjamin et al. (1996) introduced an approach where the averages of all isoprene and monoterpene emission factors reported in the literature were used to derive emission factors for individual species, including species which had not been measured. The average for the genus or family was 
used if there were no reported measurements for a species or genus. This resulted in errors due to within genera and family variability, e.g. Benjamin et al. (1996) assigned to Mediterranean evergreen species Quercus ilex and $Q$. suber, which had not been measured, the genus average isoprene emission rate of $24.8 \mu \mathrm{g} \mathrm{g}^{-1} \mathrm{~h}^{-1}$ and monoterpene emission rate of $0.6 \mu \mathrm{g} \mathrm{g}^{-1} \mathrm{~h}^{-1}$. However, both species turned out to have very low, if any, isoprene emissions and to be strong monoterpene emitters (Kesselmeier et al., 1996; Owen et al., 2001; Staudt et al., 2004). On the other hand, some studies have reported exceptionally high emissions not substantiated by other investigations. For instance, Owen et al. (2002) reported significant isoprene emissions from Mediterranean Pinus pinea, in contrast to all other studies (Nuñez et al., 2002; Sabillón and Cremades, 2001; Staudt et al., 2000, 1997).

Additional errors were associated with emission rates assigned based on studies that employed semi-quantitative or non-quantitative techniques. For example, Benjamin et al. (1996) assigned to some North American oaks, e.g. Quercus lobata, Quercus prinus, emission rates between 3 and $9 \mu \mathrm{gg}^{-1} \mathrm{~h}^{-1}$ which was an order of magnitude lower than the later measurements (Geron et al., 2001). Overall, the early studies and emission databases focused more heavily on isoprene emission potentials. Lack of evidence for significant monoterpene emissions was often interpreted as zero emission in the modeling community. This early focus on isoprene was due in large part to the perceived importance of isoprene in atmospheric chemistry models and the early development of experimental sampling systems well suited for quantifying isoprene emissions (Sect. 3.1); analogous systems for accurate measurement of many other more challenging BVOC lagged behind. Although significant errors can result from the taxonomic approach, it is still used for species-rich floras such as Amazonian rainforests due to practical reasons (Harley et al., 2004). In such species-rich floras, canopy-scale emission factors derived from flux measurements could be more practical for predictive purposes (Guenther et al., 2006) than trying to measure every single species.

A further problem with large screening exercises and meta-databases is accurate species identification. In particular, species misidentification can occur in species-rich floras where important traits for species identification such as generative organs may not be present for all species sampled, but also lack of botanical experience with the novel floras may result in such identification problems even with the help of local botanists. On the other hand, synonymous scientific names can generate problems in meta-database construction. Taxonomy is not a trivial point because different chemotypes have been observed even within a species (e.g. Niinemets et al., 2002a), and large variability in $E_{\mathrm{S}}$ values can occur depending on species genetic origin (Staudt et al., 2004). This inherent variability raises the question of how best allocate the resources to describe the emission potential of a certain flora. In the case of complete lack of information of species emission capacity, a stepwise procedure is recommended, conducting first crude measurements to gain insight into the overall variability in emission potentials among the species, and then focusing on the emission controls in species identified as key emitters in the area.

Part of the problem with the early meta-databases is that many entries were not based on publications in mainstream peer-refereed journals, but were taken from hard to access research reports and graduate theses. In addition, many values in the databases were taken from reviews rather than from primary literature. Use of non-primary literature is particularly dangerous as it leads to propagation of errors from study to study. In some modeling studies, it has even been deemed acceptable not to mention the data sources used for emission inventory construction (e.g. for partly missing data sources see Parra et al., 2004). Thus, the whole range of reporting errors discussed above (Sects. 4.2-4.4) can be propagated, including those associated with unit conversions, basis of expression and standardization and averaging errors. Nonstandard problems such as different emission factors derived on the basis of the same studies can also occur.

As BVOC modeling work relies heavily on meta-data, more care is needed in constructing emission inventory databases. BVOC emission databases should be based only on peer-reviewed primary data which include sufficient information on the experimental protocols necessary to assess the data quality. This philosophy of database construction is increasingly being followed in recent undertakings (Ortega et al., 2008) and to some extent in http://bai.acd.ucar.edu/Data/ BVOC/index.shtml), but many modeling studies continue to uncritically use values reported in early databases. In the following, we suggest standardized protocols for obtaining reliable $E_{\mathrm{S}}$ data and for assessing the quality of past studies.

\section{Towards a standardized emission inventory}

As discussed in Sects. 2 and 3, the BVOC emission measuring community employs a wide variety of sampling devices and methodologies. In addition, a variety of methods is employed in calculating BVOC emission factors and the results are often expressed in non-standard units. All these issues contribute to study-to-study variations in $E_{\mathrm{S}}$ estimates and complicate construction of reliable emission inventories. Given this vast heterogeneity in the field, we argue that a standardized protocol for measuring and reporting BVOC emission data is urgently needed. Apart from the sampling and reporting issues highlighted here, additional error sources can be associated with compound quantification and identification. Detailed consideration of these issues is beyond this review, but we note that more intercomparison exercises between different analytical systems are clearly required, and availability of common BVOC standards would 
greatly contribute towards standardization of different analytical procedures.

\subsection{Standardization of measurement and sampling systems used for $\boldsymbol{E}_{\mathrm{S}}$ determination}

Given the large problems, such as diffusion leaks, excessive alteration of chamber environment etc., associated with static or closed systems, we suggest that only dynamic, open systems be used for quantitative sampling of BVOC emissions. The open systems used for BVOC sampling need to satisfy the following criteria:

1. the measurement chamber should have well-mixed (turbulent) atmosphere, such that no concentration gradients or pockets of dead air are present in the chamber;

2. flow rate through the system must be sufficiently high to assure complete exchange of chamber air at least every $2-3 \mathrm{~min}$ and avoid water condensation onto the enclosure walls;

3. preferably, leaf-scale emission factors should be estimated on single leaves, except for species such as needle-leaved conifers, with small leaves and/or highly clumped foliage. In the case of measurements with aggregated foliage elements, the degree of aggregation should be clearly denoted in reporting the emission factors (shoot, branch, whole plant emission factors). In the case of measurements with aggregated foliage, taking of digital images of the enclosed plant part are ideally included in experimental protocols;

4. chamber, sampling lines and fittings should be made of inert materials, minimizing memory effects due to BVOC adsorption/desorption on system surfaces. Chambers should minimize the gasket area relative to chamber cross-sectional area. In the case of available commercial clip-on chambers, chambers with crosssectional area of at least $6-8 \mathrm{~cm}^{2}$ should be used to minimize errors associated with diffusion leaks and adsorption/desorption;

5. in species with specialized storage tissues for BVOC, such as conifers with resin ducts, Eucalyptus and Citrus species and species from Labiatae with internal and/or surface oil glands, chambers that minimize the contact between the plant surface and chamber parts should be used to avoid "rough handling" problems (Sect. 2.5). The site of leaf or shoot insertion should be carefully prepared (e.g. stem axis remaining inside the seal wrapped in Teflon ${ }^{\circledR}$ tape) at least $24 \mathrm{~h}$ before the measurements;

6. to assess plant physiological status, the systems should include fast (infra-red) $\mathrm{CO}_{2}$ and water vapor analyzers to measure plant photosynthesis and transpiration rates, and allow for water vapour flow corrections;
7. ideally, chambers with temperature, humidity, light and $\mathrm{CO}_{2}$ control should be used so that measurements can be made under ambient conditions as well as under controlled conditions differing from ambient. In all cases, the systems should be equipped with quantum flux, chamber air and leaf temperature sensors;

8. studies investigating more reactive BVOCs such as some mono- and sesquiterpenes should use air purified by oxidant scrubbers or synthetic air (i.e. oxidant-free air) to correctly assess the plant source strength;

9. steady-state conditions should be established before taking the emission rate readings, considering chamber responsiveness, memory effects and plant physiological status;

10. when sampling onto adsorbent cartridges, multi-bed cartridges filled with different hydrophobic adsorbents having surface areas ranging from $8-10$ to 200 $300 \mathrm{~m}^{2} \mathrm{~g}^{-1}$ are suggested to quantitatively assess the entire spectrum of volatile isoprenoids (Sect. 3.1). After sampling, it is advisable to remove the bulk of ozone and water from the sampled cartridge using helium or pure nitrogen flow, and store the cartridges in a cooled container kept at $T<0^{\circ} \mathrm{C}$.

If such a protocol is followed, high-quality BVOC emission data for estimation of $E_{\mathrm{S}}$ values as well as data for verification of BVOC emission models under field conditions can be obtained, although we are conscious that under some circumstances compromises have to be made, for instance, when studying BVOCs emitted at very low rates. While many measurements in the past have been conducted following rigorous protocols satisfying all or most of the criteria outlined here, the majority have not. As discussed in Sects. 2 and 3 and summarized in Table 1, there are inherent errors associated with failure to satisfy these criteria. In addition, some experimental approaches are inherently more accurate, and exhibit higher resolution power, than others. Thus, to some degree, uncertainties in reported $E_{\mathrm{S}}$ can be constrained by a prioritization of techniques, with assignment of greatest weight to those techniques with the highest accuracy. However, the exact magnitude of experimental errors is often impossible to quantify a posteriori. As emission measurement techniques have improved in the past four decades, distinctions in the quality of emission measurement data have emerged, but it remains difficult to quantify the accuracy of any reported emission factor. Most studies either do not report an uncertainty estimate or they present a value based on measurable uncertainties (e.g. flow rates, leaf area, VOC measurement precision) but ignore other equally important components (e.g. disturbances associated with the presence of the enclosure). Developers of emission factor databases thus typically select the best available observations, rather than the average of all observations, but this is 
done in a subjective manner given the lack of quantitative uncertainties associated with emission rate data. Therefore, we suggest that past measurements should be divided into three different quality classes depending on the way measurements have been carried out: A - quantitative measurements, $\mathrm{B}$ - semi-quantitative measurements, and $\mathrm{C}-$ nonquantitative measurements. Quantitative, class A, measurements are those conducted according to rigorous protocols satisfying the criteria specified above. Semi-quantitative, class B, measurements are those failing in one or several criteria, but nevertheless providing information on the magnitude of $E_{\mathrm{S}}$. Non-quantitative, class C, measurements provide information on whether or not a given species can emit given BVOCs (emitter vs. non-emitter), but the potential errors are sufficiently large, more than an order of magnitude, that the magnitude of the emissions cannot be assessed with any accuracy. For instance, measurements conducted with closed (no flow through) or semi-closed (flow-through rate approximately equals the low flow rate used to draw the air for cartridges) systems without quantifying environmental drivers and imprecisely estimating the emission flux will typically fall into class $\mathrm{C}$.

While class A and to a certain extent class B data can be used for constructing BVOC emission inventories, class $\mathrm{C}$ data should serve only as a basis for further measurements, and not be used for BVOC modeling. We recommend that the data in existing BVOC databases be critically examined for reliability and distributed into these broad quality classes. In some regions the best available observations may be semiquantitative measurements obtained using a quick screening approach. These can still be useful inputs as they were with the Zimmerman (1979) data when they were the only existing emission rate data. Regions that currently have no reported BVOC emission rate observations can benefit from local scientists utilizing simple and inexpensive emission screening techniques, but emission rate measurement studies in Europe, US and other regions where considerable emission data are already available should be limited to quantitative emission estimates.

We suggest that the future models need to explicitly deal with the problem of $E_{\mathrm{S}}$ experimental uncertainties. For example, Bayesian approaches allow accommodation of a priori probability distributions of $E_{\mathrm{S}}$ parameter, and yield appropriate uncertainties in model simulations. So far, the use of Bayesian approaches in BVOC emission simulations has focused on spatial variability in $E_{\mathrm{S}}$ and species-to-species variabilities, but the error sources of $E_{\mathrm{S}}$ estimations for any given species have not been addressed (Curci et al., 2010; Shim et al., 2005).

\subsection{Set of variables to be reported in standard emission inventories}

Apart from standardization of emission measurement protocols, it is equally important to agree on a minimum set of variables to be reported with the emission measurements. As shown in Sect. 4 and Table 1, shortcomings in data processing and reporting can lead to errors as significant as the measurement errors. The data characterizing every BVOC emission measurement can be divided into four broad categories: (1) $E_{\mathrm{S}}$ and associated meta-data; (2) sample-specific structural and chemical data; (3) sample-specific physiological data and (4) plant- and site-specific data.

$E_{\mathrm{S}}$ and associated data include the $E_{\mathrm{S}}$ value itself, and light and temperature for measurement and standardization. We recommend that the studies also report the ambient $\mathrm{CO}_{2}$ concentration in the chamber to allow for correction of $\mathrm{CO}_{2}$ effects (Niinemets et al., 2010c; Wilkinson et al., 2009). Although the BVOC emission data are not routinely standardized for $\mathrm{CO}_{2}$ effects, and $\mathrm{CO}_{2}$ responses of BVOC emissions are not yet sufficiently understood, especially for sesquiterpenes and (stored) monoterpenes (Niinemets et al., 2010c; Peñuelas and Staudt, 2010), such standardization may be needed for constructing BVOC emission models for future climates. When the data are normalized to standard light and temperature conditions, the studies should clearly report the function together with actual parameterization used for extrapolation and the extrapolation range. For mono- and sesquiterpenes, the compound spectrum should also be reported, if available.

Sample-specific structural and chemical data include leaf dry mass per unit area $\left(M_{\mathrm{A}}\right)$, total to projected area ratio $\left(A_{\mathrm{T}} / A_{\mathrm{P}}\right)$ for conifers, temperature and duration of drying for leaf dry mass estimation, and a clear indication of the basis of expression (projected area, total area). Ideally, the content of carbon and key mineral nutrients $(\mathrm{N}, \mathrm{P})$, providing information of plant nutrient status, should also be measured.

Sample-specific physiological data serve to determine whether the plants were measured under non-stressed or stressed conditions. The data best serving this task are the rate of photosynthesis $(P)$, stomatal conductance $\left(g_{\mathrm{s}}\right)$ and intercellular $\mathrm{CO}_{2}$ concentration, calculated from $P, g_{\mathrm{s}}$ and ambient $\mathrm{CO}_{2}$ concentration (e.g. Flexas et al., 2004 for a review of stress-driven changes in photosynthesis rates and stomatal openness). In addition, chemical signatures of emitted BVOCs are highly useful, e.g. hexenals and other C6 compounds are characteristic of mechanical damage (Loreto et al., 2006) and ozone stress (Beauchamp et al., 2005), and ocimenes, dimethylnonatriene (DMNT), $\alpha$-farnesene and linalool are often indicators of recent herbivory (Arimura et al., 2000; Copolovici et al., 2011; Paré and Tumlinson, 1997, 1999; Wu and Baldwin, 2009).

Sample, plant- and site-specific data should include the exact species identity, i.e. the date of sampling, information about phenological characteristics (leaf age status, e.g. young, adult, senescent) and position in the canopy, exact scientific name with authorship, origin and provenance of plant, approximate plant age, geographical coordinates of the site, altitude and quantitative description of the stand characteristics (height, density, age) and site climate (annual 
and growing season temperature, and precipitation). Ideally, information of plant water status, and information about past environmental conditions (e.g. average temperature and light conditions during the $48 \mathrm{~h}$ preceding the measurements) should also be provided as these environmental drivers are strongly correlated with $E_{\mathrm{S}}$ values in the field (e.g. Geron et al., 2000a; Sharkey et al., 1999). Although such information might be difficult to obtain for any given sample location, nearby meteorological stations can provide highly valuable information, useful for interpreting variations in $E_{\mathrm{S}}$ values from any given study or between different studies. As the most simple estimate of water availability, soil water content (as e.g. incorporated in MEGAN, Guenther et al., 2006) can be used. If possible, more sophisticated estimates including predawn leaf water potential and stomatal conductance would be highly informative. Any visible signs of present or past herbivory and pathogen attack, if available, should also be noted as this can provide important information for induced BVOC emissions (some specific monoterpenes and sesquiterpenes) (Niinemets, 2010a for a review).

Although the amount of meta-information required for any single $E_{\mathrm{S}}$ measurement might seem large, this information is highly useful for understanding the variations in $E_{\mathrm{S}}$ values and thus, for developing more reliable emission inventories. Given that $E_{\mathrm{S}}$ strongly varies with leaf ontogeny, position in the canopy and with previous average environmental conditions and stress history (Niinemets et al., 2010a for physiological and ontogenetic controls), even infinitely precise $E_{\mathrm{S}}$ measurements are insufficient for making reliable emission predictions without attached meta-information.

\section{Conclusions}

This analysis demonstrates that in addition to inherently dynamic nature of the BVOC emission factor, $E_{\mathrm{S}}$, important uncertainties in the experimental estimation of the emission capacity at any given moment of time can be associated with analytical shortcomings as well as with data processing following emission measurements (Table 1). In particular, the use of a wide variety of experimental approaches and the lack of a standardized measurement protocol contribute significantly to uncertainties in $E_{\mathrm{S}}$ measurements. Incompatible adsorbents as well as incompatible sampling methods, e.g. sampling in $\mathrm{O}_{3}$ enriched atmospheres without removing $\mathrm{O}_{3}$ from the enclosures during sampling, can result in complete loss of sampled compounds as well as modified emission composition, emphasizing that the analytical errors can potentially be substantial. Interlaboratory comparisons have demonstrated large, several-fold, variations in the quantification of major BVOC species among different analytical setups (BVOC trapping, desorption and GC separation) (Larsen et al., 1997). Bad cuvette design and use of inferior tubing and cuvette materials can result in similarly large variability, i.e. from non-detection to ideal detection. Obvi- ously, more intercomparisons of field sampling designs and lab analysis systems are needed and $E_{\mathrm{S}}$ estimates obtained in the past using methodology currently considered problematic need re-assessment.

Extrapolation, integration, experimental setup and unit errors can contribute to errors in $E_{\mathrm{S}}$ equal to or greater than analytical limitations. We call for consistent application of the suggested experimental protocol and rigorous documentation of the measurements, collectively making it possible to develop high quality emission factor databases. Reliable leaflevel $E_{\mathrm{S}}$ databases serve as a valuable foundation that can be directly used for atmospheric chemistry models scaling from leaf to canopy and landscape and that can be used to develop canopy-level emission factors for models operating at larger scales (Guenther et al., 2006). A community effort to systematically and quantitatively assess the accuracy and precision of enclosure BVOC emission rate measurement systems is required and needs to include comparison with above canopy eddy covariance techniques that do not have the inherent disturbance of an enclosure. Issues such as the number of samples required to represent a population mean could be established in this way. This activity should also be integrated with efforts to examine the factors that contribute to emission variability but are not accounted for in current approaches for calculating emission factors (e.g. stress, chemotype variability). This would improve our understanding of how these data can be used to parameterize emission models and would guide efforts to further standardize the protocols for measuring and reporting BVOC emission data.

Acknowledgements. We thank the European Science Foundation (VOCBAS and INTROP programs) for travel support. The authors' studies on BVOCs have been funded by the Estonian Ministry of Science and Education (grant SF1090065s07), the Estonian Science Foundation (grant 7645), European Commission through European Regional Fund (the Center of Excellence in Environmental Adaptation), the US National Science Foundation and the US Environmental Protection Agency, the Spanish Ministry of Science (grants CGL2006-04025/BOS and Consolider-Ingenio Montes CSD2008-00040), the Catalan Department of Science (grant SGR 2009-458), and the Max Planck Society. Ü. N., A. A., and R. K. M. acknowledge support from the Human Frontier Science Program.

Edited by: G. Wohlfahrt

\section{References}

Allaire, S. E., Yates, S. R., Ernst, F., and Papiernik, S. K.: Gas-phase sorption-desorption of propargyl bromide and 1,3dichloropropene on plastic materials, J. Environ. Qual., 32, 1915-1921, 2003.

Apel, E. C., Calvert, J. G., Gilpin, T. M., Fehsenfeld, F. C., Parrish, D. D., and Lonneman, W. A.: The nonmethane hydrocarbon intercomparison experiment (NOMHICE): task 3, J. Geophys. Res.-Atmos., 104, 26069-26086, 1999.

Arimura, G. I., Tashiro, K., Kuhara, S., Nishioka, T. O. R., and Takabayashi, J.: Gene responses in bean leaves induced by herbivory 
and by herbivory-induced volatiles, Biochem. Bioph. Res. Commun., 277, 305-310, 2000.

Arneth, A., Schurgers, G., Hickler, T., and Miller, P. A.: Effects of species composition, land surface cover, $\mathrm{CO}_{2}$ concentration and climate on isoprene emissions from European forests, Plant Biol., 10, 150-162, 2008.

Arnts, R. R.: Reduction of biogenic VOC sampling losses from ozone via trans-2-butene addition, Environ. Sci. Technol., 42, 7663-7669, 2008.

Arnts, R. R.: Evaluation of adsorbent sampling tube materials and Tenax-TA for analysis of volatile biogenic organic compounds, Atmos. Environ., 44, 1579-1584, 2010.

Avison, S. J., Gray, D. A., Davidson, G. M., and Taylor, A. J.: Infusion of volatile flavor compounds into low-density polyethylene, J. Agr. Food Chem., 49, 270-275, 2001.

Ball, J. T.: Calculations related to gas exchange, in: Stomatal function, edited by: Zeiger, E., Farquhar, G. D., and Cowan, I. R., Stanford University Press, Stanford, 445-476, 1987.

Ball, J. T., Woodrow, I. E., and Berry, J. A.: A model predicting stomatal conductance and its contribution to the control of photosynthesis under different environmental conditions, in: Progress in photosynthesis research. Proc. VII Int. Photosynthesis congress, edited by: Biggens, J., Martinus Nijhoff Publishers, Dordrecht, 221-224, 1987.

Bamberger, I., Hörtnagl, L., Ruuskanen, T. M., Schnitzhofer, R., Müller, M., Graus, M., Karl, T., Wohlfahrt, G., and Hansel, A.: Deposition fluxes of terpenes over grassland, J. Geophys. Res.Atmos., 116, D14305, doi:10.1029/2010JD015457, 2011.

Bates, M. S., Gonzalez-Flesca, N., Sokhi, R., and Cocheo, V.: Atmospheric volatile organic compound monitoring. Ozone induced artefact formation, Environ. Monit. Assess., 65, 89-97, 2000.

Batterman, S. A., Zhang, G.-Z., and Baumann, M.: Analysis and stability of aldehydes and terpenes in electropolished canisters, Atmos. Environ., 32, 1647-1655, 1998.

Beauchamp, J., Wisthaler, A., Hansel, A., Kleist, E., Miebach, M., Niinemets, Ü., Schurr, U., and Wildt, J.: Ozone induced emissions of biogenic VOC from tobacco: relations between ozone uptake and emission of LOX products, Plant Cell Environ., 28, 1334-1343, 2005.

Benjamin, M. T., Sudol, M., Bloch, L., and Winer, A. M.: Lowemitting urban forests: a taxonomic methodology for assigning isoprene and monoterpene emission rates, Atmos. Environ., 30, 1437-1452, 1996.

Bertin, N. and Staudt, M.: Effect of water stress on monoterpene emissions from young potted holm oak (Quercus ilex L.) trees, Oecologia, 107, 456-462, 1996.

Brancaleoni, E., Scovaventi, M., Frattoni, M., Mabilia, R., and Ciccioli, P.: Novel family of multi-layer cartridges filled with a new carbon adsorbent for the quantitative determination of volatile organic compounds in the atmosphere, J. Chromatogr. A, 845, 317-328, 1999.

Brilli, F., Ciccioli, P., Frattoni, M., Prestininzi, M., Spanedda, A. F., and Loreto, F.: Constitutive and herbivore-induced monoterpenes emitted by Populus $x$ euroamericana leaves are key volatiles that orient Chrysomela populi beetles, Plant Cell Environ., 32, 542-552, 2009.

Cahill, T. M., Seaman, V. Y., Charles, M. J., Holzinger, R., and Goldstein, A. H.: Secondary organic aerosols formed from ox- idation of biogenic volatile organic compounds in the Sierra Nevada Mountains of California, J. Geophys. Res.-Atmos., 111, D16312, doi:10.1029/2006JD007178, 2006.

Calfapietra, C., Scarascia Mugnozza, G., Karnosky, D. F., Loreto, F., and Sharkey, T. D.: Isoprene emission rates under elevated $\mathrm{CO}_{2}$ and $\mathrm{O}_{3}$ in two field-grown aspen clones differing in their sensitivity to $\mathrm{O}_{3}$, New Phytol., 179, 55-61, 2008.

Calogirou, A., Larsen, B. R., Brussol, C., Duane, M., and Kotzias, D.: Decomposition of terpenes by ozone during sampling on Tenax, Anal. Chem., 68, 1499-1506, 1996.

Calogirou, A., Duane, M., Kotzias, D., Lahaniati, M., and Larsen, B. R.: Polyphenylensulfide, Noxon ${ }^{\circledR}$, and ozone scavenger for the analysis of oxygenated terpenes in air, Atmos. Environ., 31, 2741-2751, 1997a.

Calogirou, A., Kotzias, D., and Kettrup, A.: Product analysis of the gas-phase reaction of $\beta$-caryophyllene with ozone, Atmos. Environ., 31, 283-285, 1997b.

Cao, X.-L. and Hewitt, C. N.: Thermal desorption characteristics of four adsorbent/adsorbate systems commonly used in air sampling programmes, Chemosphere, 27, 695-705, 1993.

Cappellina, L., Biasioli, F., Fabris, A., Schuhfried, E., Soukoulis, C., Märk, T. D., and Gasperi, F.: Improved mass accuracy in PTR-TOF-MS: another step towards better compound identification in PTR-MS, Int. J. Mass Spectrom., 290, 60-63, 2010.

Cerqueira, M. A., Pio, C. A., Gomes, P. A., Matos, J. S., and Nunes, T. V.: Volatile organic compounds in rural atmospheres of central Portugal, Sci. Total Environ., 313, 49-60, 2003.

Cescatti, A. and Niinemets, Ü.: Sunlight capture. Leaf to landscape, in: Photosynthetic adaptation. Chloroplast to landscape, edited by: Smith, W. K., Vogelmann, T. C., and Chritchley, C., Ecological Studies, 178, Springer Verlag, Berlin, 42-85, 2004.

Cescatti, A. and Zorer, R.: Structural acclimation and radiation regime of silver fir (Abies alba Mill.) shoots along a light gradient, Plant Cell Environ., 26, 429-442, 2003.

Chameides, W., Lindsay, R., Richardson, J., and Kiang, C.: The role of biogenic hydrocarbons in urban photochemical smog: Atlanta as a case study, Science, 241, 1473-1475, 1988.

Chen, X. and Hopke, P. K.: A chamber study of secondary organic aerosol formation by linalool ozonolysis, Atmos. Environ., 43, 3935-3940, 2009.

Ciccioli, P., Cecinato, A., Brancaleoni, E., Frattoni, M., and Liberti, A.: Use of carbon adsorption traps combined with high resolution gas chromatography - mass spectrometry for the analysis of polar and non-polar $\mathrm{C}_{4}-\mathrm{C}_{14}$ hydrocarbons involved in photochemical smog pollution, J. High Res. Chromatog., 15, 75-84, 1992.

Ciccioli, P., Brancaleoni, E., Cecinato, A., Sparapani, R., and Frattoni, M.: Identification and determination of volatile organic compounds in forest areas of Northern and Southern Europe and remote sites of the Himalaya region by high-resolution gas chromatography-mass spectrometry, J. Chromatogr. A, 643, 5569, 1993.

Ciccioli, P., Brancaleoni, E., Frattoni, M., Di Palo, V., Valentini, R., Tirone, G., Seufert, G., Bertin, N., Hansen, U., Csiky, O., Lenz, R., and Sharma, M.: Emission of reactive terpene compounds from orange orchards and their removal by within-canopy processes, J. Geophys. Res., 104, 8077-8094, 1999.

Ciccioli, P., Brancaleoni, E., and Frattoni, M.: Sampling of atmospheric volatile organic compounds (VOCs) with sorbent tubes 
and their analysis by GC-MS, in: Environmental monitoring handbook, edited by: Burden, F. R., McKelvie, I., Forstner, U., and Guenther, A., McGraw-Hill, New York, 21.21-21.85, 2002.

Clausen, P. A. and Wolkoff, P.: Degradation products of Tenax TA formed during sampling and thermal desorption analysis: indicators of reactive species indoors, Atmos. Environ., 31, 715-725, 1997.

Coeur, C., Jacob, V., Denis, I., and Foster, P.: Decomposition of $\alpha$ pinene and sabinene on solid sorbents, Tenax TA and Carboxen, J. Chromatogr. A, 786, 185-187, 1997.

Copolovici, L. and Niinemets, Ü.: Flooding induced emissions of volatile signalling compounds in three tree species with differing waterlogging tolerance, Plant Cell Environ., 33, 1582-1594, doi:10.1111/j.1365-3040.2010.02166.x, 2010.

Copolovici, L., Kännaste, A., and Niinemets, Ü.: Gas chromatography-mass spectrometry method for determination of monoterpene and sesquiterpene emissions from stressed plants, Stud. Univ. Babes-Bol. Chemia, 54, 329-339, 2009.

Copolovici, L., Kännaste, A., Remmel, T., Vislap, V., and Niinemets, Ü.: Volatile emissions from Alnus glutinosa induced by herbivory are quantitatively related to the extent of damage, J. Chem. Ecol., 37, 18-28, 2011.

Copolovici, L. O. and Niinemets, Ü.: Temperature dependencies of Henry's law constants and octanol/water partition coefficients for key plant volatile monoterpenoids, Chemosphere, 61, 13901400, doi:10.1016/j.chemosphere.2005.05.003, 2005.

Copolovici, L. O., Filella, I., Llusià, J., Niinemets, Ü., and Peñuelas, J.: The capacity for thermal protection of photosynthetic electron transport varies for different monoterpenes in Quercus ilex, Plant Physiol., 139, 485-496, 2005.

Curci, G., Palmer, P. I., Kurosu, T. P., Chance, K., and Visconti, G.: Estimating European volatile organic compound emissions using satellite observations of formaldehyde from the Ozone Monitoring Instrument, Atmos. Chem. Phys., 10, 11501-11517, doi:10.5194/acp-10-11501-2010, 2010.

Day, M. E., Greenwood, M. S., and White, A. S.: Age-related changes in foliar morphology and physiology in red spruce and their influence on declining photosynthetic rates and productivity with tree age, Tree Physiol., 21, 1195-1204, 2001.

Dettmer, K. and Engewald, W.: Adsorbent materials commonly used in air analysis for adsorptive enrichment and thermal desorption of volatile organic compounds, Anal. Bioanal. Chem., 373, 490-500, 2002.

Dettmer, K. and Engewald, W.: Ambient air analysis of volatile organic compounds using adsorptive enrichment, Chromatographia, 57, S339-S347, 2003.

Dettmer, K., Knobloch, T., and Engewald, W.: Stability of reactive low boiling hydrocarbons on carbon based adsorbents typically used for adsorptive enrichment and thermal desorption, Fresen. J. Anal. Chem., 366, 70-78, 2000.

Di Carlo, P., Brune, W. H., Martinez, M., Harder, H., Lesher, R., Ren, X., Thornberry, T., Carroll, M. A., Young, V., Shepson, P. B., Riemer, D., Apel, E., and Campbell, C.: Missing OH reactivity in a forest: evidence for unknown reactive biogenic VOCs, Science, 304, 722-724, 2004.

Dindorf, T., Kuhn, U., Ganzeveld, L., Schebeske, G., Ciccioli, P., Holzke, C., Köble, R., Seufert, G., and Kesselmeier, J.: Significant light and temperature dependent monoterpene emissions from European beech (Fagus sylvatica L.) and their potential im- pact on the European volatile organic compound budget, J. Geophys. Res.-Atmos., 111, D16305, doi:10.1029/2005JD006751, 2006.

Drewitt, G. B., Curren, K., Steyn, D. G., Gillesspie, T. J., and Niki, H.: Measurement of biogenic hydrocarbon emissions from vegetation in the lower Fraser Valley, British Columbia, Atmos. Environ., 32, 3457-3466, 1998.

Ekberg, A., Arneth, A., Hakola, H., Hayward, S., and Holst, T.: Isoprene emission from wetland sedges, Biogeosciences, 6, 601613, doi:10.5194/bg-6-601-2009, 2009.

Ezquerro, O., Pons, B., and Tena, M. T.: Direct quantitation of volatile organic compounds in packaging materials by headspace solid-phase microextraction-gas chromatographymass spectrometry, J. Chromatogr. A, 985, 247-257, 2003.

Fall, R. and Monson, R. K.: Isoprene emission rate and intercellular isoprene concentration as influenced by stomatal distribution and conductance, Plant Physiol., 100, 987-992, 1992.

Fall, R., Karl, T., Jordan, A., and Lindinger, W.: Biogenic C5 VOCs: release from leaves after freeze-thaw wounding and occurrence in air at a high mountain observatory, Atmos. Environ., 35, 3905-3916, 2001.

Fick, J., Pommer, L., Andersson, B., and Nilsson, C.: Ozone removal in the sampling of parts per billion levels of terpenoid compounds: an evaluation of different scrubber materials, Environ. Sci. Technol., 35, 1458-1462, 2001.

Field, C. B., Ball, J. T., and Berry, J. A.: Photosynthesis: principles and field techniques, in: Plant physiological ecology. Field methods and instrumentation, edited by: Pearcy, R. W., Ehleringer, J. R., Mooney, H. A., and Rundel, P. W., Chapman and Hall, London - New York, 209-253, 1989.

Filella, I. and Peñuelas, J.: Daily, weekly, and seasonal time courses of VOC concentrations in a semi-urban area near Barcelona, Atmos. Environ., 40, 7752-7769, 2006.

Fischbach, R. J., Staudt, M., Zimmer, I., Rambal, S., and Schnitzler, J. P.: Seasonal pattern of monoterpene synthase activities in leaves of the evergreen tree Quercus ilex, Physiol. Plant., 114, 354-360, 2002.

Fleck, S.: Integrated analysis of relationships between 3D-structure, leaf photosynthesis, and branch transpiration of mature Fagus sylvatica and Quercus petraea trees in a mixed forest stand, Bayreuther Forum Ökologie, 97, BITÖK, Bayreuth, 183 pp., 2003.

Flexas, J., Bota, J., Loreto, F., Cornic, G., and Sharkey, T. D.: Diffusive and metabolic limitations to photosynthesis under drought and salinity in $\mathrm{C}_{3}$ plants, Plant Biol., 6, 269-279, 2004.

Flexas, J., Díaz-Espejo, A., Berry, J. A., Cifre, J., Galmés, J., Kaldenhoff, R., Medrano, H., and Ribas-Carbó, M.: Analysis of leakage in IRGA's leaf chambers of open gas exchange systems: quantification and its effects in photosynthesis parameterization, J. Exp. Bot., 58, 1533-1543, 2007.

Fuentes, J. D., Wang, D., den Hartog, G., Neumann, H. H., Dann, T. F., and Puckett, K. J.: Modelled and field measurements of biogenic hydrocarbon emissions from a Canadian deciduous forest, Atmos. Environ., 29, 3003-3017, 1995.

Fuentes, J. D., Lerdau, M., Atkinson, R., Baldocchi, D., Bottenheim, J. W., Ciccioli, P., Lamb, B., Geron, C., Gu, L., Guenther, A., Sharkey, T. D., and Stockwell, W.: Biogenic hydrocarbons in the atmospheric boundary layer: A review, Bull. Am. Meteorol. Soc., 81, 1537-1575, 2000. 
Fujii, M., Shinohara, N., Lim, A., Otake, T., Kumagai, K., and Yanagisawa, Y.: A study on emission of phthalate esters from plastic materials using a passive flux sampler, Atmos. Environ., 37, 5495-5504, 2003.

Garnier, E., Shipley, B., Roumet, C., and Laurent, G.: A standardized protocol for the determination of specific leaf area and leaf dry matter content, Funct. Ecol., 15, 688-695, 2001.

Gawlowski, J., Gierczak, T., Jeżo, A., and Niedzielski, J.: Adsorption of water vapour in the solid sorbents used for the sampling of volatile organic compounds, The Analyst, 124, 1553-1558, 1999.

Gawrys, M., Fastyn, P., Gawlowski, J., Gierczak, T., and Niedzielski, J.: Prevention of water vapour adsorption by carbon molecular sieves in sampling humid gases, J. Chromatogr. A, 933, 107$116,2001$.

Geosyntec consultants Inc.: Final scoping assessment of soil vapour monitoring protocols for evaluating subsurface vapour intrusion into indoor air. Prepared for Canadian Council of Ministers of the Environment, Report PN 1427, Canadian Council of Ministers of the Environment, Guelph, Ontario, 49 pp., 2009.

Geron, C., Guenther, A., Sharkey, T., and Arnts, R. R.: Temporal variability in basal isoprene emission factor, Tree Physiol., 20, 799-805, 2000a.

Geron, C., Rasmussen, R., Arnts, R. R., and Guenther, A.: A review and synthesis of monoterpene speciation from forests in the United States, Atmos. Environ., 34, 1761-1781, $2000 \mathrm{~b}$.

Geron, C., Harley, P., and Guenther, A.: Isoprene emission capacity for US tree species, Atmos. Environ., 35, 3341-3352, 2001.

Geron, C., Guenther, A. B., Greenberg, J., Karl, T., and Rasmussen, R.: Biogenic volatile organic compound emissions from desert vegetation of the southwestern US, Atmos. Environ., 40, 16451660, 2006a.

Geron, C., Owen, S., Guenther, A., Greenberg, J., Karl, T., Rasmussen, R., Bai, J. H., Li, Q.-J., and Baker, B.: Volatile organic compounds from vegetation in southern Yunnan Province, China: emission rates and some potential regional implications, Atmos. Environ., 40, 1759-1773, $2006 \mathrm{~b}$.

Geron, C. D., Guenther, A. B., and Pierce, T. E.: An improved model for estimating emissions of volatile organic compounds from forests in the eastern United States, J. Geophys. Res., 99, 12773-12791, 1994.

Gershenzon, J., Murtagh, G. J., and Croteau, R.: Absence of rapid terpene turnover in several diverse species of terpeneaccumulating plants, Oecologia, 96, 583-592, 1993.

Ghirardo, A., Koch, K., Taipale, R., Zimmer, I., Schnitzler, J. P., and Rinne, J.: Determination of de novo and pool emissions of terpenes from four common boreal/alpine trees by ${ }^{13} \mathrm{CO}_{2}$ labelling and PTR-MS analysis, Plant Cell Environ., 33, 781-792, 2010.

Gog, L., Berenbaum, M. R., DeLucia, E. H., and Zangerl, A. R.: Autotoxic effects of essential oils on photosynthesis in parsley, parsnip, and rough lemon, Chemoecology, 15, 115-119, 2005.

Gray, D. W., Goldstein, A. H., and Lerdau, M.: Thermal history regulates methylbutenol basal emission rate in Pinus ponderosa, Plant Cell Environ., 29, 1298-1308, 2006.

Guenther, A., Zimmerman, P. R., and Wildermuth, M.: Natural volatile organic compound emission rates for U.S. woodland landscapes, Atmos. Environ., 28, 1197-1210, 1994.

Guenther, A., Hewitt, C. N., Erickson, D., Fall, R., Geron, C., Graedel, T., Harley, P., Klinger, L., Lerdau, M., McKay, W. A.,
Pierce, T., Scholes, B., Steinbrecher, R., Tallamraju, R., Taylor, J., and Zimmerman, P.: A global model of natural volatile compound emissions, J. Geophys. Res., 100, 8873-8892, 1995.

Guenther, A., Geron, C., Pierce, T., Lamb, B., Harley, P., and Fall, R.: Natural emissions of non-methane volatile organic compounds, carbon monoxide, and oxides of nitrogen from North America, Atmos. Environ., 34, 2205-2230, 2000.

Guenther, A., Karl, T., Harley, P., Wiedinmyer, C., Palmer, P. I., and Geron, C.: Estimates of global terrestrial isoprene emissions using MEGAN (Model of Emissions of Gases and Aerosols from Nature), Atmos. Chem. Phys., 6, 3181-3210, doi:10.5194/acp-63181-2006, 2006.

Guenther, A. B., Monson, R. K., and Fall, R.: Isoprene and monoterpene emission rate variability: observations with $\mathrm{Eu}$ calyptus and emission rate algorithm development, J. Geophys. Res., 96, 10799-10808, 1991.

Guenther, A. B., Zimmerman, P. R., Harley, P. C., Monson, R. K., and Fall, R.: Isoprene and monoterpene emission rate variability: model evaluations and sensitivity analyses, J. Geophys. Res., 98, 12609-12617, 1993.

Guth, S. and Frenzel, B.: Epicuticular wax of silver fir (Abies alba Mill.) and the present forest decline. 2. The chemical composition of cuticular waxes and needle lipids, Angew. Bot., 63, 259277, 1989.

Hakola, H., Rinne, J., and Laurila, T.: The hydrocarbon emission rates of tea-leafed willow (Salix phylicifolia), silver birch (Betula pendula) and European aspen (Populus tremula), Atmos. Environ., 32, 1825-1833, 1998.

Hakola, H., Laurila, T., Lindfors, V., Hellen, H., Gaman, A., and Rinne, J.: Variation of the VOC emission rates of birch species during the growing season, Boreal Environ. Res., 6, 237-249, 2001.

Hakola, H., Tarvainen, V., Bäck, J., Ranta, H., Bonn, B., Rinne, J., and Kulmala, M.: Seasonal variation of mono- and sesquiterpene emission rates of Scots pine, Biogeosciences, 3, 93-101, doi:10.5194/bg-3-93-2006, 2006.

Hallquist, M., Wenger, J. C., Baltensperger, U., Rudich, Y., Simpson, D., Claeys, M., Dommen, J., Donahue, N. M., George, C., Goldstein, A. H., Hamilton, J. F., Herrmann, H., Hoffmann, T., Iinuma, Y., Jang, M., Jenkin, M. E., Jimenez, J. L., Kiendler-Scharr, A., Maenhaut, W., McFiggans, G., Mentel, Th. F., Monod, A., Prévôt, A. S. H., Seinfeld, J. H., Surratt, J. D., Szmigielski, R., and Wildt, J.: The formation, properties and impact of secondary organic aerosol: current and emerging issues, Atmos. Chem. Phys., 9, 5155-5236, doi:10.5194/acp-95155-2009, 2009.

Hanson, P. J., Samuelson, L. J., Wullschleger, S. D., Tabberer, T. A., and Edwards, G. S.: Seasonal patterns of light-saturated photosynthesis and leaf conductance for mature and seedling Quercus rubra L. foliage: differential sensitivity to ozone exposure, Tree Physiol., 14, 1351-1366, 1994.

Harley, P., Guenther, A., and Zimmerman, P.: Effects of light, temperature and canopy position on net photosynthesis and isoprene emission from sweetgum (Liquidambar styraciflua) leaves, Tree Physiol., 16, 25-32, 1996.

Harley, P., Guenther, A., and Zimmerman, P.: Environmental controls over isoprene emission in deciduous oak canopies, Tree Physiol., 17, 705-714, 1997.

Harley, P., Vasconcellos, P., Vierling, L., De S. Pinheiro, C., 
Greenberg, J., Guenther, A., Klinger, L., Soares De Almeida, S., Neill, D., Baker, T., Phillips, O., and Malhi, Y.: Variation in potential for isoprene emissions among Neotropical forest sites, Glob. Change Biol., 10, 630-650, 2004.

Harogoppad, S. B. and Aminabhavi, T. M.: Diffusion and sorption of organic liquids through polymer membranes. II. Neoprene, SBR, EPDM, NBR, and natural rubber versus n-alkanes, J. Appl. Polym. Sci., 42, 2329-2336, 1991.

Harrison, D., Hunter, M. C., Lewis, A. C., Seakins, P. W., Bonsang, B., Gros, V., Kanakidou, M., Touaty, M., Kavouras, I., Mihalopoulos, N., Stephanou, E., Alves, C., Nunes, T., and Pio, C.: Ambient isoprene and monoterpene concentrations in a Greek fir (Abies borisii-regis) forest. Reconciliation with emissions measurements and effects on measured $\mathrm{OH}$ concentrations, Atmos. Environ., 35, 4699-4711, 2001.

Hartman, T.: Determination of off-odors and other volatile organics in food packaging films by direct thermal analysis-GC-MS, SISWEB Application Note, 1a, 7 pp., 1999.

Hayes, H. C., Benton, D. J., and Khan, N.: Impact of sampling media on soil gas measurements, A\&WMA "Vapor Intrusion The Next Great Environmental Challenge - An Update", 13-15 September 2006, Los Angeles, CA, USA, 2006.

Heiden, A. C., Kobel, K., Komenda, M., Koppmann, R., Shao, M., and Wildt, J.: Toluene emissions from plants, Geophys. Res. Lett., 26, 1283-1286, 1999.

Helmig, D. and Greenberg, J.: Artifact formation from the use of potassium-iodide-based ozone traps during atmospheric sampling of trace organic gases, J. High Res. Chromatog., 18, 15-18, 1995.

Helmig, D. and Vierling, L.: Water adsorption capacity of the solid adsorbents Tenax TA, Tenax GR, Carbotrap, Carbotrap C, Carbosive SIII and Carboxen 569 and water management techniques for the atmospheric sampling of volatile organic trace gases, Anal. Chem., 67, 4380-4386, 1995.

Helmig, D.: Ozone removal techniques in the sampling of atmospheric volatile organic trace gases, Atmos. Environ., 31, 36353651, 1997.

Helmig, D., Revermann, T., Pollmann, J., Kaltschmidt, O., Hernandez, A. J., Bocquet, F., and David, D.: Calibration system and anlytical considerations for quantitative sesquiterpene measurements in air, J. Chromatogr. A, 1002, 193-211, 2003.

Helmig, D., Bocquet, F., Pollmann, J., and Revermann, T.: Analytical techniques for sesquiterpene emission rate studies in vegetation enclosure experiments, Atmos. Environ., 38, 557-572, 2004.

Helmig, D., Ortega, J., Guenther, A., Herrick, J. D., and Geron, C.: Sesquiterpene emissions from loblolly pine and their potential contribution to biogenic aerosol formation in the Southeastern US, Atmos. Environ., 40, 4150-4157, 2006.

Hills, A. J. and Zimmerman, P. R.: Isoprene measurement by ozone-induced chemiluminescence, Anal. Chem., 62, 10551060, 1990.

Himanen, S. J., Blande, J. D., Klemola, T., Pulkkinen, J., Heijari, J., and Holopainen, J. K.: Birch (Betula spp.) leaves adsorb and rerelease volatiles specific to neighbouring plants - a mechanism for associational herbivore resistance?, New Phytol., 186, 722$732,2010$.

Hodgson, S. C., O'Connor, M. J., Casey, R. J., and Bigger, S. W.: Toward an optimized dynamic headspace method for the study of volatiles in low-density polyethylene, J. Agr. Food Chem., 46, 1397-1405, 1998.

Hoffmann, T.: Adsorptive preconcentration technique including oxidant scavenging for the measurement of reactive natural hydrocarbons in ambient air, Fresen. J. Anal. Chem., 351, 41-47, 1995.

Huff Hartz, K. E., Rosenørn, T., Ferchak, S. R., Raymond, T. M., Bilde, M., Donahue, N. M., and Pandis, S. N.: Cloud condensation nuclei activation of monoterpene and sesquiterpene secondary organic aerosol, J. Geophys. Res.-Atmos., 110, D14208, doi:14210.11029/12004JD005754, 2005.

Hüve, K., Christ, M. M., Kleist, E., Uerlings, R., Niinemets, Ü., Walter, A., and Wildt, J.: Simultaneous growth and emission measurements demonstrate an interactive control of methanol release by leaf expansion and stomata, J. Exp. Bot., 58, 1783-1793, 2007.

Ishizuka, Y., Tokumura, M., Mizukoshi, A., Noguchi, M., and Yanagisawa, Y.: Measurement of secondary products during oxidation reactions of terpenes and ozone based on the PTR-MS analysis: effects of coexistent carbonyl compounds, Int. J. Environ. Res. Public Health, 7, 3853-3870, 2010.

Janson, R., De Serves, C., and Romero, R.: Emission of isoprene and carbonyl compounds from a boreal forest and wetland in Sweden, Agr. Forest Meteorol., 98-99, 671-681, 1999.

Jasse, B., Seuvre, A. M., and Mathlouthi, M.: Permeability and structure in polymer packaging materials, in: Food packaging and preservation, edited by: Mathlouthi, M., Aspen Publishers, Inc., Gaithersburg, Maryland, 1-22, 1999.

Jurik, T. W.: Temporal and spatial patterns of specific leaf weight in successional northern hardwood tree species, Am. J. Bot., 73, 1083-1092, 1986.

Karl, T., Prazeller, P., Mayr, D., Jordan, A., Rieder, J., Fall, R., and Lindinger, W.: Human breath isoprene and its relation to serum cholesterol levels: measurements and modelling, J. Appl. Physiol., 91, 762-770, 2001.

Karl, T., Harley, P., Guenther, A., Rasmussen, R., Baker, B., Jardine, K., and Nemitz, E.: The bi-directional exchange of oxygenated VOCs between a loblolly pine (Pinus taeda) plantation and the atmosphere, Atmos. Chem. Phys., 5, 3015-3031, doi:10.5194/acp-5-3015-2005, 2005.

Keenan, T., Niinemets, Ü., Sabate, S., Gracia, C., and Peñuelas, J.: Seasonality of monoterpene emission potentials in Quercus ilex and Pinus pinea: Implications for regional BVOC emissions modelling, J. Geophys. Res.-Atmos., 114, D22202, doi:10.1029/2009JD011904, 2009.

Kesselmeier, J. and Staudt, M.: Biogenic volatile organic compounds (VOC): an overview on emission, physiology and ecology, J. Atmos. Chem., 33, 23-88, 1999.

Kesselmeier, J., Meixner, F. X., Hofmann, U., Ajavon, A., Leimbach, S., and Andreae, M. O.: Reduced sulfur compound exchange between the atmosphere and tropical tree species in southern Cameroon, Biogeochemistry, 23, 23-45, 1993.

Kesselmeier, J., Schäfer, L., Ciccioli, P., Brancaleoni, E., Cecinato, A., Frattoni, M., Foster, P., Jacob, V., Denis, J., Fugit, J. L., Dutaur, L., and Torres, L.: Emission of monoterpenes and isoprene from a Mediterranean oak species Quercus ilex L. measured within the BEMA (biogenic emissions in the Mediterranean area) project, Atmos. Environ., 30, 1841-1850, 1996.

Kesselmeier, J., Bode, K., Hofmann, U., Müller, H., Schäfer, L., Wolf, A., Ciccioli, P., Brancaleoni, E., Cecinato, A., Frattoni, M., 
Foster, P., Ferrari, C., Jacob, V., Fugit, J. L., Dutaur, L., Simon, V., and Torres, L.: Emission of short chained organic acids, aldehydes and monoterpenes from Quercus ilex L. and Pinus pinea L. in relation to physiological activities, carbon budget and emission algorithms, Atmos. Environ., 31, 119-133, 1997.

Kesselmeier, J., Bode, K., Gerlach, C., and Jork, E. M.: Exchange of atmospheric formic and acetic acids with trees and crop plants under controlled chamber and purified air conditions, Atmos. Environ., 32, 1765-1775, 1998.

Kesselmeier, J., Kuhn, U., Wolf, A., Andreae, M. O., Ciccioli, P., Brancaleoni, E., Frattoni, M., Guenther, A., Greenberg, J., de Castro Vasconcellos, P., de Oliva, T., Tavares, T., and Artaxo, P.: Atmospheric volatile organic compounds (VOC) at a remote tropical forest site in central Amazonia, Atmos. Environ., 34, 4063-4072, 2000.

Kesselmeier, J., Kuhn, U., Rottenberger, S., Biesenthal, T., Wolf, A., Schebeske, G., Andreae, M. O., Ciccioli, P., Brancaleoni, E., Frattoni, M., Oliva, S. T., Botelho, M. L., Silva, C. M. A., and Tavares, T. M.: Concentrations and species composition of atmospheric volatile organic compounds (VOC) as observed during the wet and dry season in Rondõnia (Amazonia), J. Geophys. Res., 107(D20), 8053, doi:10.1029/2000JD000267, 2002.

Kirschbaum, M. U. F., Niinemets, Ü., Bruhn, D., and Winters, A. J.: How important is aerobic methane release by plants?, Functional Plant Science and Biotechnology, 1, 138-145, 2007.

Kleindienst, T. E., Lewandowski, M., Offenberg, J. H., Jaoui, M., and Edney, E. O.: Ozone-isoprene reaction: re-examination of the formation of secondary organic aerosol, Geophys. Res. Lett., 34, L01805, doi:10.1029/2006GL027485, 2007.

Klenø, J. G., Wolkoff, P., Clausen, P. A., Wilkins, C. K., and Pedersen, T.: Degradation of the adsorbent Tenax TA by nitrogen oxides, ozone, hydrogen peroxide, $\mathrm{OH}$ radical, and limonene oxidation products, Environ. Sci. Technol., 36, 4121-4126, 2002.

Klingler, H., Frosch, S., and Wagner, E.: In vitro effects of monoterpenes on chloroplast membranes, Photosynth. Res., 28, 109-118, 1991.

Komenda, M., Parusel, E., Wedel, A., and Koppmann, R.: Measurements of biogenic VOC emissions: sampling, analysis and calibration, Atmos. Environ., 35, 2069-2080, 2001.

Kuhn, U., Rottenberger, S., Biesenthal, T., Ammann, C., Wolf, A., Schebeske, G., Oliva, S. T., Tavares, T. M., and Kesselmeier, J.: Exchange of short-chain monocarboxylic acids by vegetation at a remote tropical forest site in Amazonia, J. Geophys. Res., D107, 8069, doi:10.1029/2000JD000303, 2002a.

Kuhn, U., Rottenberger, S., Biesenthal, T., Wolf, A., Schebeske, G., Ciccioli, P., Brancaleoni, E., Frattoni, M., Tavares, T. M., and Kesselmeier, J.: Isoprene and monoterpene emissions of Amazonian tree species during the wet season: direct and indirect investigations on controlling environmental functions, J. Geophys. Res., D107, 8071, doi:10.1029/2001JD000978, 2002b.

Kuhn, U., Rottenberger, S., Biesenthal, T., Wolf, A., Schebeske, G., Ciccioli, P., and Kesselmeier, J.: Strong correlation between isoprene emission and gross photosynthetic capacity during leaf phenology of the tropical tree species Hymenaea courbaril with fundamental changes in volatile organic compounds emission composition during early leaf development, Plant Cell Environ., 27, 1469-1485, 2004.

Kuhn, U., Dindorf, T., Ammann, C., Rottenberger, S., Guyon, P., Holzinger, R., Ausma, S., Kenntner, T., Helleis, F., and
Kesselmeier, J.: Design and field application of an automated cartridge sampler for VOC concentration and flux measurements, J. Environ. Monitor., 7, 568-576, 2005.

Kulmala, M., Hienola, J., Pirjola, L., Vesala, T., Shimmo, M., A1timir, N., and Hari, P.: A model for $\mathrm{NO}_{\mathrm{x}}-\mathrm{O}_{3}$-terpene chemistry in chamber measurements of plant gas exchange, Atmos. Environ., 33, 2145-2156, 1999.

Lappi, J. and Smolander, H.: Integration of the hyperbolic radiationresponse function of photosynthesis, Photosynthetica, 18, 402410, 1984.

Lappi, J. and Smolander, H.: A comment on "A note on estimating the mean level of photosynthesis from radiation measurements" by Chris Koen, Agr. Forest Meteorol., 44, 39-45, 1988.

Larsen, B., Bomboi-Mingarro, T., Brancaleoni, E., Calogirou, A., Cecinato, A., Coeur, C., Chatzianestis, I., Duane, M., Frattoni, M., Fugit, J.-L., Hansen, U., Jacob, V., Mimikos, N., Hoffmann, T., Owen, S., Perez-Pastor, R., Reichmann, A., Seufert, G., Staudt, M., and Steinbrecher, R.: Sampling and analysis of terpenes in air. An interlaboratory comparison, Atmos. Environ., 31, 35-49, 1997.

Lärstad, M., Loh, C., Ljungkvist, G., Olin, A.-C., and Toren, K.: Determination of ethane, pentane and isoprene in exhaled air using a multi-bed adsorbent and end-cut gas-solid chromatography, Analyst, 127, 1440-1445, 2002.

Lavoir, A.-V., Staudt, M., Schnitzler, J. P., Landais, D., Massol, F., Rocheteau, A., Rodriguez, R., Zimmer, I., and Rambal, S.: Drought reduced monoterpene emissions from the evergreen Mediterranean oak Quercus ilex: results from a throughfall displacement experiment, Biogeosciences, 6, 1167-1180, doi:10.5194/bg-6-1167-2009, 2009.

Lee, J. H., Batterman, S. A., Jia, C., and Chernyak, S.: Ozone artifacts and carbonyl measurements using Tenax GR, Tenax TA, Carbopack B, and Carbopack X adsorbents, J. Air Waste Manage., 56, 1503-1517, 2006.

Lehning, A., Zimmer, W., Zimmer, I., and Schnitzler, J. P.: Modeling of annual variations of oak (Quercus robur L.) isoprene synthase activity to predict isoprene emission rates, J. Geophys. Res., 106, 3157-3166, 2001.

Li-Cor Inc.: Interfacing custom chambers to the LI-6400 sensor head. LI-6400 portable photosynthesis system: application note 3, Li-Cor, Inc, Lincoln, Nebraska, USA, 7 pp., 2001.

Lindinger, W., Hansel, A., and Jordan, A.: Proton-transfer-reaction mass spectrometry (PTR-MS): on-line monitoring of volatile organic compounds at pptv levels, Chem. Soc. Rev., 27, 347-354, 1998a.

Lindinger, W., Hansel, A., and Jordan, A.: On-line monitoring of volatile organic compounds at pptv levels by means of protontransfer-reaction mass spectrometry (PTR-MS): medical applications, food control and environmental research, Int. J. Mass Spectrom., 173, 191-241, 1998b.

Lindskog, A. and Potter, A.: Terpene emission and ozone stress, Chemosphere, 30, 1171-1181, 1995.

Litvak, M. E. and Monson, R. K.: Patterns of induced and constitutive monoterpene production in conifer needles in relation to insect herbivory, Oecologia, 114, 531-540, 1998.

Llusià, J. and Peñuelas, J.: Seasonal patterns of terpene content and emission from seven Mediterranean woody species in field conditions, Am. J. Bot., 87, 133-140, 2000.

Loivamäki, M., Mumm, R., Dicke, M., and Schnitzler, J. P.: 
Isoprene interferes with the attraction of bodyguards by herbaceous plants, Proc. Natl. Acad. Sci. USA, 105, 17430-17435, 2008.

Long, S. P. and Bernacchi, C. J.: Gas exchange measurements, what can they tell us about the underlying limitations to photosynthesis? Procedures and sources of error, J. Exp. Bot., 54, 23932401, 2003.

Long, S. P., Farage, P. K., and Garcia, R. L.: Measurement of leaf and canopy photosynthetic $\mathrm{CO}_{2}$ exchange in the field, J. Exp. Bot., 47, 1629-1642, 1996.

Loreto, F. and Schnitzler, J.-P.: Abiotic stresses and induced BVOCs, Trends Plant Sci., 15, 154-166, 2010.

Loreto, F. and Velikova, V.: Isoprene produced by leaves protects the photosynthetic apparatus against ozone damage, quenches ozone products, and reduces lipid peroxidation of cellular membranes, Plant Physiol., 127, 1781-1787, 2001.

Loreto, F., Ciccioli, P., Cecinato, A., Brancaleoni, E., Frattoni, M., and Tricoli, D.: Influence of environmental factors and air composition on the emission of $\alpha$-pinene from Quercus ilex leaves, Plant Physiol., 110, 267-275, 1996.

Loreto, F., Nascetti, P., Graverini, A., and Mannozzi, M.: Emission and content of monoterpenes in intact and wounded needles of the Mediterranean pine, Pinus pinea, Funct. Ecol., 14, 589-595, 2000.

Loreto, F., Mannozzi, M., Maris, C., Nascetti, P., Ferranti, F., and Pasqualini, S.: Ozone quenching properties of isoprene and its antioxidant role in leaves, Plant Physiol., 126, 993-1000, 2001.

Loreto, F., Barta, C., Brilli, F., and Nogues, I.: On the induction of volatile organic compound emissions by plants as consequence of wounding or fluctuations of light and temperature, Plant Cell Environ., 29, 1820-1828, 2006.

Manes, F., Seufert, G., Vitale, M., Donate, E., Csiky, O., and Silli, V.: Ecophysiological characterization of Citrus sinensis (L.) Osbeck and relationships with type and amount of biogenic emissions, Phys. Chem. Earth B, 24, 699-703, 1999.

Manura, J. J.: Detection and identification of volatile and semivolatile organics in synthetic polymers used in food and pharmaceutical packaging, SISWEB Application Note, 21a, 5 pp., 1999.

Massey, L. K.: Properties of plastics and elastomers. A guide to packaging and barrier materials, 2nd edn., Plastic Design Library, William Andrew Publishing, Norwick, NY, 601 pp., 2003.

Mastrogiacomo, A. R., Pierini, E., and Sampaolo, L.: A comparison of the critical parameters of some adsorbents employed in trapping and thermal desorption of organic pollutants, Chromatographia, 41, 599-604, 1995.

Matisová, E. and Škrabáková, S.: Carbon sorbents and their utilization for the preconcentration of organic pollutants in environmental samples, J. Chromatogr. A, 707, 145-179, 1995.

Matsui, K.: Green leaf volatiles: hydroperoxide lyase pathway of oxylipin metabolism, Curr. Opin. Plant Biol., 9, 274-280, doi:10.1016/j.pbi.2006.03.002, 2006.

Matsunaga, S. N., Guenther, A. B., Potosnak, M. J., and Apel, E. C.: Emission of sunscreen salicylic esters from desert vegetation and their contribution to aerosol formation, Atmos. Chem. Phys., 8, 7367-7371, doi:10.5194/acp-8-7367-2008, 2008.

McClenny, W. A., Oliver, K. D., Jacumin Jr., H. H., and Daughtrey Jr., E. H.: Ambient level volatile organic compound (VOC) monitoring using solid adsorbents - Recent US EPA studies, J.
Environ. Monit., 4, 695-705, 2002.

Morison, J. I. L.: Intercellular $\mathrm{CO}_{2}$ concentration and stomatal response to $\mathrm{CO}_{2}$, in: Stomatal function, edited by: Zeiger, E., Farquhar, G. D., and Cowan, I. R., Stanford University Press, Stanford, 229-251, 1987.

Moukhtar, S., Bessagnet, B., Rouil, L., and Simon, V.: Monoterpene emissions from beech (Fagus sylvatica) in a French forest and impact on secondary pollutants formation at regional scale, Atmos. Environ., 39, 3535-3547, 2005.

Neeb, P., Bode, K., Beck, J., Schäfer, L., Kesselmeier, J., and Moortgart, G. K.: Influence of gas-phase oxidation on estimated emission rates of biogenic hydrocarbons, in: The oxidizing capacity of the troposphere. Proceedings of the 7th European symposium on physico-chemical behavior of atmospheric pollutants, edited by: Larson, B., Versino, B., and Angeletti, G., European Commission, Brussels, 295-299, 1996.

Niinemets, Ü.: Stomatal conductance alone does not explain the decline in foliar photosynthetic rates with increasing tree age and size in Picea abies and Pinus sylvestris, Tree Physiol., 22, 515535, 2002.

Niinemets, Ü.: Photosynthesis and resource distribution through plant canopies, Plant Cell Environ., 30, 1052-1071, 2007.

Niinemets, Ü.: Getting hold of terpene emissions from vegetation, ILeaps Newsletter, 5, 40-42, www.ileaps.org, 2008.

Niinemets, Ü.: A review of light interception in plant stands from leaf to canopy in different plant functional types and in species with varying shade tolerance, Ecol. Res., 25, 693-714, doi:10.1007/s11284-010-0712-4, 2010a.

Niinemets, Ü.: Mild versus severe stress and BVOCs: thresholds, priming and consequences, Trends Plant Sci., 15, 145-153, 2010b.

Niinemets, Ü.: Whole plant photosynthesis, in: Terrestrial photosynthesis in a changing environment. The molecular, physiological and ecological bases of photosynthesis driving its response to the environmental changes, edited by: Flexas, J., Loreto, F., and Medrano, H., Cambridge University Press, Cambridge, in press, 2011.

Niinemets, Ü. and Anten, N. P. R.: Packing photosynthesis machinery: from leaf to canopy, in: Photosynthesis in silico: understanding complexity from molecules to ecosystems, edited by: Laisk, A., Nedbal, L., and Govindjee, Advances in photosynthesis and respiration, 29, Springer Verlag, Berlin, 363-399, 2009.

Niinemets, Ü. and Reichstein, M.: A model analysis of the effects of nonspecific monoterpenoid storage in leaf tissues on emission kinetics and composition in Mediterranean sclerophyllous Quercus species, Global Biogeochem. Cy., 16, 1110, doi:1110.1029/2002GB001927, 2002.

Niinemets, Ü. and Reichstein, M.: Controls on the emission of plant volatiles through stomata: a sensitivity analysis, J. Geophys. Res.-Atmos., 108, 4211, doi:4210.1029/2002JD002626, 2003a.

Niinemets, Ü. and Reichstein, M.: Controls on the emission of plant volatiles through stomata: sensitivity or insensitivity of the emission rates to stomatal closure explained, J. Geophys. Res.Atmos., 108, 4208, doi:4210.1029/2002JD002620, 2003b.

Niinemets, Ü., Tenhunen, J. D., Harley, P. C., and Steinbrecher, R.: A model of isoprene emission based on energetic requirements for isoprene synthesis and leaf photosynthetic properties for Liquidambar and Quercus, Plant Cell Environ., 22, 13191336, 1999. 
Niinemets, Ü., Hauff, K., Bertin, N., Tenhunen, J. D., Steinbrecher, R., and Seufert, G.: Monoterpene emissions in relation to foliar photosynthetic and structural variables in Mediterranean evergreen Quercus species, New Phytol., 153, 243-256, 2002a.

Niinemets, Ü., Seufert, G., Steinbrecher, R., and Tenhunen, J. D.: A model coupling foliar monoterpene emissions to leaf photosynthetic characteristics in Mediterranean evergreen Quercus species, New Phytol., 153, 257-276, 2002b.

Niinemets, Ü., Kull, O., and Tenhunen, J. D.: Within canopy variation in the rate of development of photosynthetic capacity is proportional to integrated quantum flux density in temperate deciduous trees, Plant Cell Environ., 27, 293-313, 2004.

Niinemets, Ü., Tobias, M., Cescatti, A., and Sparrow, A. D.: Sizedependent variation in shoot light-harvesting efficiency in shadeintolerant conifers, Int. J. Plant Sci., 167, 19-32, 2006.

Niinemets, Ü., Arneth, A., Kuhn, U., Monson, R. K., Peñuelas, J., and Staudt, M.: The emission factor of volatile isoprenoids: stress, acclimation, and developmental responses, Biogeosciences, 7, 2203-2223, doi:10.5194/bg-7-2203-2010, 2010a.

Niinemets, Ü., Copolovici, L., and Hüve, K.: High within-canopy variation in isoprene emission potentials in temperate trees: implications for predicting canopy-scale isoprene fluxes, J. Geophys. Res.-Biogeo., 115, G04029, doi:10.1029/2010JG001436, 2010 b.

Niinemets, Ü., Monson, R. K., Arneth, A., Ciccioli, P., Kesselmeier, J., Kuhn, U., Noe, S. M., Peñuelas, J., and Staudt, M.: The leaflevel emission factor of volatile isoprenoids: caveats, model algorithms, response shapes and scaling, Biogeosciences, 7, 18091832, doi:10.5194/bg-7-1809-2010, 2010c.

Noe, S. M., Copolovici, L., Niinemets, Ü., and Vaino, E.: Foliar limonene uptake scales positively with leaf lipid content: "nonemitting" species absorb and release monoterpenes, Plant Biol., 10, 129-137, doi:10.1055/s-2007-965239, 2008.

Noe, S. M., Niinemets, Ü., and Schnitzler, J.-P.: Modeling the temporal dynamics of monoterpene emission by isotopic labeling in Quercus ilex leaves, Atmos. Environ., 44, 392-399, 2010.

Noe, S. M., Kimmel, V., Hüve, K., Copolovici, L., Portillo-Estrada, M., Püttsepp, Ü., Jõgiste, K., Niinemets, Ü., Hörtnagl, L., and Wohlfahrt, G.: Ecosystem-scale biosphere-atmosphere interactions of a hemiboreal mixed forest stand at Järvselja, Estonia, Forest Ecol. Manag., 262, 71-81, 2011.

Nuñez, L., Plaza, J., Pérez-Pastor, R., Pujadas, M., Gimeno, B. S., Bermejo, V., and García-Alonso, S.: High water vapour pressure deficit influence on Quercus ilex and Pinus pinea field monoterpene emission in the central Iberian Peninsula (Spain), Atmos. Environ., 36, 4441-4452, 2002.

Okumura, M., Tani, A., Kominami, Y., Takanashi, S., Kosugi, Y., Miyama, T., and Tohno, S.: Isoprene emission characteristics of Quercus serrata in a deciduous broad-leaved forest, Journal of Agricultural Meteorology, Japan, 64, 49-60, 2008.

Oliver, K. D., Adams, J. R., Daughtrey Jr., E. H., McClenny, W. A., Yoong, M. J., and Pardee, M. A.: Technique for monitoring ozone precursor hydrocarbons in air at photochemical assessment monitoring stations: sorbent preconcentration, closed-cycle cooler cryofocusing, and GC-FID analysis, Atmos. Environ., 30, 2751-2757, 1996.

Ortega, J. and Helmig, D.: Approaches for quantifying reactive and low-volatility biogenic organic compound emissions by vegeta- tion enclosure techniques - Part A, Chemosphere, 72, 343-364, 2008.

Ortega, J., Helmig, D., Daly, R. W., Tanner, D. M., Guenther, A. B., and Herrick, J. D.: Approaches for quantifying reactive and low-volatility biogenic organic compound emissions by vegetation enclosure techniques - Part B: applications, Chemosphere, 72, 365-380, 2008.

Owen, S.: Emissions of isoprene and monoterpenes from native Mediterranean vegetation, Ph.D. thesis, Lancaster University, Lancaster, 1998.

Owen, S. M., Boissard, C., and Hewitt, C. N.: Volatile organic compounds (VOCs) emitted from 40 Mediterranean plant species: VOC speciation and extrapolation to habitat scale, Atmos. Environ., 35, 5393-5409, 2001.

Owen, S. M., Harley, P., Guenther, A., and Hewitt, C. N.: Light dependency of VOC emissions from selected Mediterranean plant species, Atmos. Environ., 36, 3147-3159, 2002.

Palluau, F., Mirabel, P., and Millet, M.: Influence of relative humidity and ozone on the sampling of volatile organic compounds on Carbotrap/Carbosieve adsorbents, Environ. Monit. Assess., 127, 177-187, 2007.

Palva, L., Garam, E., Manoochehri, F., Sepponen, R., Hari, P., Rajala, K., Ruotoistenmäki, H., and Seppälä, I.: A novel multipoint measuring system of photosynthetically active radiation, Agr. Forest Meteorol., 89, 141-147, 1998a.

Palva, L., Garam, E., Siivola, E., Sepponen, R., and Hari, P.: Quantifying spatial variability of photosynthetically active radiation within canopies using a multipoint measuring system, Agr. Forest Meteorol., 92, 163-171, 1998b.

Pape, L., Ammann, C., Nyfeler-Brunner, A., Spirig, C., Hens, K., and Meixner, F. X.: An automated dynamic chamber system for surface exchange measurement of non-reactive and reactive trace gases of grassland ecosystems, Biogeosciences, 6, 405429, doi:10.5194/bg-6-405-2009, 2009.

Papiez, M. R., Potosnak, M. J., Goliff, W. S., Guenther, A. B., Matsunaga, S. N., and Stockwell, W. R.: The impacts of reactive terpene emissions from plants on air quality in Las Vegas, Nevada, Atmos. Environ., 43, 4109-4123, 2009.

Paré, P. W. and Tumlinson, J. H.: De novo biosynthesis of volatiles induced by insect herbivory in cotton plants, Plant Physiol., 114, 1161-1167, 1997.

Paré, P. W. and Tumlinson, J. H.: Plant volatiles as a defense against insect herbivores, Plant Physiol., 121, 325-331, 1999.

Parkinson, K. J.: Porometry, in: Instrumentation for environmental physiology, edited by: Marshall, B. and Woodward, F. I., Society for experimental biology seminar series, 22, Cambridge University Press, Cambridge - New York - New Rochelle - Melbourne - Sydney, 171-191, 1985.

Parra, R., Gassó, S., and Baldasano, J. M.: Estimating the biogenic emissions of non-methane volatile organic compounds from the North Western Mediterranean vegetation of Catalonia, Spain, Sci. Total Environ., 329, 241-259, 2004.

Pellizzari, E. D. and Krost, K. J.: Chemical transformations during ambient air sampling for organic vapors, Anal. Chem., 56, 18131819, 1984.

Peñuelas, J. and Staudt, M.: BVOCs and global change, Trends Plant Sci., 15, 133-144, 2010.

Peñuelas, J., Filella, I., Seco, R., and Llusià, J.: Increase in isoprene and monoterpene emissions after re-watering of droughted 
Quercus ilex seedlings, Biol. Plant., 53, 351-354, 2009.

Pier, P. A.: Isoprene emission rates from northern red oak using a whole-tree chamber, Atmos. Environ., 29, 1347-1353, 1995.

Pier, P. A. and McDuffie Jr., C.: Seasonal isoprene emission rates and model comparisons using whole-tree emissions from white oak, J. Geophys. Res.-Atmos., 102, 23963-23971, 1997.

Pierce, T. E. and Waldruff, P. S.: PC-BEIS - a personal-computer version of the biogenic emissions inventory system, J. Air Waste Manage., 41, 937-941, 1991.

Pio, C. A. and Valente, A. A.: Atmospheric fluxes and concentrations of monoterpenes in resin-tapped pine forests, Atmos. Environ., 32, 683-691, 1998.

Planchais, I. and Sinoquet, H.: Foliage determinants of light interception in sunny and shaded branches of Fagus sylvatica L., Agr. Forest Meteorol., 89, 241-253, 1998.

Plass-Dülmer, C., Schmidbauer, N., Slemr, J., Slemr, F., and D'Souza, H.: European hydrocarbon intercomparison experiment AMOHA part 4: Canister sampling of ambient air, J. Geophys. Res.-Atmos., 111, D04306, doi:10.1029/2005JD006351, 2006.

Pollmann, J., Ortega, J., and Helmig, D.: Analysis of atmospheric sesquiterpenes: sampling losses and mitigation of ozone interferences, Environ. Sci. Technol., 39, 9620-9629, 2005.

Poorter, H., Niinemets, Ü., Poorter, L., Wright, I. J., and Villar, R.: Tansley review. Causes and consequences of variation in leaf mass per area (LMA): a meta-analysis, New Phytol., 182, 565588, 2009a.

Poorter, H., Walter, A., Fiorani, F., Schurr, U., and Niinemets, Ü.: Meta-phenomics: building a unified framework for interpreting plant growth responses to diverse environmental variables, Comp. Biochem. Physiol. A, 153, p. S224, 2009b.

Poorter, H., Niinemets, Ü., Walter, A., Fiorani, F., and Schurr, U.: A method to construct dose-response curves for a wide range of environmental factors and plant traits by means of a metaanalysis of phenotypic data, J. Exp. Bot., 61, 2043-2055, 2010.

Raguso, R. A., Levin, R. A., Foose, S. E., Holmberg, M. W., and McDade, L. A.: Fragrance chemistry, nocturnal rhythms and pollination "syndromes" in Nicotiana, Phytochemistry, 63, 265284, 2003.

Räisänen, T., Ryyppö, A., and Kellomäki, S.: Impact of timber felling on the ambient monoterpene concentration of a Scots pine (Pinus sylvestris L.) forest, Atmos. Environ., 42, 6759-6766, 2008.

Rasulov, B., Copolovici, L., Laisk, A., and Niinemets, Ü.: Postillumination isoprene emission: in vivo measurements of dimethylallyldiphosphate pool size and isoprene synthase kinetics in aspen leaves, Plant Physiol., 149, 1609-1618, 2009a.

Rasulov, B., Hüve, K., Välbe, M., Laisk, A., and Niinemets, Ü.: Evidence that light, carbon dioxide and oxygen dependencies of leaf isoprene emission are driven by energy status in hybrid aspen, Plant Physiol., 151, 448-460, 2009b.

Rasulov, B., Hüve, K., Bichele, I., Laisk, A., and Niinemets, Ü.: Temperature response of isoprene emission in vivo reflects a combined effect of substrate limitations and isoprene synthase activity: a kinetic analysis, Plant Physiol., 154, 1558-1570, 2010.

Riba, M. L., Randrianalimanana, E., Mathieu, J., Torres, L., and Namiesnik, J.: Preconcentration of atmospheric terpenes on solid sorbents, Int. J. Environ. An. Ch., 19, 133-143, 1985.
Rodeghiero, M., Niinemets, Ü., and Cescatti, A.: Major diffusion leaks of clamp-on leaf cuvettes still unaccounted: how erroneous are the estimates of Farquhar et al. model parameters?, Plant Cell Environ., 30, 1006-1022, 2007.

Rothweiler, H., Wäger, P. A., and Schlatter, C.: Comparison of Tenax TA and Carbotrap for sampling and analysis of volatile organic compounds in air, Atmos. Environ., 25B, 231-235, 1991.

Ruuskanen, T. M., Hakola, H., Kajos, M. K., Hellén, H., Tarvainen, V., and Rinne, J.: Volatile organic compound emissions from Siberian larch, Atmos. Environ., 41, 5807-5812, 2007.

Sabillón, D. and Cremades, L. V.: Diurnal and seasonal variation of monoterpene emission rates for typical Mediterranean species (Pinus pinea and Quercus ilex) from field measurements - relationship with temperature and PAR, Atmos. Environ., 35, 44194431, 2001.

Schade, G. W. and Goldstein, A. H.: Increase of monoterpene emissions from a pine plantation as a result of mechanical disturbances, Geophys. Res. Lett., 30, 1380, doi:10.1029/2002GL016138, 2003.

Schäfer, L., Kesselmeier, J., and Helas, G.: Formic and acetic acid emission from conifers measured with a "cuvette" technique, in: Field measurements and interpretation of species related to photooxidants and acid deposition. CEC air pollution research, 39, edited by: Beilke, S., Slanina, J., and Angeletti, G., European Commission, Brussels, 23-45, 1992.

Schmid, C.: Sorptions- und Permeationseigenschaften der pflanzlichen Kutikula für Monoterpene, Dr. rer. nat. Thesis, Technische Universität München, 1991.

Schuh, G., Wildt, J., and Kley, D.: Bestimmung von Emissionsraten pflanzlicher Kohlenwasserstoffe bei Sonnenblumen in Abhängigkeit von Temperatur, Lichtintensität und Streß, insbesondere von der Belastung mit Ozon, Berichte des Forschungszentrums Jülich, 3261, Institut für Chemie und Dynamik der Geosphäre 2: Chemie der Belasteten Atmosphäre, Forschungszentrum Jülich, Jülich, 225 pp., 1996.

Schulze, E. D., Turner, N. C., Gollan, T., and Schackel, K. A.: Stomatal responses to air humidity and to soil drought, in: Stomatal function, edited by: Zeiger, E., Farquhar, G. D., and Cowan, I. R., Stanford University Press, Stanford, 311-321, 1987.

Seybold, S. J., Huber, D. P. W., Lee, J. C., Graves, A. D., and Bohlmann, J.: Pine monoterpenes and pine bark beetles: a marriage of convenience for defense and chemical communication, Phytochem. Rev., 5, 143-178, 2006.

Shao, M., Czapiewski, K. V., Heiden, A. C., Kobel, K., Komenda, M., Koppmann, R., and Wildt, J.: Volatile organic compound emissions from Scots pine: mechanisms and description by algorithms, J. Geophys. Res., 106, 20483-20491, 2001.

Sharkey, T. D., Singsaas, E. L., Lerdau, M. T., and Geron, C. D.: Weather effects on isoprene emission capacity and applications in emissions algorithms, Ecol. Appl., 9, 1132-1137, 1999.

Shim, C., Wang, Y., Choi, Y., Palmer, P. I., Abbot, D. S., and Chance, K.: Constraining global isoprene emissions with Global Ozone Monitoring Experiment (GOME) formaldehyde column measurements, J. Geophys. Res.-Atmos., 110, D24301, doi:10.1029/2004JD005629, 2005.

Simpson, D., Guenther, A., Hewitt, C. N., and Steinbrecher, R.: Biogenic emissions in Europe. 1. Estimates and uncertainties, J. Geophys. Res., 100, 22875-22890, 1995.

Simpson, D., Winiwarter, W., Börjesson, G., Cinderby, S., Ferreiro, 
A., Guenther, A., Hewitt, C. N., Janson, R., Khalil, M. A. K., Owen, S., Pierce, T. E., Puxbaum, H., Shearer, M., Skiba, U., Steinbrecher, R., Tarrasón, L., and Öquist, M. G.: Inventorying emissions from nature in Europe, J. Geophys. Res.-Atmos., 104, 8113-8152, 1999.

Sinha, V., Williams, J., Lelieveld, J., Ruuskanen, T. M., Kajos, M. K., Patokoski, J., Hellen, H., Hakola, H., Mogensen, D., Boy, M., Rinne, J., and Kulmala, M.: OH reactivity measurements within a boreal forest: evidence for unknown reactive emissions, Environ. Sci. Technol., 44, 6614-6620, doi:10.1021/es101780b, 2010.

Spracklen, D. V., Bonn, B., and Carslaw, K. S.: Boreal forests, aerosols and the impacts on clouds and climate, Philos. T. R. Soc. Lond., 366, 4613-4626, 2008.

Staudt, M.: Untersuchungen der Monoterpen-Abgabe an europäischen Nadelbaumarten in Abhängigkeit von Umweltfaktoren, Documenta Naturae, 111, Ph.D. thesis, University of Stuttgart-Hohenheim, 166 pp., 1997.

Staudt, M., Bertin, N., Hansen, U., Seufert, G., Ciccioli, P., Foster, P., Frenzel, B., and Fugit, J. L.: Seasonal and diurnal patterns of monoterpene emissions from Pinus pinea (L.) under field conditions, Atmos. Environ., 31, 145-156, 1997.

Staudt, M., Bertin, N., Frenzel, B., and Seufert, G.: Seasonal variation in amount and composition of monoterpenes emitted by young Pinus pinea trees - implications for emission modeling, J. Atmos. Chem., 35, 77-99, 2000.

Staudt, M., Joffre, R., and Rambal, S.: How growth conditions affect the capacity of Quercus ilex leaves to emit monoterpenes, New Phytol., 158, 61-73, 2003.

Staudt, M., Mir, C., Joffre, R., Rambal, S., Bonin, A., Landais, D., and Lumaret, R.: Isoprenoid emissions of Quercus spp. (Q. suber and $Q$. ilex) in mixed stands contrasting in interspecific genetic introgression, New Phytol., 163, 573-584, 2004.

Steinbrecher, R., Eichstädter, G., Schürmann, W., Torres, L., Clement, B., Simon, V., Kotzias, D., Daiber, R., and van Eijsk, J.: Monoterpenes in air samples: European intercomparison experiments, Int. J. Environ. An. Ch., 54, 283-297, 1994.

Steinbrecher, R., Hauff, K., Rabong, R., and Steinbrecher, J.: Isoprenoid emission of oak species typical for the Mediterranean area: source strength and controlling variables, Atmos. Environ., 31, 79-88, 1997.

Steinbrecher, R. and Hauff, K.: Isoprene and monoterpene emission from Mediterranean oaks, in: The proceedings of EUROTRAC symposium '96, edited by: Borrell, P. M., Borrell, P., Cvitas, T., Kelly, K., and Seiler, W., Computational Mechanics Publications, Southampton, 229-233, 1996.

Stenberg, P., Linder, S., Smolander, H., and Flower-Ellis, J.: Performance of the LAI-2000 plant canopy analyzer in estimating leaf area index of some Scots pine stands, Tree Physiol., 14, 981-995, 1994.

Stenberg, P., Smolander, H., Sprugel, D. G., and Smolander, S.: Shoot structure, light interception, and distribution of nitrogen in an Abies amabilis canopy, Tree Physiol., 18, 759-767, 1998.

Stewart-Jones, A. and Poppy, G. M.: Comparison of glass vessels and plastic bags for enclosing living plant parts for headspace analysis, J. Chem. Ecol., 32, 845-864, 2006.

Street, R. A., Hewitt, C. N., and Mennicken, S.: Isoprene and monoterpene emissions from a Eucalyptus plantation in Portugal, J. Geophys. Res.-Atmos., 102, 15875-15887, 1997.
Sturm, P., Leuenberger, M., Sirignano, C., Neubert, R. E. M., Meijer, H. A. J., Langenfelds, R., Brand, W. A., and Tohjima, Y.: Permeation of atmospheric gases through polymer O-rings used in flasks for air sampling, J. Geophys. Res.-Atmos., 109, D04309, doi:04310.01029/02003JD004073, 2004.

Sun, Z., Niinemets, Ü., and Copolovici, L.: Foliar isoprene emission during autumn senescence in aspen (Populus tremula), Geochim. Cosmochim. Ac., 73, A1295, doi:10.1016/j.gca.2009.05.015, 2009.

Sun, Z., Copolovici, L., and Niinemets, Ü.: Can the capacity for isoprene emissions acclimate to environmental modifications during autumn senescence in aspen (Populus tremula)?, J. Plant Res., doi:10.1007/s10265-011-0429-7, in press, 2011.

Tani, A., Hayward, S., and Hewitt, C. N.: Measurement of monoterpenes and related compounds by proton transfer reaction-mass spectrometry (PTR-MS), Int. J. Mass Spectrom., 223-224, 561578, 2003.

Tarvainen, V., Hakola, H., Hellén, H., Bäck, J., Hari, P., and Kulmala, M.: Temperature and light dependence of the VOC emissions of Scots pine, Atmos. Chem. Phys., 5, 989-998, doi:10.5194/acp-5-989-2005, 2005.

Theis, N.: Fragrance of Canada thistle (Cirsium arvense) attracts both floral herbivores and pollinators, J. Chem. Ecol., 32, 917927, 2006.

Tholl, D., Boland, W., Hansel, A., Loreto, F., Rose, U. S. R., and Schnitzler, J.-P.: Practical approaches to plant volatile analysis, Plant J., 45, 540-560, 2006.

Tiwary, A., Fuentes, J. D., Barr, J. G., Wang, D., and Colls, J. J.: Inferring the source strength of isoprene from ambient concentrations, Environ. Modell. Softw., 22, 1281-1293, 2007.

US Environmental Protection Agency: Compendium of methods for the determination of toxic organic compounds in ambient air, 2nd edn., U.S. Environmental Protection Agency, Office of Research and Development, National Risk Management Research Laboratory, Center for Environmental Research Information, Cincinnati, Ohio, 37 pp., 1999.

UNECE/EMEP Task Force on Emissions Inventories and Projections: Group 11. Other sources and sinks, in: EMEP/CORINAIR emission inventory guidebook - 2007, Technical report, 16/2007, EEA (European Environment Agency), 2007.

Velikova, V., Pinelli, P., Pasqualini, S., Reale, L., Ferranti, F., and Loreto, F.: Isoprene decreases the concentration of nitric oxide in leaves exposed to elevated ozone, New Phytol., 166, 419-426, 2005a.

Velikova, V., Tsonev, T., Pinelli, P., Alessio, G. A., and Loreto, F.: Localized ozone fumigation system for studying ozone effects on photosynthesis, respiration, electron transport rate and isoprene emission in field-grown Mediterranean oak species, Tree Physiol., 25, 1523-1532, 2005b.

von Caemmerer, S. and Farquhar, G. D.: Some relationships between the biochemistry of photosynthesis and the gas exchange of leaves, Planta, 153, 376-387, 1981.

Vuorinen, T., Reddy, G. V. P., Nerg, A.-M., and Holopainen, J. K.: Monoterpene and herbivore-induced emissions from cabbage plants grown at elevated atmospheric $\mathrm{CO}_{2}$ concentration, Atmos. Environ., 38, 675-682, 2004.

Wang, D., Jiang, W., Gao, H., and Jiang, Z.: Diffusion and swelling of carbon dioxide in amorphous poly(ether ether ketone)s, J. Membrane Sci., 281, 203-210, 2006. 
Wang, D. K. W. and Austin, C. C.: Determination of complex mixtures of volatile organic compounds in ambient air: canister methodology, Anal. Bioanal. Chem., 386, 1099-1120, 2006.

Wang, M. and Lincoln, D. E.: Effects of light intensity and artificial wounding on monoterpene production in Myrica cerifera from two different ecological habitats, Can. J. Bot., 82, 1501-1508, 2004.

Westerhout, R. W. J., Waanders, J., Kuipers, J. A. M., and van Swaaij, W. P. M.: Kinetics of the low-temperature pyrolysis of polyethylene, polypropylene, and polystyrene modeling, experimental determination, and comparison with literature models and data, Ind. Eng. Chem. Res., 36, 1955-1964, 1997.

Wiedinmyer, C., Friedfeld, S., Baugh, W., Greenberg, J., Guenther, A., Fraser, M., and Allen, D.: Measurement and analysis of atmospheric concentrations of isoprene and its reaction products in central Texas, Atmos. Environ., 35, 1001-1013, 2001.

Wiedinmyer, C., Guenther, A., Harley, P., Hewitt, C. N., Geron, C., Artaxo, P., Steinbrecher, R., and Rasmussen, R.: Global organic emissions from vegetation, in: Emissions of atmospheric trace compounds, edited by: Granier, C., Artaxo, P., and Reeves, C. E., Kluwer Academic Publishers Dordrecht, The Netherlands, 115170, 2004.

Wildt, J., Kobel, K., Schuh-Thomas, G., and Heiden, A. C.: Emissions of oxygenated volatile organic compounds from plants. Part II: Emissions of saturated aldehydes, J. Atmos. Chem., 45, 173-196, 2003.
Wilkinson, M. J., Monson, R. K., Trahan, N., Lee, S., Brown, E., Jackson, R. B., Polley, H. W., Fay, P. A., and Fall, R.: Leaf isoprene emission rate as a function of atmospheric $\mathrm{CO}_{2}$ concentration, Glob. Change Biol., 15, 1189-1200, 2009.

Wu, J. and Baldwin, I. T.: Herbivory-induced signalling in plants: perception and action, Plant Cell Environ., 32, 1161-1174, 2009.

Zabaras, D. and Wyllie, S. G.: Rearrangement of p-menthane terpenes by Carboxen during HS-SPME, J. Sep. Sci., 25, 685-690, 2002.

Zeiller, E., Benetka, E., Koller, M., and Schorn, R.: Dry mass determination: what role does it play in combined measurement uncertainty? A case study using IAEA 392 and IAEA 413 algae reference materials, Accredit. Qual. Assur., 12, 295-302, 2007.

Zhang, Y., Huang, J.-P., Henze, D. K., and Seinfeld, J. H.: Role of isoprene in secondary organic aerosol formation on a regional scale, J. Geophys. Res.-Atmos., 112, D20207, doi:10.1029/2007JD008675, 2007.

Zimmerman, P. R.: Determination of emission rates of hydrocarbons from indigenous species of vegetation in the Tampa/St Petersburg, Florida Area. EPA Contract No. 904/9-77-028, prepared for Environmental Protection Agency, Environmental Protection Agency, Atlanta, Georgia, USA, 1979. 